$\longrightarrow$

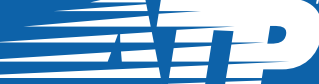

ADVANGEDTECHNOLOCY PROCRAM
Development, Commercialization, and Diffusion of Enabling Technologies: Progress Report 


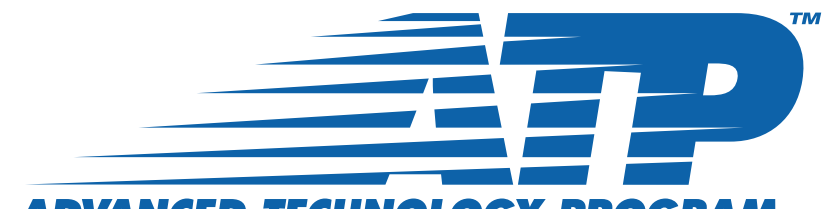

ADVANCED TECHNOLOGY PROGRAM

\title{
Development, Commercialization, and Diffusion of Enabling Technologies: Progress Report
}

\author{
Jeanne W. Powell
}

Karen L. Lellock

U.S. DEPARTMENT OF COMMERCE Technology Administration

National Institute of Standards and Technology

Advanced Technology Program

April 2000

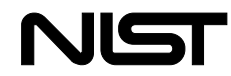




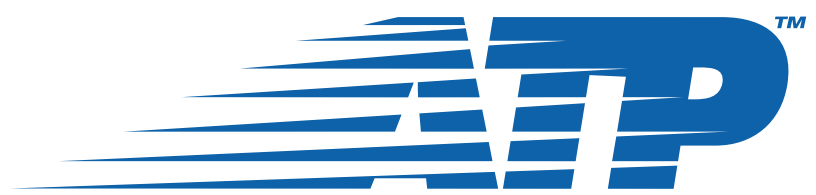

\section{Development, Commercialization, and Diffusion of Enabling Technologies: Progress Report}

Jeanne W. Powell

Karen L. Lellock

U.S. DEPARTMENT OF COMMERCE Technology Administration National Institute of Standards and Technology Advanced Technology Program

April 2000

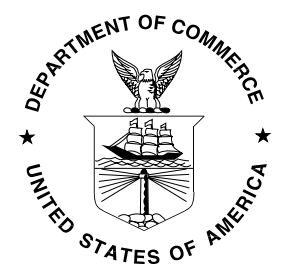

U.S. DEPARTMENT OF COMMERCE William M. Daley, Secretary

TECHNOLOGY ADMINISTRATION

Dr. Cheryl L. Shavers, Under Secretary of Commerce for Technology 


\section{Abstract}

This report presents a statistical picture of progress in early 1998 as reported by 539 organizations which received ATP awards during the period from 1993 through 1997. Using data collected through the ATP's Business Reporting System (BRS) in reports filed during the year ended March 31, 1998, the report examines plans for commercialization for evidence of opportunities for economic spillovers and national economic benefit; it provides indicators of ATP's effect in accelerating $\mathrm{R} \& \mathrm{D}$, stimulating collaborations, and increasing private-sector investment in high-risk technology development; and it examines progress of ATP-funded technologies during the award period. The report updates the December 1997 ATP report Development, Commercialization, and Diffusion of Enabling Technologies: Progress Report for Projects Funded 1993-1995.

The study provides evidence that the ATP has funded projects with considerable opportunity for broad economic benefit. More specifically, participants in 261 projects have identified more than 1,200 potential uses of their technologies under development, and outlined business plans for nearly 1,000 of these. Acceleration of R\&D, and collaboration with other organizations for R\&D and for commercializing their technologies, are reported by 86 percent of participants having received at least one year of ATP funding. Industry has increased its own investment in the ATP-funded technology development areas by over $\$ 300 \mathrm{M}$, representing a 58 percent increase over what would have been invested from industry sources without the ATP awards. Seventy-three percent of organizations report that they are able to undertake a project of higher technical risk as a result of ATP funding.

Although substantial commercialization results from ATP-funded projects will usually take a number of years after ATP funding ends, considerable business planning activity is underway and many companies report achievement of early commercialization milestones. Sixty-four percent of projects have completed a production prototype for at least one application; 17 percent of companies report earning revenues from their ATP-funded technology.

\section{Keywords}

Acceleration; Advanced Technology Program; collaboration; commercialization; program evaluation; small firms; technology development

\section{Acknowledgments}

This report was made possible through the cooperation of hundreds of ATP-funded organizations who are providing information through ATP's Business Reporting System in support of program evaluation and project monitoring efforts. Stephen F. Weber, Building and Fire Research Laboratory, developed the BRS software, which has proved critical to timely and efficient data analysis, and has provided assistance in use of the data over the course of numerous reports. Many individuals in the ATP contributed to the report: Jo Ann Brooks, graphics artist, prepared the diverse illustrations; Rosalie Ruegg provided insightful and detailed reviews; Robert Sienkiewicz and Cita Furlani provided additional comments and suggestions. Paul Doremus, NIST Program Office, provided assistance and advice for linking this and subsequent BRS-based reports to NIST's performance plan. 


\section{Preface}

The Advanced Technology Program (ATP), administered by the U.S. Commerce Department's National Institute of Standards and Technology (NIST), partners with U.S. industry to fund the development of high risk and enabling technologies, with significant potential for stimulating U.S. economic growth. Industry submits proposals containing a research plan for the work to be performed, an explanation of how the nation will benefit broadly from the new technical capability, a business plan for future commercialization of at least some of the goods and services that may derive from the technology, plans for diffusing the technology beyond the innovators, and a project budget indicating the proposed costshare arrangement. Through a highly competitive peer review process, involving a mix of technical experts from government laboratories, and business and economic experts from the private sector and government, projects with both high technical and business/economic merit are selected for funding. The ATP costs shares with industry the R\&D costs of the award-winning projects; the companies are fully responsible for business planning and product development costs.

The ATP provides funding for both single-company and joint-venture projects. Eligible joint ventures consist of a minimum of two for-profit companies participating in the R\&D and contributing cost share, and may contain additional companies, universities, or research organizations. Only U.S.-owned companies or U.S. subsidiaries of foreign-owned companies are eligible to receive awards and the latter only if they meet certain tests. Single company proposers may receive funding of up to $\$ 2$ million in direct costs over three years and must cover their own indirect costs. (Beginning in 1998, large singlecompany proposers -- Fortune 500 or equivalent -- must cover at least 60 percent of total project costs.) Joint ventures may propose a project of any size for up to five years of funding but must cover more than 50 percent of total project costs.

Since its first congressional appropriation in 1990, the Advanced Technology Program has funded 468 projects, with over 1,000 participating organizations across a mix of 311 single company projects and 157 joint venture projects; and over 1,000 organizations in subcontract relationships. Project awards amount to $\$ 1.496 \mathrm{~B}$, with industry committing an additional $\$ 1.499 \mathrm{~B}$ in cost share.

This report uses the ATP's Business Reporting System (BRS) to update the ATP report Development, Commercialization, and Diffusion of Enabling Technologies: Progress Report for Projects Funded 1993-1995, published in December 1997. The average stage of evolution for the portfolio of projects funded since FY1993 aged by approximately a year and a half between the first and second reports. A new chapter entitled "Changes in Competitiveness" has been added. A direct comparison of results from the two reports for a number of major indicators of progress is provided in Appendix B.

This report is offered as one component of ATP's on-going evaluation program, which provides feedback to ATP management and meets the many outside requests for program performance information. Other studies by the Economic Assessment Office (EAO) staff and outside contractors include detailed case studies of ATP-funded projects, statistical and econometric studies, status reports on the accomplishments of completed projects, methodological studies, and other topics of interest to the evaluation community. For copies of EAO reports, see "publications" at the EAO Web site (http://www.eao.atp.nist.gov), or contact the EAO directly at (301) 975-4332.

NIST Disclaimer: Certain commercial firms and trade names are identified in this report in order to specify aspects of the NIST Advanced Technology Program. Such identification is not intended to imply the recommendation or endorsement by the National Institute of Standards and Technology, nor is it intended to imply that related products or services are necessarily the best available. 


\section{EXECUTIVE SUMMARY}

This report provides a statistical overview of progress reported by hundreds of companies and other organizations which received awards from the ATP between 1993 and 1997. The report annotates the statistics with comments from project participants. The information is based entirely on Business Reporting System (BRS) reports to the ATP filed by 539 individual organizations through March 31, 1998. While not all the companies and projects are progressing at the same rate, the statistical analysis presented here provides an overview of the level of progress towards research and commercialization goals of a large group of ATP award recipients.

Progress reports from individual firms, and aggregate summary statistics of progress for the group of projects provide evidence that the ATP is (a) providing opportunities for economic spillovers and broad national economic benefit; (b) accelerating $R \& D$ and reducing time-to-market in highly competitive markets; (c) stimulating collaboration and the effects thereof; (d) increasing private sector investment in high risk technology development; and (e) encouraging progress towards ultimate commercialization of the resulting technologies.

Opportunities for economic spillovers and national economic benefit:

- $\quad$ Early on in their projects, participants are identifying plans to commercialize their ATP-funded technologies in diverse applications.

- Participants in 261 projects have identified more than 1,200 different applications (or uses) of the technologies under development, providing evidence that the technologies funded by ATP are highly enabling.

- Companies indicated that they are pursuing commercialization of nearly 1,000 applications spanning the spectrum of industries.

- Most of the technologies under development offer new types of solutions to market needs or substantial performance and productivity improvements over existing capabilities.

- Most of the technologies under development feed into the early stages of the production chain, creating a greater opportunity for intermediate producers and downstream customers in multiple application areas to benefit from market spillovers.

- Patent and copyright activity and dissemination of knowledge created with ATP funding have been vigorous for many projects.

- About 240 new patents have been filed, representing an average of 1.2 patents per project for the period covered. Thus far 23 patents have been issued. Patent and copyright activities facilitate dissemination of knowledge through patent disclosure and provide additional commercialization opportunities by others through licensing arrangements. Licensing to others is a primary or secondary strategy for commercializing 47 percent of the planned applications.

- An average of 3.6 conference papers were presented and 1.3 professional journal articles published per project during the period covered. Conference activity and publication of papers were particularly vigorous in some projects. Publications facilitate the broad dissemination of knowledge developed in ATP projects. 
Acceleration of $R \& D$ and reduction of time-to-market in highly competitive markets:

- $\quad$ ATP funding increases the chances that new technologies will be ready in time to meet critical windows of opportunity in the marketplace.

- Speed-to-market is considered "critical" or "important" for 98 percent of the commercial applications. The window of opportunity for successful entry into the marketplace is perceived by the companies as two years or less after the ATP funding ends for 73 percent of currently identified applications.

- Eighty-six percent of organizations indicated they are ahead in their R\&D cycle as a result of ATP funding; of these, 24 percent believe they would not have started the project at all without ATP funding; most of the remainder say they would have proceeded at a significantly slower rate without ATP funding.

- Acceleration by two years or more is anticipated for 65 percent of planned commercial applications.

Stimulation of Collaborations and Collaboration Effects:

- The ATP is stimulating collaborative relationships among companies, universities, and other research organizations.

- For the projects that have completed at least one year, 86 percent of the organizations reporting indicated that their ATP project involved collaboration with other organizations. Among these, 88 percent indicated that the ATP was responsible to a moderate or great extent for their collaborations.

- Benefits of collaborating were reported by a far larger percentage of those reporting collaborative relationships than costs, suggesting that collaboration is having a largely positive influence on technology development. Of those reporting collaboration:

- The most frequent effect of collaboration, reported by 97 percent of the organizations, was that it helped stimulate creative thinking.

- Other important effects reported included helping them save time, helping them obtain R\&D expertise, accelerating entry into the marketplace, and encouraging them to undertake future collaborations.

- As might be expected, collaboration can cause higher project management costs. Fifty-six percent reported a significant or moderate increase in project coordination costs.

- Other costs of collaborating were reported by a minority of companies: significant or moderate delays in beginning the R\&D due to collaboration were reported by 18 percent, and time delays in market entry as a result of collaboration difficulties were reported by eight percent.

- Of the 86 percent of organizations reporting collaboration with other organizations, nearly all indicated significant or moderate benefits from one or more collaboration effects, compared

Development, Commercialization, and Diffusion of Enabling Technologies: Progress Report 
with 56 percent who indicated moderate or significant increase in project coordination and management costs.

- In addition to R\&D collaboration, ATP-funded companies are planning and pursuing alliances to commercialize their technologies, with small companies particularly focused on this strategy. One hundred fifty-six strategic alliances have been formed, and 42 license agreements have been signed for the purpose of commercializing technologies developed in ATP projects.

Increased investment in high risk, long-term, broader-scope technology development:

- With the assistance of ATP funding, organizations are pursuing different R\&D than they would have undertaken without ATP funding.

- Seventy-three percent of organizations report that they are pursuing a higher level of technical risk as a result of the ATP. Sixty-seven percent report that ATP funding has increased their interest in performing long-term research, and 61 percent report their project encompasses a broader scope as a result of the ATP. (These effects are in addition to the accelerated pace mentioned earlier.)

- For 30 percent of applications anticipating a performance or cost improvement, performance improvements of 100 percent or more are anticipated. Cost reductions of 25 percent or more are anticipated for 40 percent of these applications. Expectations that large improvements in performance or large reductions in production costs will result from the ATP-funded projects are evidence that industry is pursuing "discontinuous" or "breakthrough" innovations, and suggestive of relatively risky $R \& D$.

- Thirty-eight percent of applications are considered by the project participants to be "new-tothe-world" solutions to a market need or problem with the potential to create totally new markets, another indication of the "breakthrough" nature of the ATP-funded innovation. Many companies plan to utilize their ATP-funded technology in a mix of "new-to-the-world" products and cost reduction and performance improvements in existing products, processes, or services.

- $\quad$ ATP funding has encouraged organizations to invest more of their own industry funds in the ATPfunded technology areas than they would have otherwise.

- Industry has increased its investment in the ATP-funded technology development areas, beyond what would have occurred in the absence of the ATP awards, by an estimated $\$ 320$ million; i.e., across the group of projects, companies have expanded the scale of their R\&D efforts in the ATP-funded areas by the amount of ATP funding received plus an additional $\$ 320$ million, in addition to what they would have put into the effort without ATP. This represents an estimated 58 percent increase in industry funding in addition to the ATP funding.

- The ATP-funded companies have attracted \$200 million of new funding from outside sources to support their ATP-related development or commercialization work.

\section{Progress towards commercialization of ATP-funded technologies:}

- $\quad$ Progress is being made towards developing new capabilities and achieving cost savings through new and improved processes. 
- Fifty-four percent of the companies, representing 66 percent of the projects, report they are now able to make a new or improved product, even though the product may not yet be ready for the marketplace.

- Thirty-nine percent of companies, representing 51 percent of the projects, report they have already adopted process improvements resulting from their ATP technology.

- Companies are engaging in commercialization planning activities, at their own expense, in order to enter the marketplace in a timely manner, once the technology is ready. (ATP funds R\&D only.)

- Companies in 84 percent of the projects have completed product/process definition for at least one application; companies in 70 percent of the projects have completed concept testing for at least one application of their technology; and concept testing has been conducted for 44 percent of all applications being planned by the ATP-funded companies.

- Companies in 63 percent of the projects have conducted other market analysis activities, for example, sales forecasting or related product development or testing.

- Sixty-four percent of projects have completed a production prototype for at least one application, and 55 percent of projects have completed pilot production or a commercial demonstration.

- Actual production of products is already underway for 22 percent of the projects and for 10 percent of the planned commercial applications (although not necessarily for the most significant applications).

- About 17 percent of companies, representing 27 percent of projects, indicate they have earned early product or service revenues, amounting to more than $\$ 67$ million, typically from sales of samples and prototypes and early "spin-off" activities. Six percent of projects have earned \$5 million in licensing royalties.

- The large revenue flows lie in the future. Revenue is expected for about 19 percent of applications and 18 percent of companies before the end of the ATP project, and not until four or more years after the ATP project ends for nearly 8 percent of applications and 12 percent of projects. For most, revenue is expected for most within four years after the ATP project ends.

- $\quad$ Most ATP-funded technologies are keeping pace with developments in fast-paced international markets. Fifty-five percent of companies report their overall competitive standing is unchanged, and forty-two percent report their overall competitive standing has improved for at least one application. A number of companies believe their competitors are advancing on them and in a few cases have caught up with them.

Taken as a whole, the results of this report strengthen the results of earlier studies by increasing the robustness of statistical evidence that the ATP is making solid progress towards achieving its mission of economic growth through technological advancement. The BRS is a tool that allows the ATP to capture developments in the short-mid-term and report on the evolution of ATP-funded technologies towards commercialization and the generation of national economic benefits. 


\section{TABLE OF CONTENTS}

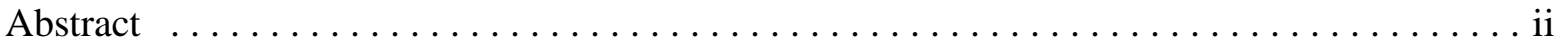

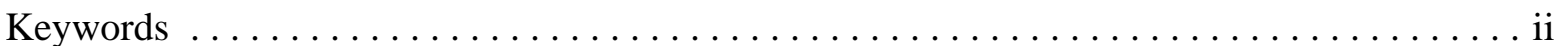

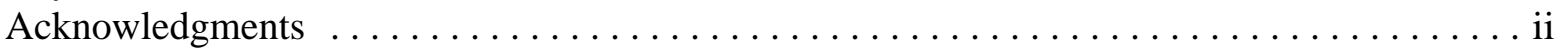

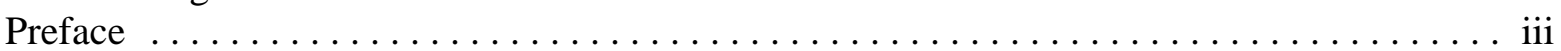

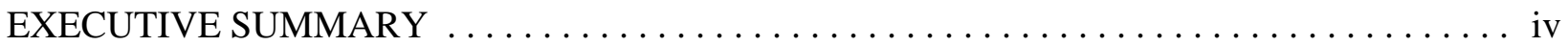

1. THE ATP'S BUSINESS REPORTING SYSTEM: A TOOL FOR ECONOMIC

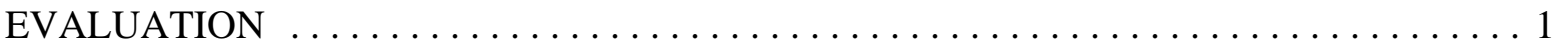

Overview of ATP's Evaluation Program $\ldots \ldots \ldots \ldots \ldots \ldots \ldots \ldots \ldots \ldots \ldots \ldots$

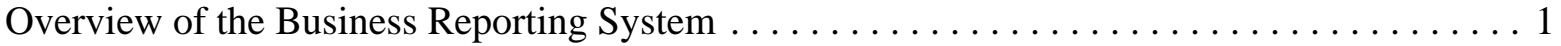

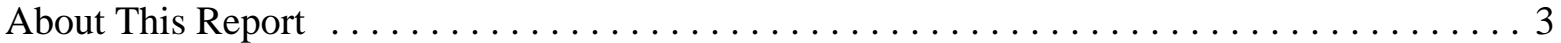

2. PATHS TO NATIONAL ECONOMIC BENEFITS $\ldots \ldots \ldots \ldots \ldots \ldots \ldots \ldots \ldots \ldots \ldots 7$

Development of Technologies with Diverse Applications $\ldots \ldots \ldots \ldots \ldots \ldots \ldots \ldots \ldots 7$

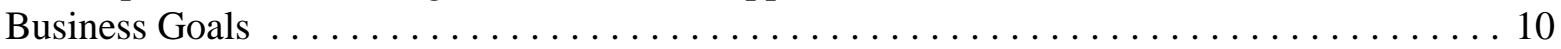

Identification of Commercialization Strategies $\ldots \ldots \ldots \ldots \ldots \ldots \ldots \ldots \ldots \ldots \ldots \ldots \ldots \ldots$

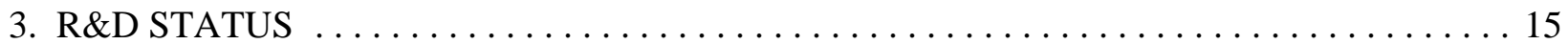

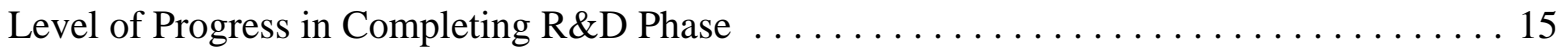

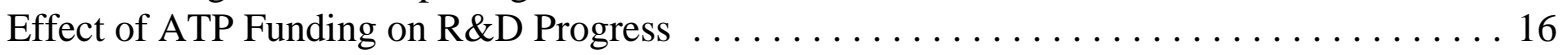

When Can Revenue Be Expected $\ldots \ldots \ldots \ldots \ldots \ldots \ldots \ldots \ldots \ldots \ldots \ldots \ldots \ldots \ldots$

4. STIMULATION OF COLLABORATION AND RELATED EFFECTS . . . . . . . . . . . 19

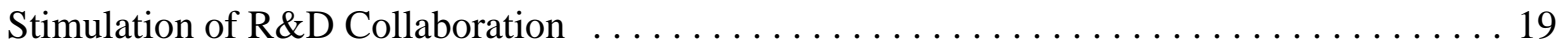

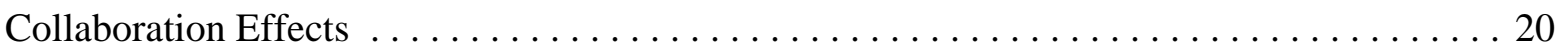

Anecdotal Comments . . . . . . . . . . . . . . . . . . . . . . . . . . . . . 22

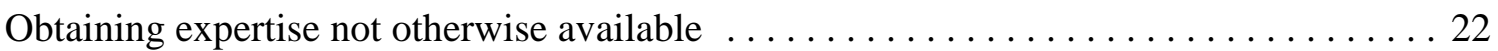

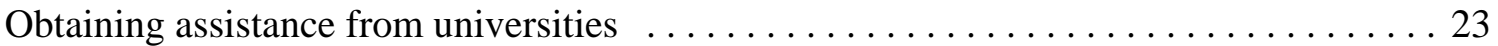

Learning more about potential markets and customer needs and accelerating entry

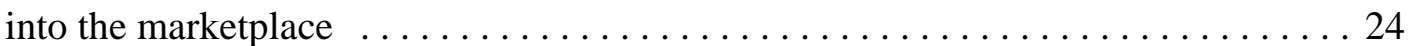

Formation of stronger supplier-customer relationships $\ldots \ldots \ldots \ldots \ldots \ldots \ldots \ldots \ldots$

Strengthening credibility within the organization and with other organizations $\ldots \ldots \ldots 26$

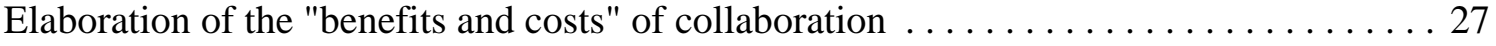

Formation of Strategic Alliances Outside the ATP Project for Commercialization of ATP-

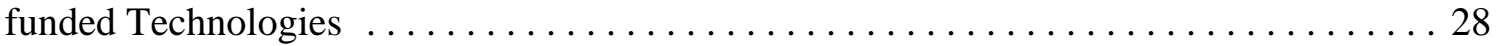

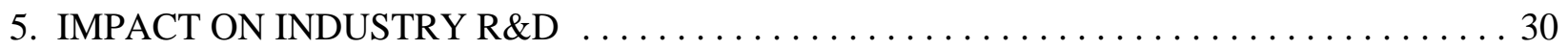

Stimulation of Private Sector Investment and Leveraging of Other Investment . . . . . . 30

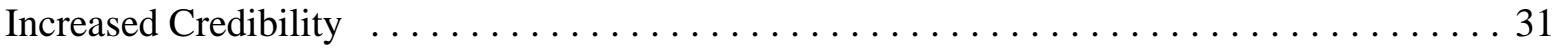

6. EARLY COMMERCIALIZATION ACTIVITIES $\ldots \ldots \ldots \ldots \ldots \ldots \ldots \ldots \ldots \ldots \ldots$

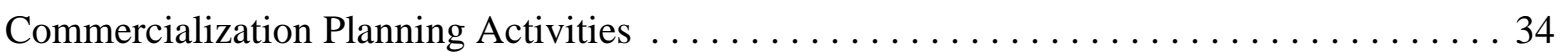

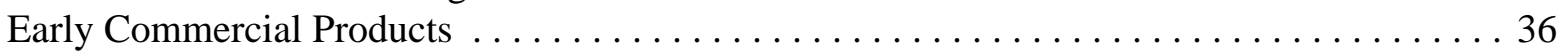

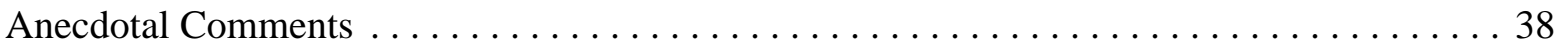

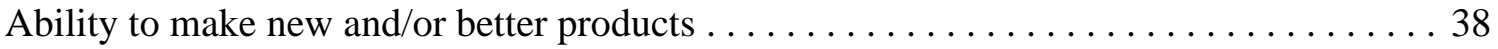




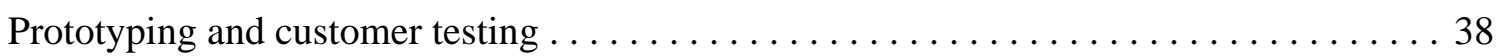

Implementation of new or improved production processes $\ldots \ldots \ldots \ldots \ldots \ldots \ldots \ldots$

7. CHANGES IN COMPETITIVENESS $\ldots \ldots \ldots \ldots \ldots \ldots \ldots \ldots \ldots \ldots \ldots \ldots \ldots \ldots \ldots$

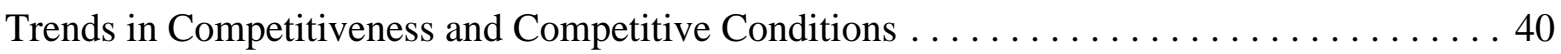

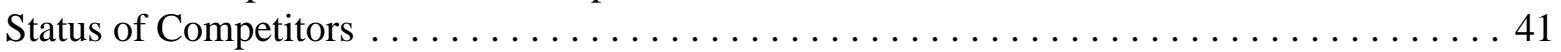

8. INTELLECTUAL PROPERTY PROTECTION AND DIFFUSION OF TECHNOLOGY . . . 43

Protection and Disclosure of Intellectual Property $\ldots \ldots \ldots \ldots \ldots \ldots \ldots \ldots \ldots \ldots \ldots$

Dissemination of Non-Proprietary Information $\ldots \ldots \ldots \ldots \ldots \ldots \ldots \ldots \ldots \ldots \ldots \ldots \ldots$

9. RELATIONSHIP TO PRIOR WORK AND CONCLUSIONS $\ldots \ldots \ldots \ldots \ldots \ldots \ldots \ldots \ldots$

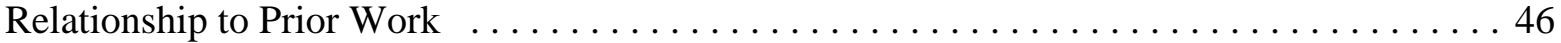

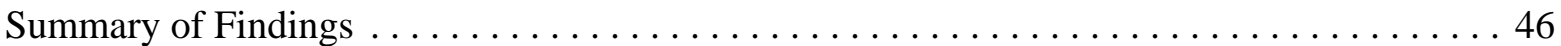

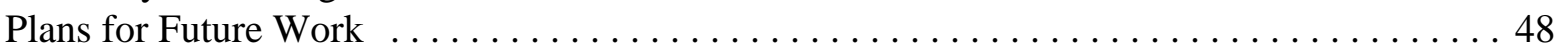

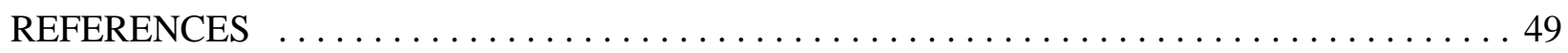

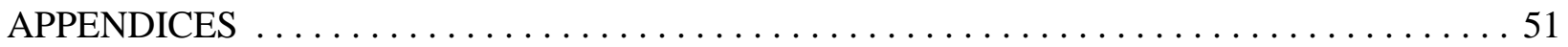

Appendix A. Planned Diverse Applications of ATP-funded Technologies . . . . . . . . 51

Appendix B. Comparison of ATP Progress at Two Points in Time $\ldots \ldots \ldots \ldots \ldots \ldots \ldots$

\section{LIST OF TABLES}

Table 1. Source of Data: Most Recent BRS Reports filed As of March 31, 1998 . . . . . . . 3

Table 2. Examples of Effect of ATP Funding on Company Goals for the Technology . . . . . . 11

Table 3. Strategic Alliances and Licensing Agreements for Commercialization . . . . . . . . . . 29

Table 4. Dissemination of Non-proprietary Information from ATP-funded Projects . . . . . . . 44

\section{LIST OF FIGURES}

Figure 1. Distribution of Types of Participation and Types of Organizations $\ldots \ldots \ldots \ldots \ldots$ Figure 2. Distribution for Organizations That Had Completed One or More Years

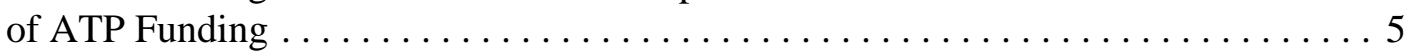

Figure 3. Technologies Under Development $\ldots \ldots \ldots \ldots \ldots \ldots \ldots \ldots \ldots \ldots \ldots \ldots \ldots \ldots \ldots \ldots \ldots \ldots \ldots$

Figure 4. Planned Diverse Applications of ATP-funded Technologies $\ldots \ldots \ldots \ldots \ldots \ldots \ldots 8$

Figure 5. How ATP-funded Technologies Are Expected Eventually To Be Deployed . . . . . . . . 9

Figure 6. Stages of Production in Which the ATP-funded Technologies Are Expected

to Be Used . . . . . . . . . . . . . . . . . . . . . . . . . . . . . 9

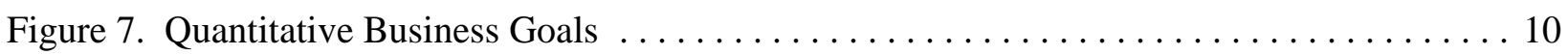

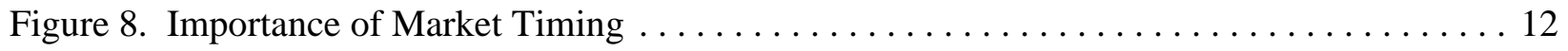

Figure 9. Strategies for Commercializing ATP-funded Technologies $\ldots \ldots \ldots \ldots \ldots \ldots \ldots \ldots$

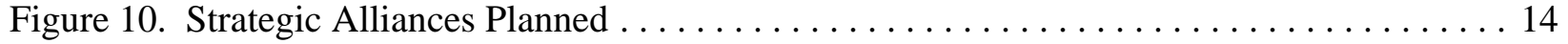

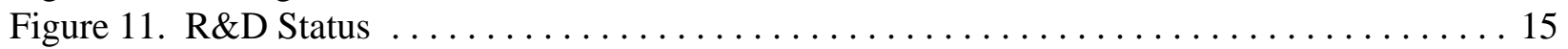

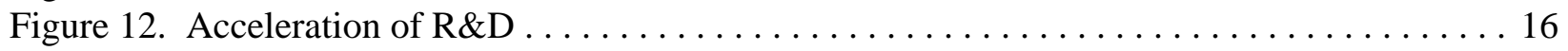

Figure 13. When Can We Expect To See Revenues from ATP-funded Technologies? . . . . . . 17 


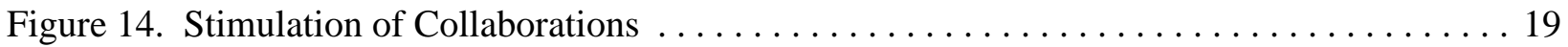

Figure 15. Effects Most Enabled by Collaboration $\ldots \ldots \ldots \ldots \ldots \ldots \ldots \ldots \ldots \ldots \ldots \ldots$

Figure 16. Other Effects Enabled by Collaboration $\ldots \ldots \ldots \ldots \ldots \ldots \ldots \ldots \ldots \ldots \ldots \ldots$

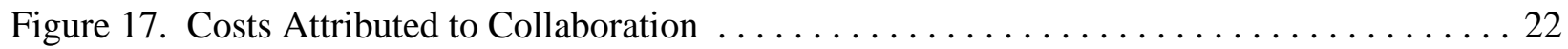

Figure 18. Stimulation of Industry R\&D Investment $\ldots \ldots \ldots \ldots \ldots \ldots \ldots \ldots \ldots \ldots \ldots \ldots$

Figure 19. Change in the Nature of Industry $R \& D \ldots \ldots \ldots \ldots \ldots \ldots \ldots \ldots \ldots \ldots \ldots \ldots$

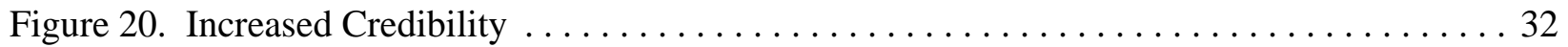

Figure 21. Increased Credibility - Small Businesses $\ldots \ldots \ldots \ldots \ldots \ldots \ldots \ldots \ldots \ldots \ldots \ldots \ldots \ldots \ldots \ldots \ldots$

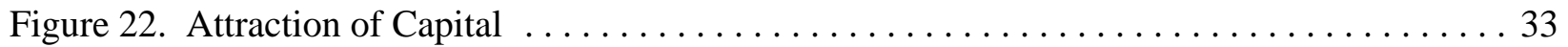

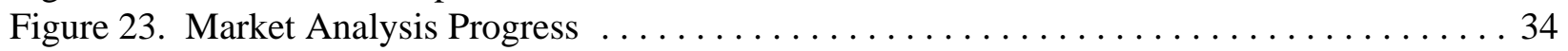

Figure 24. Progress Towards Commercial Production $\ldots \ldots \ldots \ldots \ldots \ldots \ldots \ldots \ldots \ldots \ldots \ldots$

Figure 25. Progress Towards Early Products and Processes $\ldots \ldots \ldots \ldots \ldots \ldots \ldots \ldots \ldots \ldots$

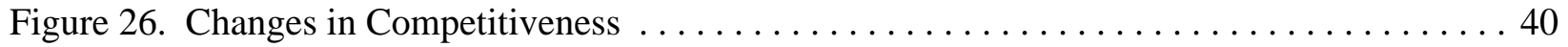

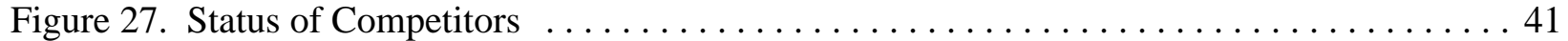

Figure 28. Intellectual Property Strategies Planned $\ldots \ldots \ldots \ldots \ldots \ldots \ldots \ldots \ldots \ldots \ldots \ldots$

Appendix A.1 Planned Diverse Applications of ATP-funded Technologies -

Information Systems $\ldots \ldots \ldots \ldots \ldots \ldots \ldots \ldots \ldots \ldots \ldots \ldots \ldots \ldots \ldots \ldots \ldots \ldots \ldots \ldots$

Appendix A.2 Planned Diverse Applications of ATP-funded Technologies -

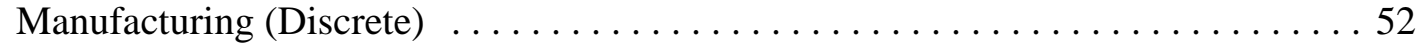

Appendix A.3 Planned Diverse Applications of ATP-funded Technologies -

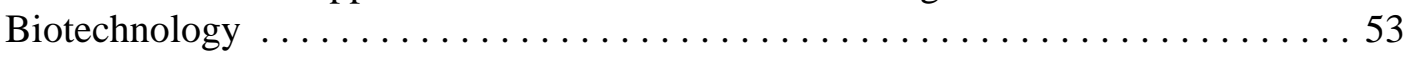

Appendix A.4 Planned Diverse Applications of ATP-funded Technologies -

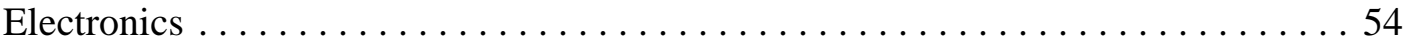

Appendix A.5 Planned Diverse Applications of ATP-funded Technologies -

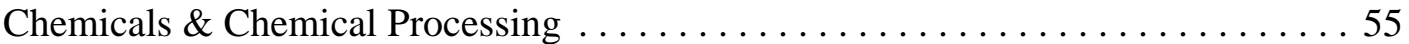

Appendix A.6 Planned Diverse Applications of ATP-funded Technologies -

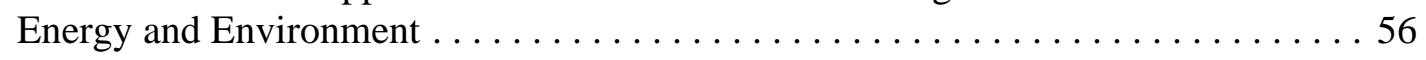

Appendix A.7: SIC Codes Included in "Other" Category . . . . . . . . . . . . . . . . 57

Appendix B.1 Distribution of Types of Participation and Types of Organizations $\ldots \ldots \ldots \ldots 58$

Appendix B.2 R\&D Status . . . . . . . . . . . . . . . . . . . . . . . . . . . 59

Appendix B.3 Early Commercialization Activities-Strategic Alliances and

Licensing Agreements . . . . . . . . . . . . . . . . . . 60

Appendix B.4 Early Commercialization Activities-Commercial Production and Sales . . . . . . 61

Appendix B.5 Protection of Intellectual Property and Dissemination of

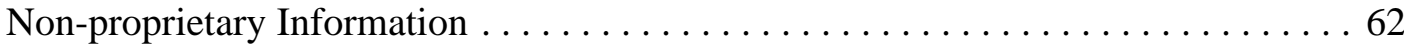




\section{THE ATP'S BUSINESS REPORTING SYSTEM: A TOOL FOR ECONOMIC EVALUATION}

\section{Overview of ATP's Evaluation Program}

Program evaluation has been a central component of ATP operations from the beginning, first, as a management tool to provide feedback to project selection and program operations; and, second, to meet requests from external sources for ATP program results. ATP's founding legislation dictated that evaluation be a feature of the program. In addition, the ATP, like other federal programs, is subject to the evaluation requirements of the 1993 Government Performance and Results Act (GPRA). The ATP's leadership in development of evaluation methodologies has been recognized through the many inquiries about its evaluation tools and methodologies from other agencies, as well as from science and technology funding programs in other countries.

The ATP has developed a multi-component evaluation strategy to provide measures of progress and performance matched to the stage of project evolution; i.e., for the short-term, from the time of project selection and over the course of the ATP-funding period; for the mid-term, as commercial applications are pursued, early spin-off products reach the market, and dissemination of knowledge created in the R\&D projects occurs; and for the longer-term, as more fully-developed ATP-funded technologies diffuse across multiple products and industries, with related net impacts on formation of new industries, job creation, and U.S. economic growth.

Short-mid term evaluation components have included 1) descriptive (statistical) profiling of applicants, projects, participants, technologies, and applications and 2) measures of project progress and performance. This report presents progress measures for projects funded from 1993 through 1997.

\section{Overview of the Business Reporting System}

In the early years of the program, the ATP relied on third-party surveys of projects to determine their progress and performance against short-mid-term program objectives. In early 1994, the ATP implemented the Business Reporting System (BRS), a comprehensive data collection tool for tracking progress of the portfolio of projects against business plans and projected economic goals. Organizations participating in ATP projects report directly to the ATP on their progress as they build upon and implement the plans presented initially in the project proposals. The survey system, electronically administered, has been implemented on a routine and regular basis for projects selected in the 1993 competition and since, from their inception. For maximum detail concerning the multiple commercialization activities of joint venture members and to ensure confidentiality of each joint venture member's plans, data is collected at the individual participant level (from individual companies, universities, and not-for-profit organizations) within a project.

The survey information collected through the BRS comprises part of the integrated ATP database framework. It is intended for use for ATP project management, as well as by researchers for performing evaluation research. Over time, the data is expected to support comprehensive analyses of the behavior of firms conducting advanced R\&D and developing new technologies; of business progress; and of diffusion of economic benefits. 
The Business Reporting System consists of five major parts:

- A Baseline Report. At the beginning of the project, in the Baseline Report, companies identify potential areas of application of the technology being developed with ATP funding. They identify quantitative business goals, including cost or performance targets; key attributes of the technology needed to achieve these goals; planned strategies for commercialization; e.g., in-house production, licensing, and strategic alliances. They outline their strategies for protecting intellectual property; and identify their plans for disseminating non-proprietary information.

- Anniversary Reports. Annually, in the Anniversary Report, companies expand upon the baseline information to cover progress towards implementing commercialization strategies. They report on early economic impacts of the project, as well as collaboration experiences, attraction of new funding, new intellectual property created, and dissemination of information through conferences, publications, and other mechanisms. They also provide a summary of company financial data.

- Quarterly Reports. At the end of each quarter, other than the baseline and anniversary quarters, companies report one or more significant business developments related to their ATP project.

- Close-out Report. At the project conclusion, in the Close-out Report, companies update Anniversary Report information and identify remaining technical and business barriers to commercialization of the technology, define specific business goals for the following five-year period, and indicate expected future effects of the ATP project outside that organization.

- $\quad$ Post-project Reports. Following the end of ATP funding, companies report three times--once every two years -- concerning actual progress in commercializing the technology and related impacts inside and outside the organization.

Companies funded in FY 1993 and later are required to submit these reports under the terms and conditions of their ATP awards. Under ATP's agreements with project participants, all information reported through the BRS is considered proprietary and confidential. Information is released and published only in aggregate, summary statistical form, or in quotes without attribution, unless companies agree to disclosure or the same information is available from company press releases.

It is recognized that surveys conducted by the ATP of its awardees may result in some self-reporting bias. Nevertheless, such instruments are essential to capturing, on a portfolio-wide, standardized basis, the rich and varied experiences of companies engaged in ATP-funded technology development, and subsequent commercialization and technology diffusion. The BRS survey instruments are subjected to extensive review for questioning bias; data are routinely reviewed for validity, quality, and completeness; and analytical results are subject to extensive NIST-wide review and critique before publication. Response rates have been high-nearly 100 percent for recipients of single-company awards and 80 percent for participants in joint-venture projects. Recently, the ATP has initiated research efforts to corroborate its data collected from project participants with data from independent sources and to use control groups where feasible. 


\section{About This Report}

This report provides a snapshot as of 1998 of plans and progress of projects funded in competitions held from 1993 through 1997, and of the pathways to achieving impact. It provides measures of program performance against major short-mid-term ATP goals: the funding of high-risk, enabling R\&D and stimulation of private-sector investment in the same; the stimulation of effective R\&D collaborations; the acceleration of technology development; and evidence of spillover knowledge and commercialization activity. This report updates the December 1997 ATP report Development, Commercialization, and Diffusion of Enabling Technologies: Progress Report for Projects Funded 1993-1995. The current report extends the coverage from projects and participants funded from FY1993 through FY1995 to those funded through 1997, and it extends the analysis of progress from December 1996 through March 1998. Appendix B provides a summary picture of progress of the ATP at two points in time for some key measures and thus captures some of the evolution of the program over the period.

The report draws on the most recent BRS reports filed by participants in the reporting system as of March 31, 1998. Table 1 illustrates the number of projects and participants covered in these BRS

Table 1. Source of Data: Most Recent BRS Reports filed As of March 31, 1998

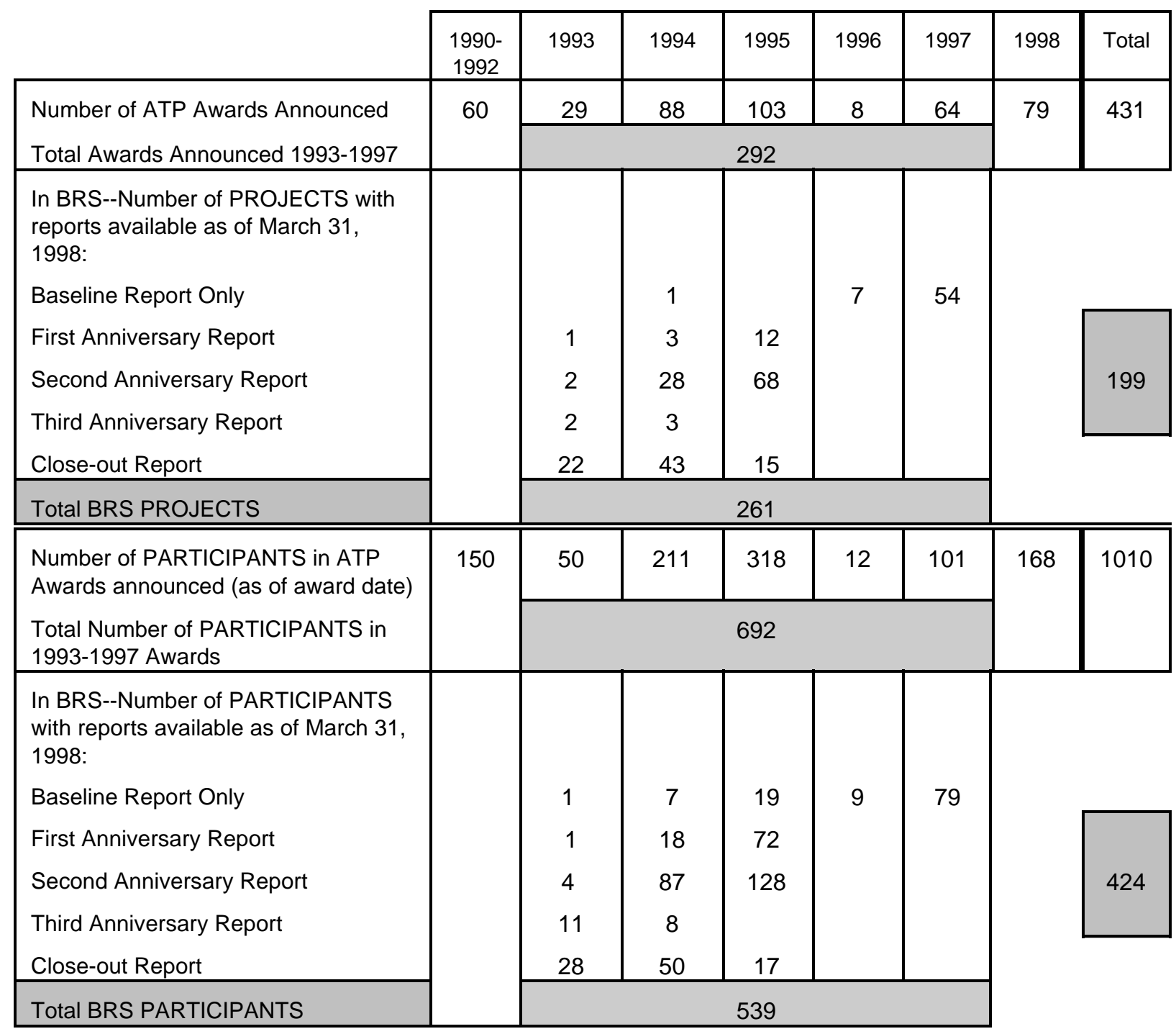


reports, broken down by the number of reports of each type -- Baseline, Anniversary, and Close-out. For reference, the number of ATP awards and project participants announced each year are also shown.

The 261 projects covered include all ATP awards made during the 1993-1997 period, with the exception of 21 projects since cancelled and 10 FY 1997 projects that had not yet started as of March 31, 1998. The projects funded in FY 1998 are not included because the awards had not been made as of March 31, 1998. The 60 projects funded between 1990 and 1992 were funded prior to implementation of the BRS. The difference between the 539 participants covered in the BRS data and the total of 692 participants in the FY 1993-1997 awards, reflects several factors: 1) cancellation of 21 projects; 2) changes in joint venture membership over the course of the awards; 3 ) limitation of BRS reporting to major participants for a few very large joint ventures and exclusion of non-profit organizations with a purely administrative function, 4) late start of $10 \mathrm{FY} 1997$ projects; and 5) some late reports.

Figure 1 illustrates the distribution of types of organizations and types of ATP projects (single-company or joint venture) included in the BRS data as of March 31, 1998. All the organizations had provided at least an initial Baseline Report by March 31, 1998, even if some had not yet reported actual progress. Reports from these organizations provide the basis for analyses of business plans and goals presented in Chapter 2.

\section{Figure 1. Distribution of Types of Participation and Types of Organizations}

Types of Project Participation

(539 Organizations)
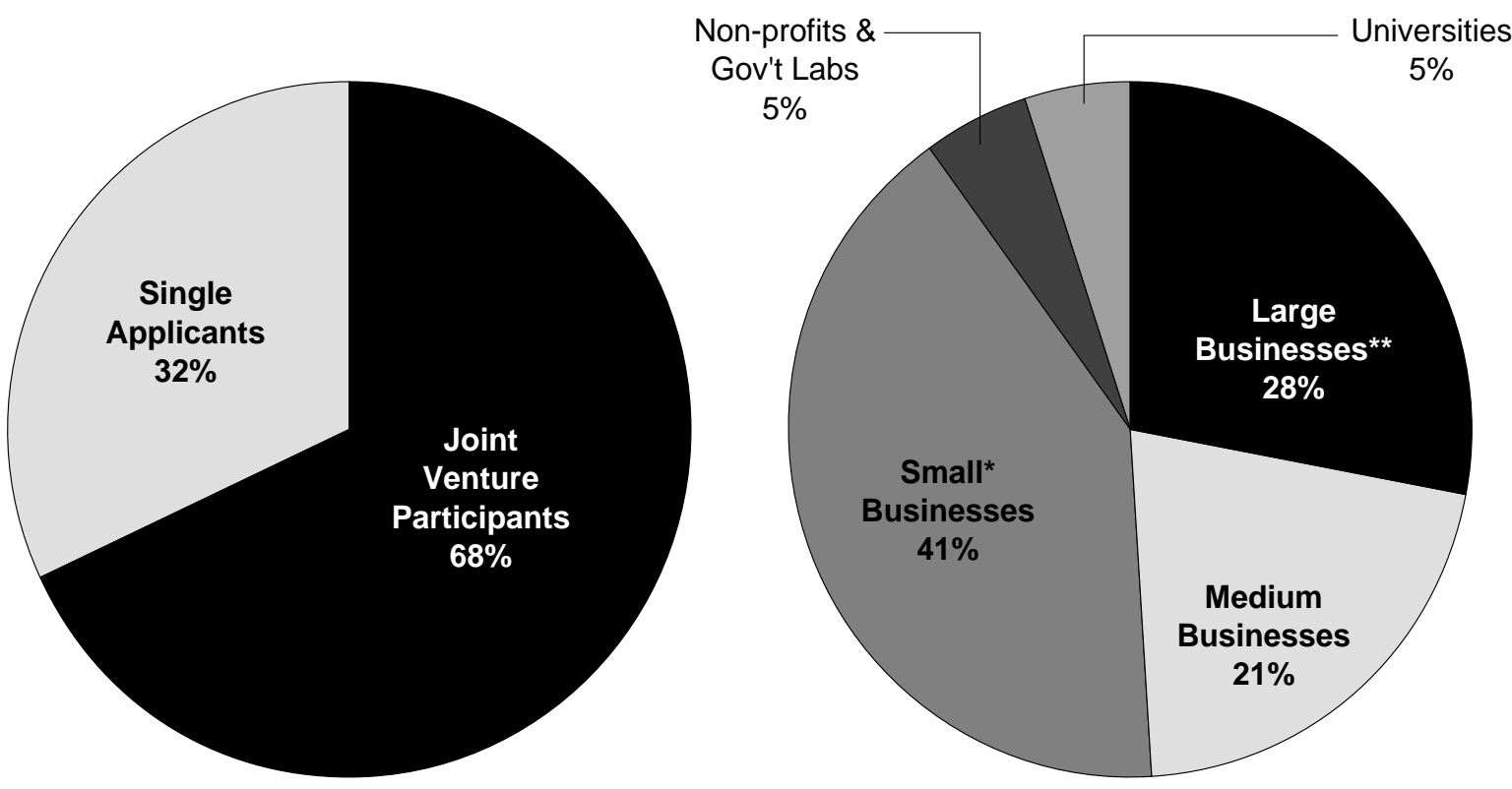

Notes: * Fewer than 500 employees.

** Fortune 500 or equivalent as of Fortune 500 listing published April 1997.

Source: Business Progress Reports from 539 organizations in 261 ATP projects funded 1993-1997. 
The subgroup of organizations reporting actual commercialization progress or other effects of ATP funding after one or more years of funding represent those shown in Table 1 as having filed at least one Anniversary Report or a Close-out Report. They are described further in Figure 2 and include 424 participants in 199 projects that had provided Anniversary or Close-out Reports after one or more years of ATP funding. Reports from these organizations provide the basis for analyses of actual progress towards project goals and other effects of ATP funding presented in Chapters 3 through 8.

Most for-profit companies report some degree of commercialization progress. This attention to commercialization even during the ATP funding period is consistent with the ATP's model that requires companies to set commercial goals up front, and to integrate plans for their R\&D goals and for their business/economic goals from the outset. Most universities and non-profits do not plan to commercialize their ATP-funded technologies but have reported on other effects of ATP funding.

\section{Figure 2. Distribution for Organizations That Had Completed One or More Years of ATP Funding}

Types of Project Participation (424 Organizations)
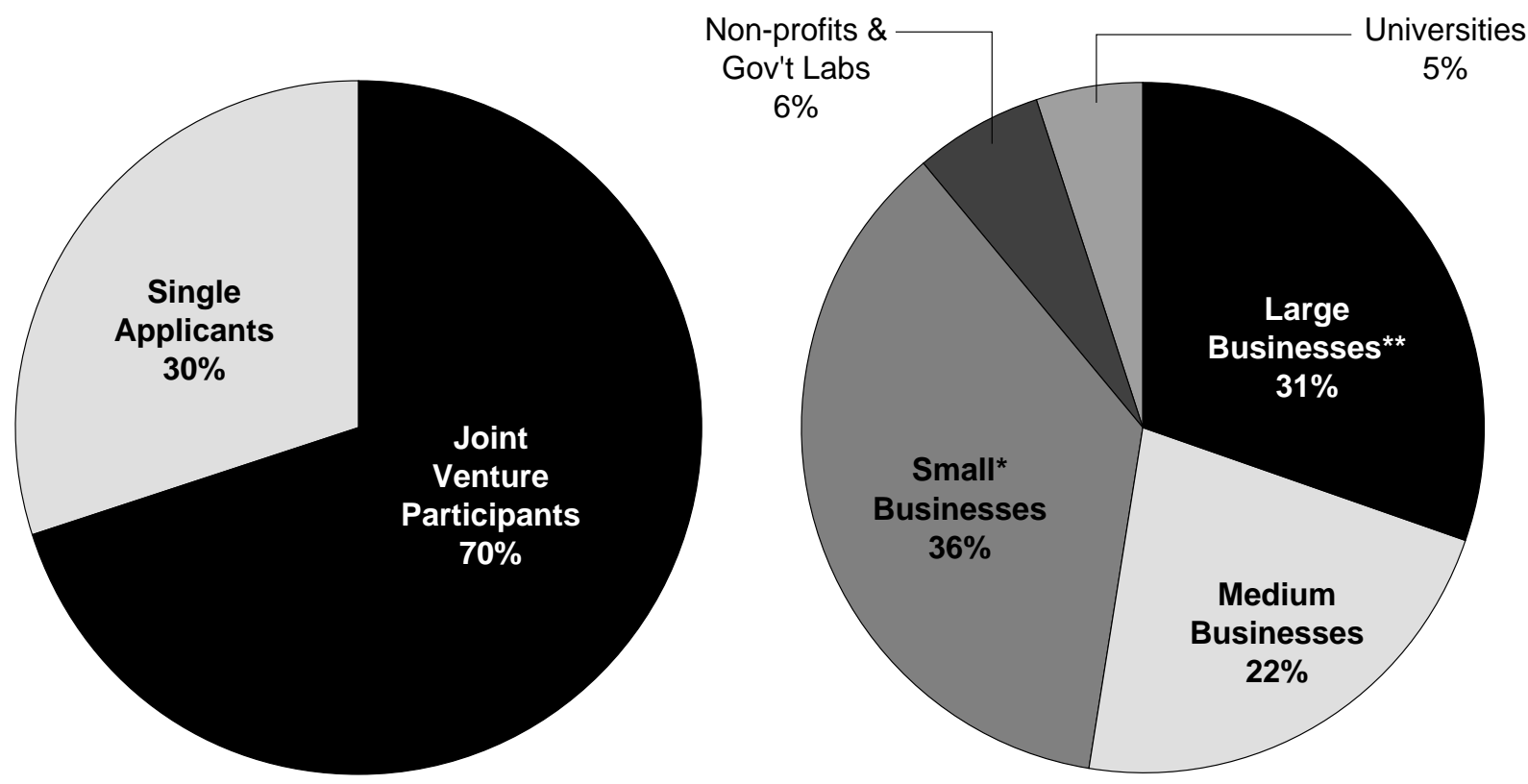

Notes: * Fewer than 500 employees

** Fortune 500 or equivalent as of Fortune 500 listing published April 1997.

Source: Business Progress Reports from 424 organizations in 199 ATP projects funded 1993-1997 after one or more years of ATP funding. 
Figure 3. Technologies Under Development

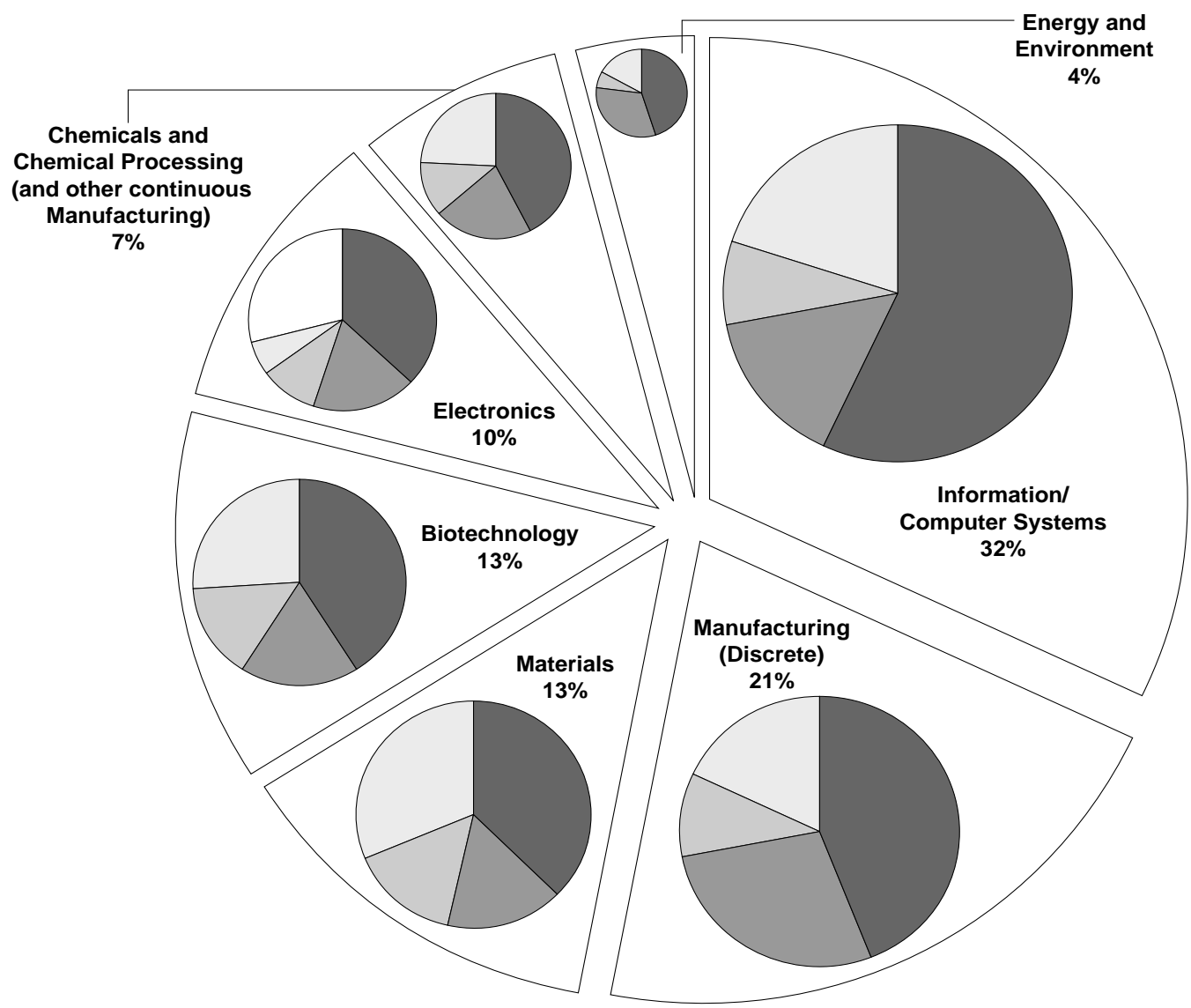

Source: Business Progress Reports from 510 organizations in 257 ATP-funded projects 1993-1997.

LEGEND for Breakdown of Technology Areas

Information/Computer Systems

Computer Software, $\mathbf{5 7 \%}$

Computer Hardware, $\mathbf{1 5 \%}$

Imaging \& Image Processing, $8 \%$

Other/Not Specified, 20\%

\section{Biotechnology}

$\square$ Human Diagnostic Biotechnology, 41\%

Human Therapeutics, $\mathbf{1 8 \%}$

Bioprocessing / Bioengineering, 15\%

Other/Not Specified, 26\%

\section{Manufacturing (Discrete)}

$\square$ Automobile Manufacturing, 44\% Machine Tools, 28\%

Intelligent Manufacturing, 10\%

Other/Not Specified, $\mathbf{1 8 \%}$

\section{Electronics}

$\square$ Displays, $\mathbf{3 7 \%}$
$\begin{aligned} & \text { Electronic Instrumentation/Sensors } \\ & \text { and Control Systems, } \mathbf{1 8 \%}\end{aligned}$
$\begin{aligned} & \text { Optics and Photonics, } \mathbf{1 0} \% \\ & \square \quad \text { Semiconductors and Microelectronic } \\ & \text { Fabrication Technology, } \mathbf{6 \%}\end{aligned}$
$\square \quad$ Other/Not Specified, $\mathbf{2 9} \%$

Energy and Environment

\begin{tabular}{|l}
$\square \quad$ Energy Distribution/ \\
Conservation, 45\% \\
Energy Resources/ \\
Generation, $\mathbf{3 2 \%}$ \\
$\square \quad$ Environment, $\mathbf{6 \%}$ \\
$\square \quad$ Other/Not specified, $\mathbf{1 7 \%}$
\end{tabular}

Chemicals and Chemical Processing (and other Continuous Manufacturing)

Catalysis/Biocatalysis, $\mathbf{4 2} \%$

$\square$ Separation Technology, $\mathbf{2 1 \%}$

$\square$ Process Control, $12 \%$

Other/Not Specified, 24\%
Materials

$\square$ Composites, $\mathbf{3 7 \%}$

$\square$ Coatings, $16 \%$

Metals and Alloys, $15 \%$

Other/Not Specified, $\mathbf{3 1} \%$ 


\section{PATHS TO NATIONAL ECONOMIC BENEFITS}

This chapter describes the pathways through which projects funded 1993-1997 are expected to achieve national economic benefits. Along the direct pathway, companies will bring new products and services into the marketplace, will use ATP-funded process technologies in in-house production, or will license their technology to other companies. Benefits will spill over to customers, licensees, and end users. At least one for-profit company in nearly all projects has reported such plans for one or more applications of the ATP-funded technologies. Most universities, non-profits, and government laboratories in joint venture projects, as well as many of the companies, have reported plans for dissemination of nonproprietary information concerning technology developed with ATP funds, an important indirect path to economic impact.

\section{Development of Technologies with Diverse Applications}

The projects covered by this report include 95 projects funded through annual General Competitions open to all technology areas and 166 projects funded through focused program competitions. Many projects and entire Focused Programs, consisting of sets of related projects, involve an interdisciplinary mix of science and technology fields. ATP-funded interdisciplinary technologies often enable economic activity across multiple industries. Other projects are tied more narrowly to a single technology area but the performance gains over existing methods are so dramatic they help spawn entirely new areas of economic activity and industries.

Figure 3 summarizes the technologies according to their multi-level code assignments. Projects are grouped into broad technology areas and then further broken down into categories more descriptive of the project focus. Thirty-two percent of the projects directly involve Information Technology/Computer Systems, either hardware or software. Discrete manufacturing, materials and biotechnology comprise major parts of the remainder. These four areas of concentration reflect the fact that 20 of the 22 ATP Focused Program areas funded in FY 1995-1997 involve substantial information technology, biotechnology, materials processing and manufacturing technology. (This distribution differs somewhat from other technology classification charts published by the ATP because the distribution shown in Figure 3 (a) reflects only the projects funded in FY 1993-1997; (b) reflects R\&D activity at the organization rather than the project level; and (c) is based purely on the number of organizations working in a given technology area, not on the relative amount of funding to the technology area. The distribution of technologies reported here is based on the classification system used by the ATP for projects funded through FY 1998. The ATP revised its technology classification in 1999.)

A second-tier analysis helps reveal the interdisciplinary component of many ATP projects. For example, Figure 3 shows that 10 percent of the work in Manufacturing (Discrete) involves "intelligent" manufacturing; 15 percent of the work in Information/Computer Systems is hardware. A third-tier analysis (not presented) would show that computer hardware has a strong electronics component; e.g., digital data storage. This next level of analysis also would reveal the overlapping of projects across disciplines and the difficulty of classifying them. For instance, some computer systems components and related manufacturing technologies are assigned to the Electronics category; e.g., Displays and Semiconductors and Microelectronic Fabrication technology. (ATP's revised technology classification for FY99 and later projects reclassifies computer-related hardware to the electronics category.) A number of biotechnology projects intermingle development of materials and electronics technologies.

About 470 project participants have identified more than 1,200 applications of the technologies under development and provided an outline of a commercialization plan for over 970 of these 
Figure 4. Planned Diverse Applications of ATP-funded Technologies

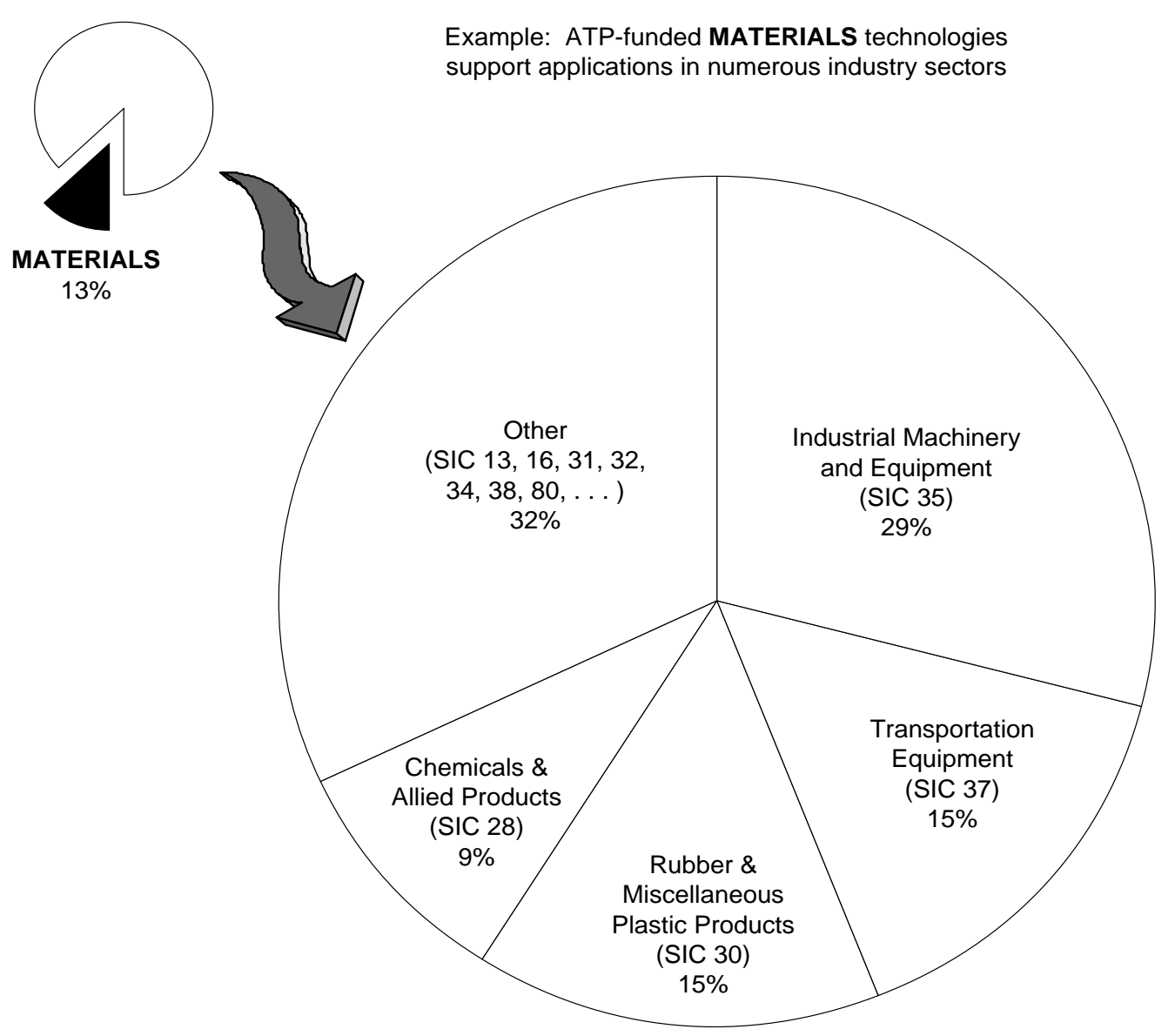

Note: "Other" SIC categories are defined in Appendix A.

Source: Business Progress Reports for 974 applications being pursued by 463 companies in 256 ATP projects funded 1993-1997.

applications spanning the spectrum of SIC industries. Figure 4 illustrates the diverse application areas of the enabling technologies designated by the companies as in the Materials area. A detailed examination of individual reports reveals more explicitly the diverse linkages. For example, company reports for one project involving coatings technology reveals planned applications in industrial machinery for internal combustion engines (SIC 35), aircraft parts and equipment (SIC 37), and health services (SIC 80). Another project involving metal and alloy technology reports applications in construction machinery (SIC 35), truck trailers (SIC 37), and fabricated structural metal products (SIC 34). Illustrations of linkages between other technology areas under development and their diverse application areas appear in Appendix A.

Commercialization of the ATP-funded technology will occur through eventual embodiment in a product, service, manufacturing process, or possibly some combination of these. Figure 5 summarizes the percentages that are expected to occur in each form. Most commercial deployment of ATP technologies will occur through manufactured products with significant advantages over existing products. Individual companies and projects are planning to use their new technical capabilities to achieve a competitive advantage in the marketplace through a mix of "new-to-the-world" solutions and cost reductions and performance improvements in products, processes, or services. For 38 percent of the applications, companies envision their application to be a "new-to-the-world" solution to a market need or problem.

Development, Commercialization, and Diffusion of Enabling Technologies: Progress Report 


\section{Figure 5. How ATP-funded Technologies Are Expected Eventually To Be Deployed}

Types of Applications

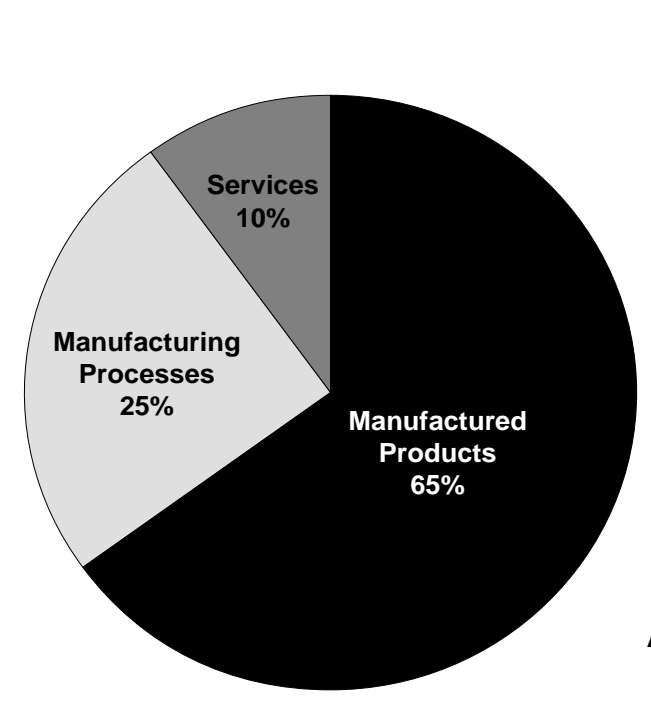

Advantages Over Existing Technologies

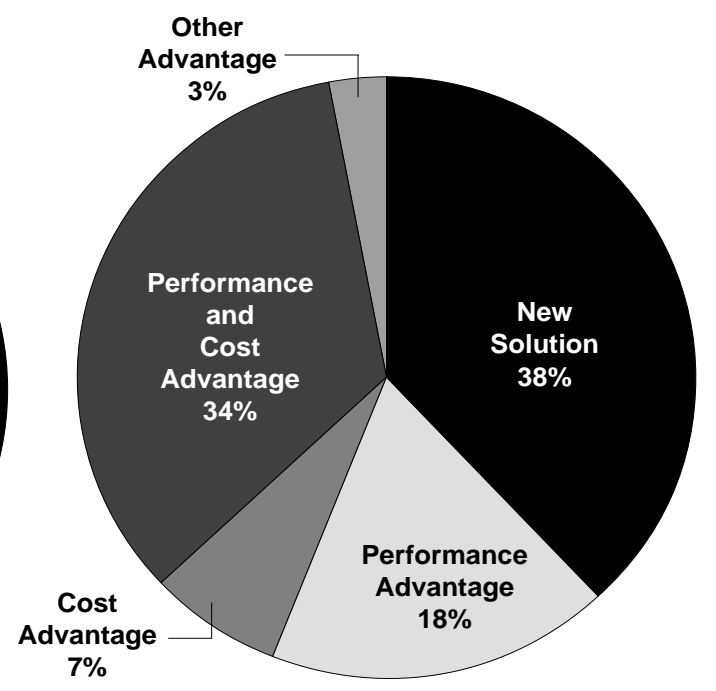

Source: Business Progress Reports for 973 applications being pursued by 462 companies in 255 ATP projects funded $1993-1997$.

As shown in Figure 6, many companies envision that products and processes embodying the ATPfunded technology will be used in multiple stages of production extending from Raw Materials Production to End User. Sixty-two percent of the technology applications involve relatively early-stage Components Manufacturing.

Figure 6. Stages of Production in Which the ATP-funded Technologies Are Expected to Be Used

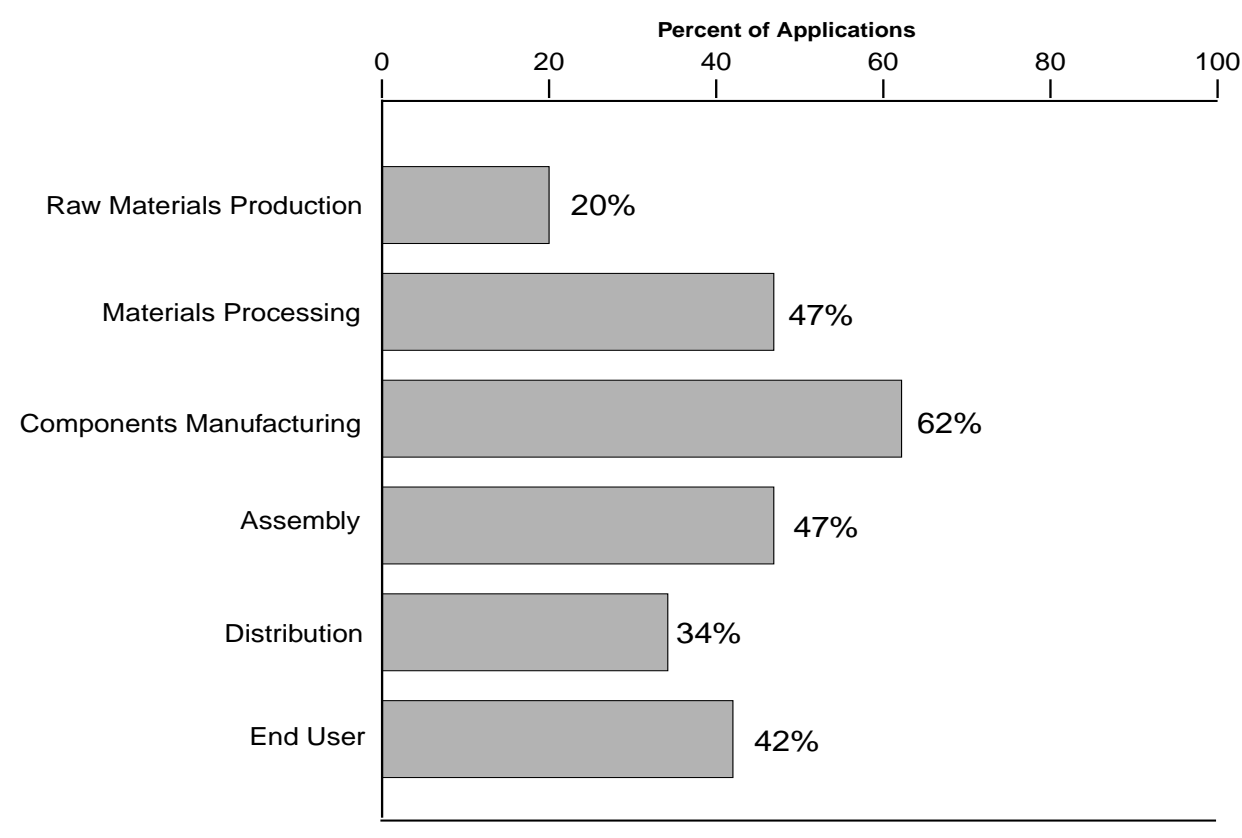

Note: Most companies plan to address more than one stage of production; many plan to address more than two.

Source: Business Progress Reports for 959 applications being pursued by 456 companies in 254 ATP projects funded $1993-1997$. 
The entry of the ATP technology into an early stage of the production cycle, in combination with the diversity of applications expected to result from individual projects and technologies, increases the opportunity for downstream customers/users to experience market spillovers (consumer surplus). This is, of course, especially true where an ATP-funded technology has significant cost or performance advantages over existing/defender technologies.

\section{Business Goals}

In the Baseline Reports, companies who reported they anticipated a performance advantage, a cost advantage or a combination of the two over existing technologies (see Figure 5) are asked to estimate their advantage in percentage terms. As shown in Figures 5 and 7, performance improvements are more frequent, and performance improvements of at least 25 percent appear to be more common than cost reductions of this magnitude. For 30 percent of applications, a performance improvement in the range of 100 percent or greater is anticipated. For 40 percent of applications, a cost reduction of 25 percent or more is expected. The performance and/or cost advantages of "new-to-the-world" solutions over existing, but entirely different, solutions to the same problem, are usually more difficult to estimate but often promise to be quite dramatic. Improvements of substantial magnitudes, particularly when combined with the emphasis on "new" products or lines of business, are consistent with definitions of "discontinuous" or "breakthrough" innovations used in the joint Rensselaer Radical Innovation Research - Industrial Research Institute Project funded by the Sloan Foundation (Leifer, 1997). (Of course, for some projects, even a small cost reduction or performance improvement can represent a significant economic benefit and important competitive advantage when measured across a large production volume.)

\section{Figure 7. Quantitative Business Goals}

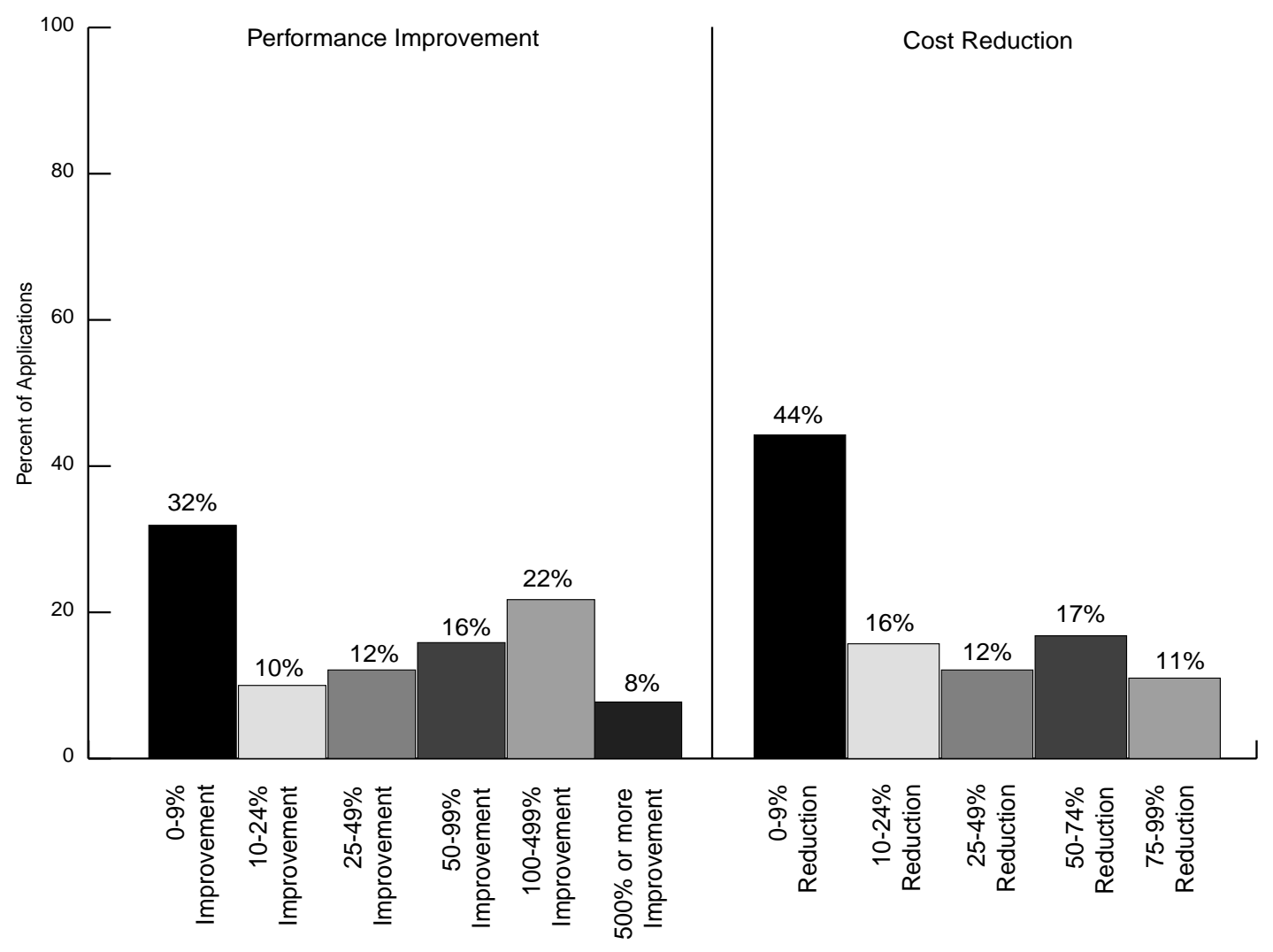

Source: Business Progress Reports for 574 applications anticipating a performance and/or cost advantage over existing technology being pursued by 313 companies in 183 ATP projects funded 1993-1997.

Development, Commercialization, and Diffusion of Enabling Technologies: Progress Report 


\section{Table 2. Examples of Effect of ATP Funding on Company Goals for the Technology}

\begin{tabular}{|c|c|c|}
\hline Conditions at Project Start & Goal Without ATP Funding & Goal with ATP Funding \\
\hline 60 microseconds process speed & 60 microseconds process speed & 10 microseconds process speed \\
\hline \$12/disk & $\$ 5 /$ disk & $\$ .50 /$ disk \\
\hline 3,300 hours lifetime & 5,000 hours lifetime & 10,000 hours lifetime \\
\hline 2,500 cars/day & 2,500 cars/day & 2,875 cars/day \\
\hline 34 trains/day & 34 trains/day & 51 trains/day \\
\hline 1,000 CPU time & $100 \mathrm{CPU}$ time & $10 \mathrm{CPU}$ time \\
\hline 60 degrees $C$ & 60 degrees $C$ & 100 degrees $C$ \\
\hline $800 \mathrm{~nm}$ & $800 \mathrm{~nm}$ & $200 \mathrm{~nm}$ \\
\hline$\$ 60,000$ per unit & $\$ 10,000$ per unit & $\$ 1,000$ per unit \\
\hline $45 \mathrm{~cm}$ & $20 \mathrm{~cm}$ & $10 \mathrm{~cm}$ \\
\hline 40 bases/minute & 533 bases/minute & 2,000 bases/minute \\
\hline$\$ 500 /$ medical test & $\$ 500 /$ medical test & $\$ 50 /$ medical test \\
\hline 1 gene/day sequencing & 5 genes/day sequencing & 100 genes/day sequencing \\
\hline 3.9 gigabytes data storage & 4.7 gigabytes data storage & 60 gigabytes data storage \\
\hline \$62/gigabyte & \$1/gigabyte & \$1/gigabyte \\
\hline
\end{tabular}

Source: Business Progress Reports for 911 applications being pursued by 431 companies in 250 ATP projects funded 1993-1997.

Table 2 provides an illustrative list of quantitative examples of how ATP funding is expected to affect the technological capabilities of companies as measured by expected changes in value for the attribute identified as most critical to commercialization for a specific application. Quantification of cost and performance advantages of the ATP-funded technology, such as provided by this business goals analysis, is useful in tracking project progress as well as assessing business opportunities and estimating the potential magnitude of economic spillovers. A comparison of goals "with" and "without ATP" is needed to assess the potential for ATP funding to make a difference relative to what would have occurred without government funding. An ex ante comparison of baseline values with project goals for key technology parameters/attributes helps to identify the anticipated degree of technological advancement and to assess the expected economic impact of the project. An ex post comparison of actual progress made against cost/performance targets will make it possible to assess the degree to which project goals for these targets are met and to consider the resulting impact on economic benefits of the project.

Acceleration of R\&D is another commonly cited business goal of ATP projects. As shown in Figure 8 , nearly all the companies expect some reduction in the time it will take to complete the R\&D phase and bring their products to market/or implement new production processes as a result of ATP funding. A reduction of at least two years is anticipated for 65 percent of all applications; a reduction of two to nearly four years is expected for 41 percent of applications; and a reduction of four or more years (including those that would not be undertaken at all without ATP funding) is expected for 24 percent of applications. 
The importance of speed-to-market is considered "important" or "critical" for 98 percent of applications; it is considered "critical" for more than half. Further emphasizing the importance of acceleration, the window of opportunity for 73 percent of the applications to enter the marketplace is considered to be within two years after ATP funding ends; i.e., it appears that companies believe they would miss the opportunity, or a significant part of it, without the acceleration enabled by ATP funding.

Figure 8. Importance of Market Timing

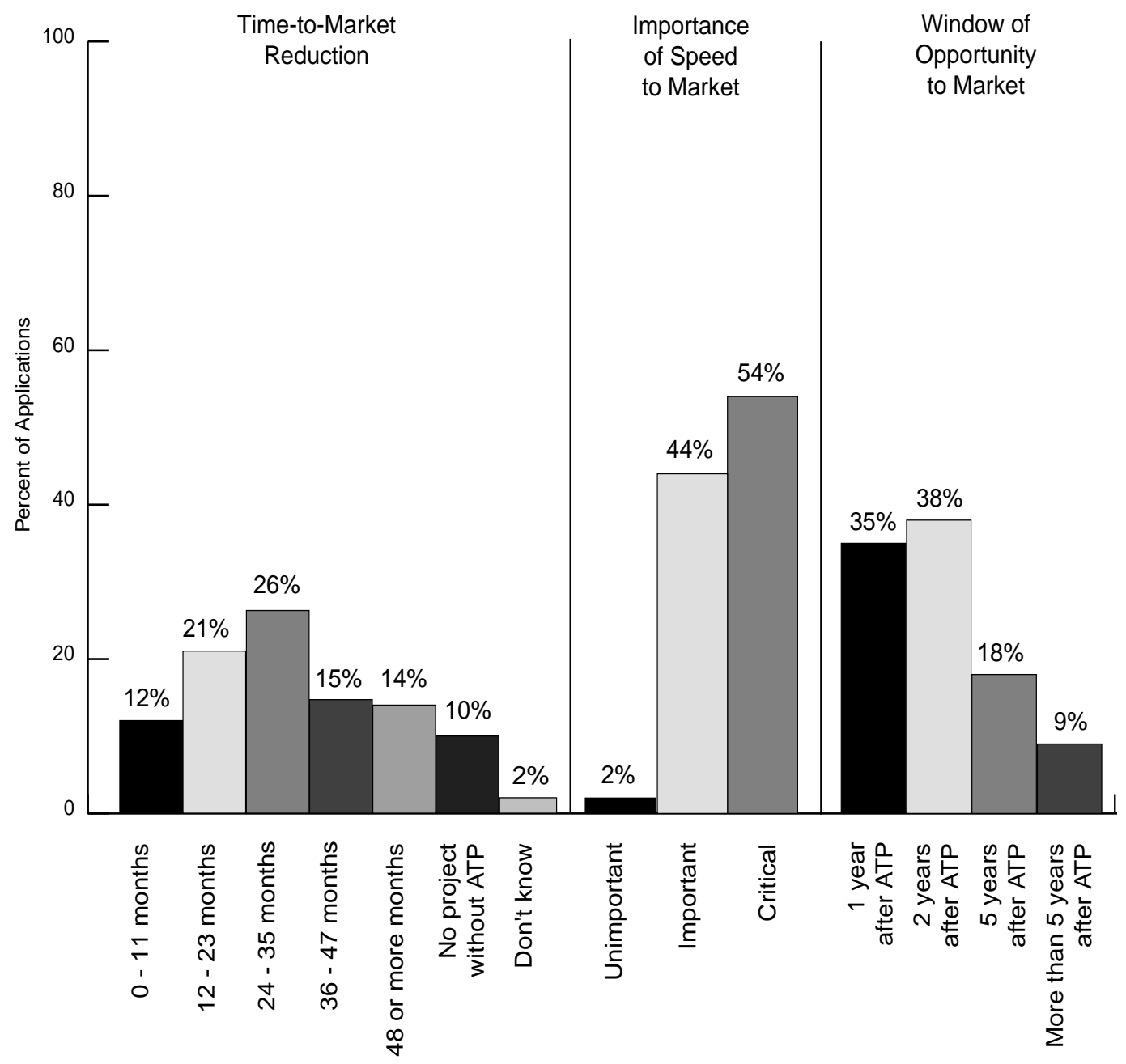

Source: Business Progress Reports for 974 applications being pursued by 464 companies in 256 ATP projects funded 1993-1997.

The following are some additional business goals cited in company business reports:

"Be \#1 supplier of ... technology"

"Obtain a licensee by end of ATP"

"Become global expert in ... technology"

"Diffuse technology to cover 5 technology niches"

"Increase market share by ..."

"Be recognized as leading vendor of ..." 


\section{Identification of Commercialization Strategies}

As their primary means of commercialization, most ATP-funded companies plan to achieve commercialization for at least one application through production of a product or service in-house, in their own existing or planned facilities. Some companies indicated more than one primary means of commercialization for a given application. As shown in Figure 9, in-house production is the focus for 62 percent of applications. For 29 percent of applications, licensing to others is the primary strategy; for 47 percent of applications, licensing is the primary or secondary means of commercialization. For 81 percent of applications, including some of those where in-house production is the primary means, licensing to others is at least a possible supplementary means, if not the primary focus. Thus companies recognize the opportunity to increase their revenues beyond what their internal production facilities can support, while at the same time increasing opportunities for diffusion of the technology to other firms and potentially other applications and industries. The potential for licensing the technology to others is a factor that makes economic spillovers relatively more likely (Jaffe, 1996).

Figure 9. Strategies for Commercializing ATP-funded Technologies

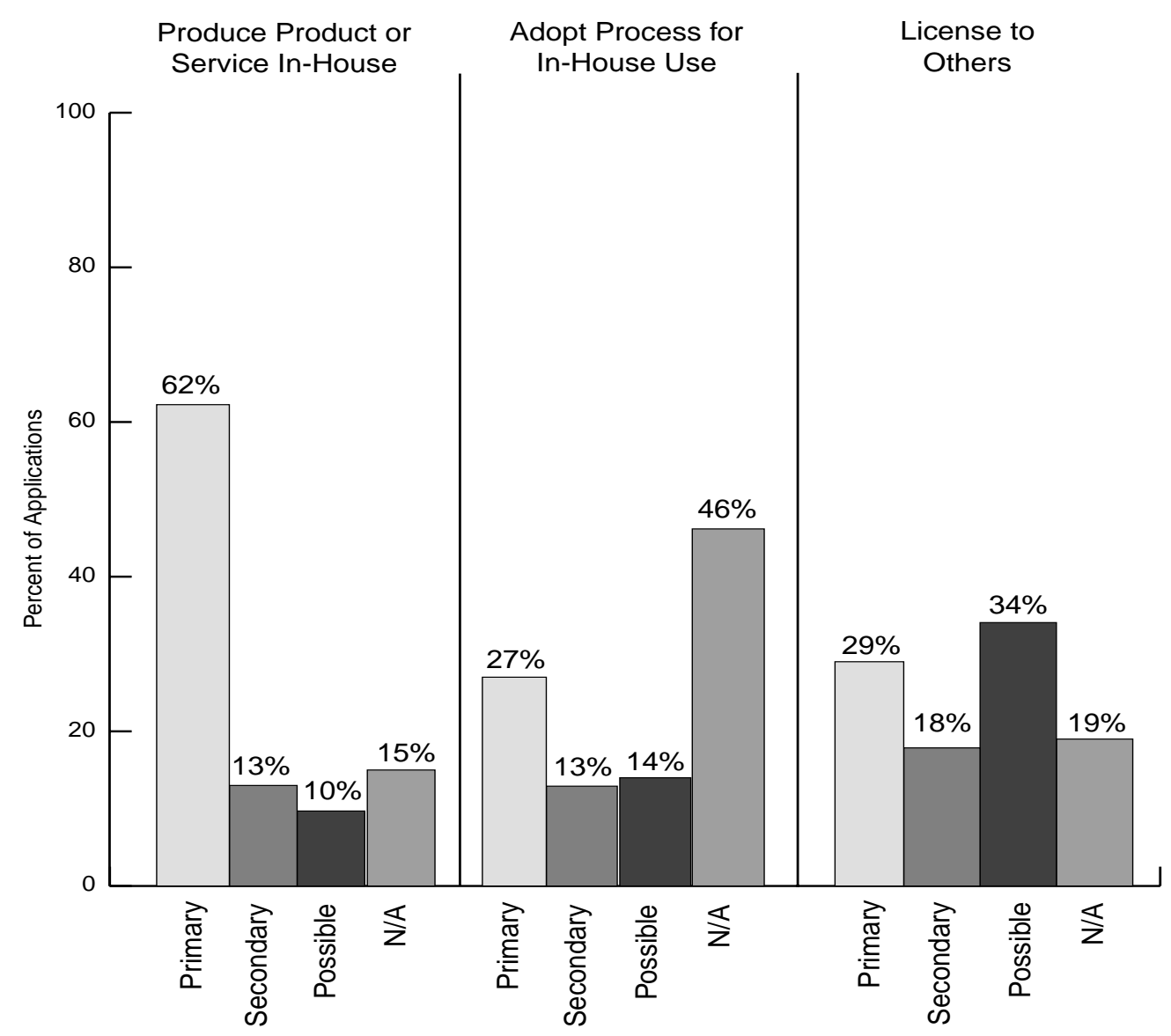

Note: Some companies reported more than one strategy as "Primary."

Source: Business Progress Reports for 972 applications being pursued by 462 companies in 256 ATP projects funded $1993-1997$.

Close supplier-customer linkages are important to successful technological innovation. Among the work that addresses this issue, von Hippel suggests that such linkages can increase the productivity of the innovation through more efficient communication of technological and market information (von Hippel, 
1994). Given the large number of small companies involved in the projects, and the rather early stages of production they address, one would expect a large number to pursue strategic alliances for commercialization. But Figure 10 shows that one-fourth or less of applications involve heavy reliance on strategic alliances with customers, suppliers, partners in joint production, or distributors, looking at each type of alliance individually.

Figure 10. Strategic Alliances Planned

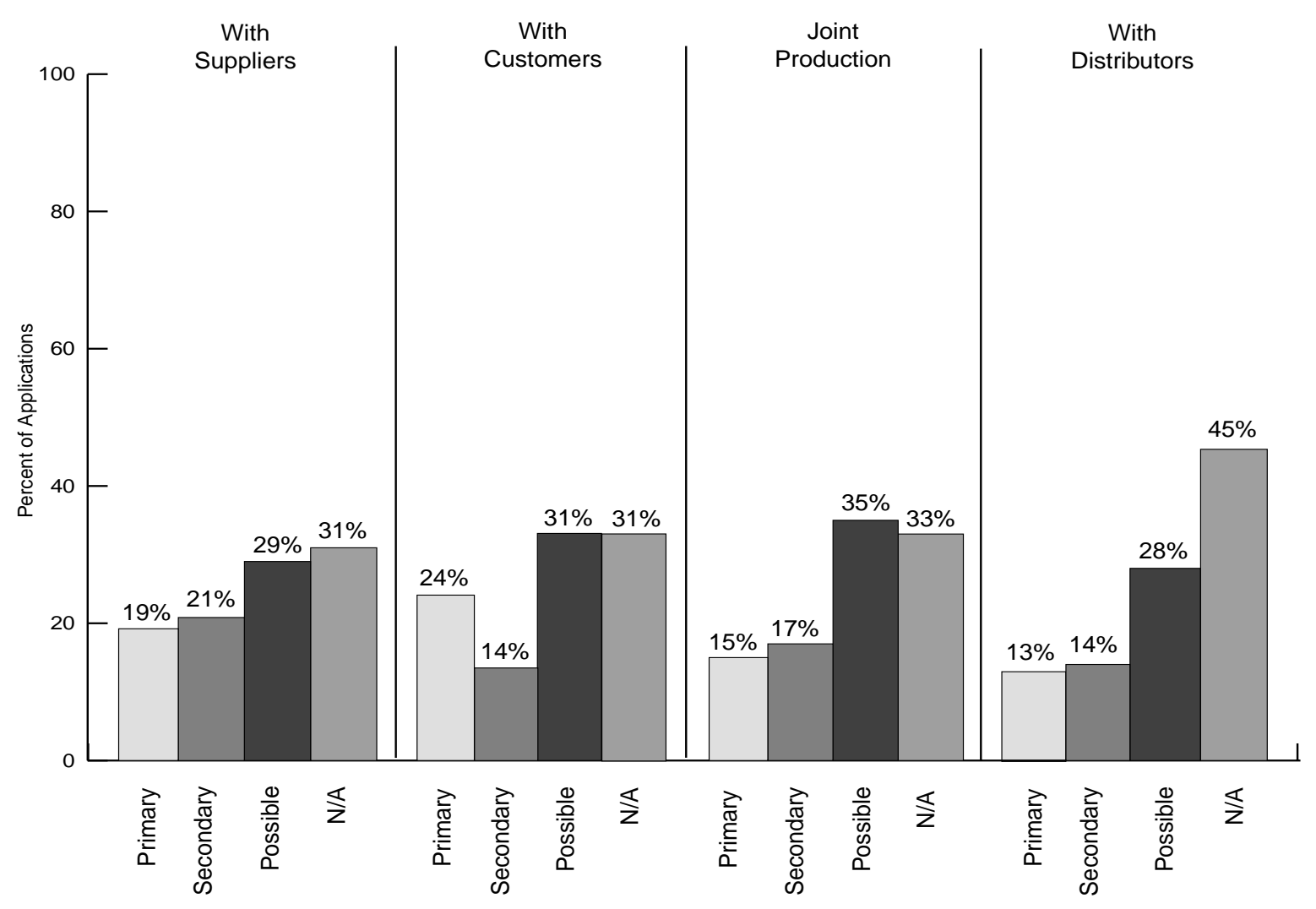

Source: Business Progress Reports for 971 applications being pursued by 462 companies in 256 ATP projects funded $1993-1997$.

Further analysis, however, reveals that (a) 94 percent of companies plan at least one of these types of alliances and (b) at least one of these types of alliances is planned in pursuing 90 percent of applications (graph not presented).

The subset of reports from small businesses reveals that strategic alliances to pursue commercialization are more important for small businesses than for larger ones, as one would anticipate. Small businesses plan alliances with customers as a primary strategy for 31 percent of applications and as a primary or secondary strategy for 49 percent of applications (compared with 24 and 38 percent respectively for all respondents); small businesses plan alliances for joint production as a primary strategy for 20 percent of applications and as a primary or secondary strategy for 44 percent of applications (compared with 15 and 32 percent respectively for all respondents); small businesses plan alliances with distributors as a primary strategy for 20 percent of applications and as a primary or secondary strategy for 39 percent of applications (compared with 13 percent and 27 percent respectively for all respondents). 


\section{R\&D STATUS}

\section{Level of Progress in Completing R\&D Phase}

Chapter 3 and the remainder of this study focus on actual progress against project plans and ATP goals. Figure 11 provides a picture of the $R \& D$ status of project participants. It indicates that 11 percent were less than 25 percent complete; 31 percent were 75-100 percent complete with their R\&D, which corresponds with the growing number of organizations that have completed the ATP funding period. The median level of completion of the ATP project is estimated for the group in the database to be 61 percent. Considering the total R\&D (including that beyond the ATP project) needed for significant commercialization to occur, the median level of R\&D completion is estimated to be 41 percent.

\section{Figure 11. R\&D Status}

\section{Current level of progress:}

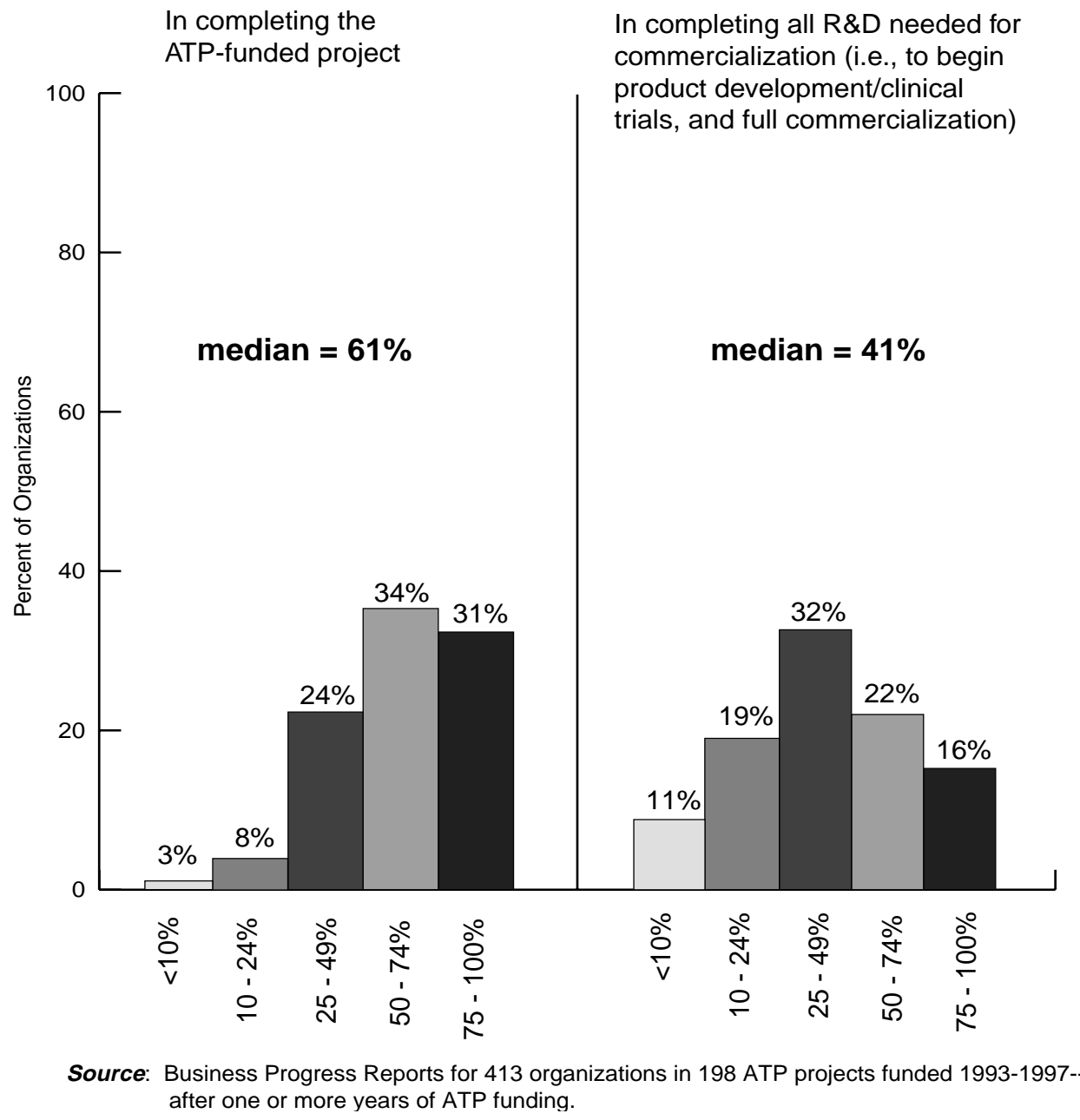

*The 62 projects for which only a Baseline Report was available were dropped from these analyses of actual progress. Of the remaining 199 projects, 119 had completed one-to-three years of ATP funding and had anniversary reports available; 80 had completed a close-out report. (See Chapter 1, Table 1.) No post-project information was available. The most recent anniversary and/or close-out report from each project participant was used. 
These two median values mean that 50 percent of the organizations have completed at least 61 percent of their ATP-funded projects but only 41 percent of the total R\&D needed for full-scale commercialization. The fact that considerable additional R\&D will be required for many organizations after the ATP funding period ends is not surprising given that ATP is funding relatively early-stage applied R\&D with considerable technical risk.

\section{Effect of ATP Funding on R\&D Progress}

Project participants indicate that they are significantly ahead in their R\&D cycle as a result of ATP funding as compared with where they would be without their ATP award. As shown in Figure 12, 86 percent indicate that ATP funding has helped accelerate R\&D efforts in the ATP-funded area. Of these, 24 percent believe they would not have pursued the R\&D at all without the ATP award; 55 percent believe they are one to three years ahead as a result of ATP funding. Only one percent indicated they were behind. Overall, measurable progress appears to have been made towards meeting critical windows of opportunity for the ATP-funded technologies.

Figure 12. Acceleration of R\&D

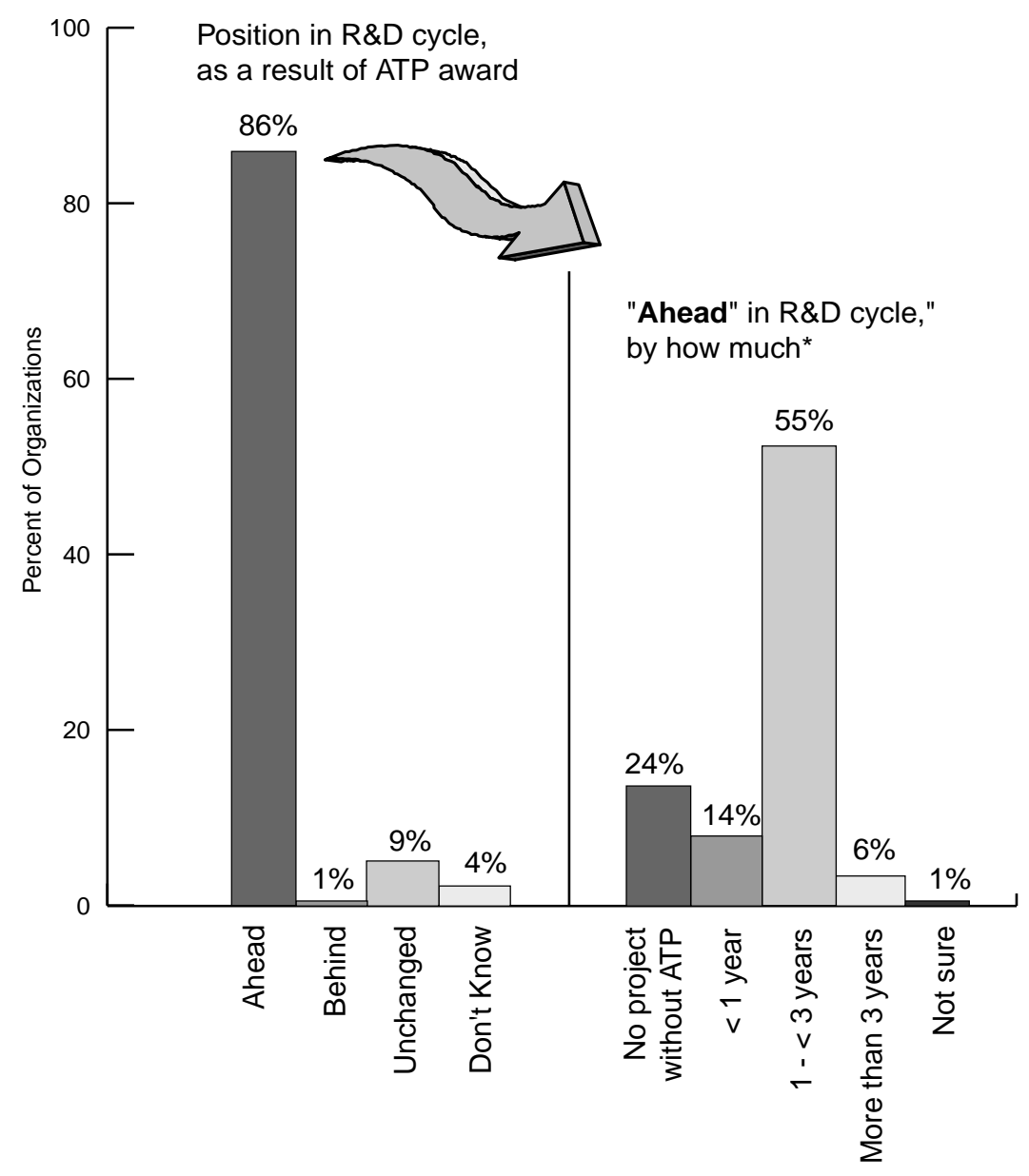

Note: *Include responses from organizations indicating "Ahead" to prior to question.

Source: Business Progress Reports from 412 organizations in 198 ATP projects funded 1993-1997--after one or more years of ATP funding. 


\section{When Can Revenue Be Expected?}

Although the ATP funds R\&D that involves considerable technical uncertainties and difficulties, technical progress tends to come in stages. Early-to-intermediate stage accomplishments may have commercial value worth capturing by incorporating newly gained knowledge in a near-term generation of products and processes even though attainment of the ultimate goals required for the full spectrum of applications remains distant.

A significant amount of commercialization planning activity is expected over the course of the ATP project, and some projects are expected to experience the beginnings of revenue generation from spin-off activities. Across the projects, companies, and applications encompassed by this report, 14 percent of the projects expect to see some revenues from at least one early application of the ATP-funded technology by the end of the ATP funding period. (See Figure 13.) For 61 percent of the projects, revenue is not expected until a year or more after the end of ATP funding; for 12 percent of projects, revenues are not expected until four or more years after the end of ATP funding. Only one percent of organizations indicated they do not expect to earn revenues at any time. These include universities and other joint venture members without a significant commercialization role, although they might be performing testing and other services important to future commercialization by companies in their joint ventures.

\section{Figure 13. When Can We Expect To See Revenues from ATP-funded Technologies?}

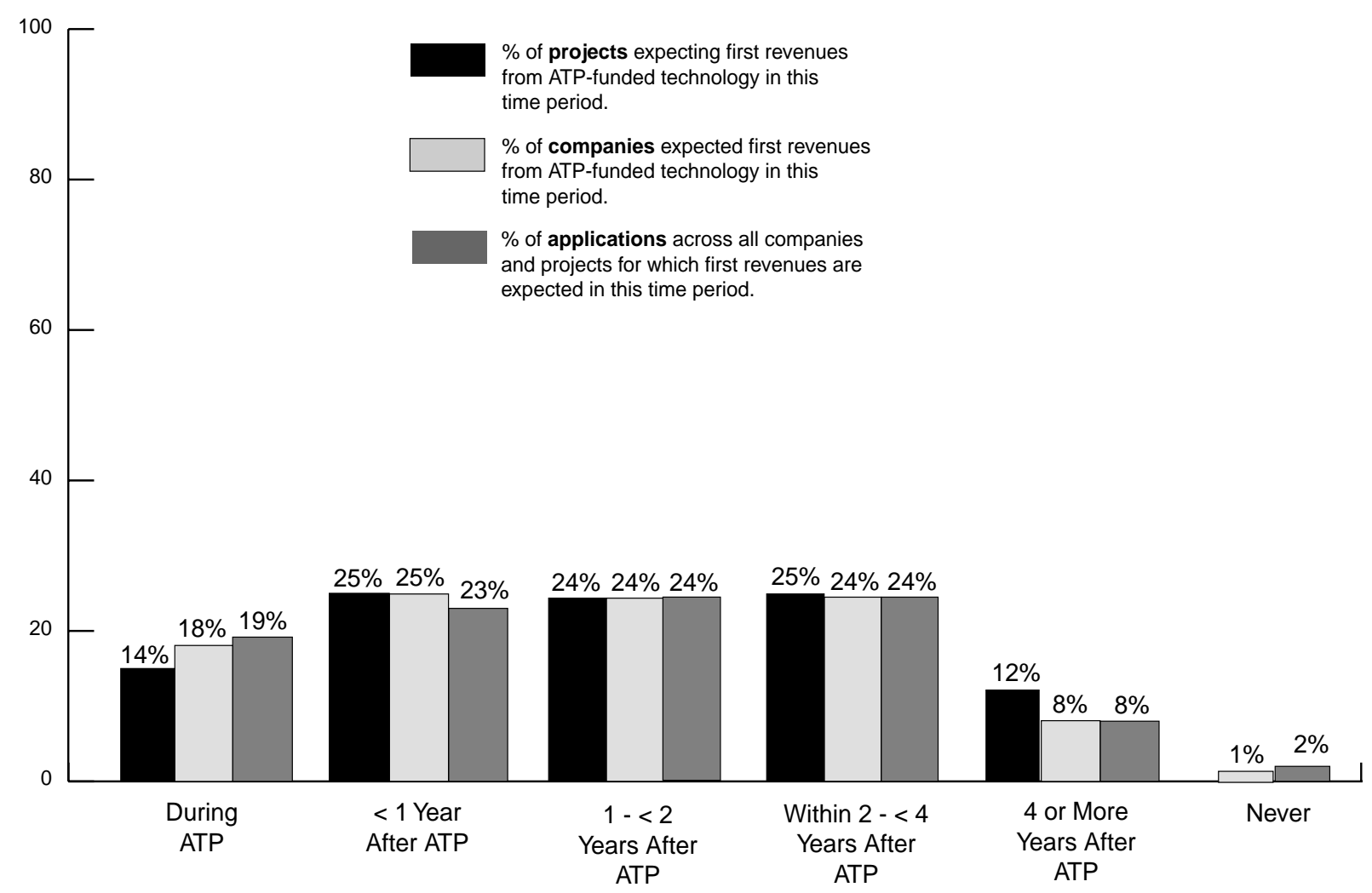

Source: Business Progress Reports for 974 applications being pursued by 463 companies in 256 ATP projects funded 1993-1997. 
Small, young companies, such as the large number of start-ups the ATP has funded, typically strive for early spin-off products and joint-development contracts with other companies to generate cash flow needed for financial survival. Taking advantage of early revenue opportunities may help them attract the private capital needed to pursue the breadth of technological development required to compete in costsensitive markets, and for a broad range of potential applications. From observation of ATP-funded companies involved in manufacturing of advanced products and from analysis of individual company reports, it appears that at any given time many of the companies are engaged in a mix of R\&D and related commercialization activities involving a single core technology. These activities may feed into the development of several different generations of products, including some entirely new product lines, which will enter the marketplace at different times over the next five or more years. In the case of biotechnologies for human therapeutics, for example, early applications may involve research tools and test kits. Significant commercialization of the targeted human medical therapeutics may not be possible for five or more years after ATP funding ends because of the lengthy regulatory processes required.

The remainder of this report describes the effects of ATP funding, actual commercialization progress, and the beginnings of technology diffusion, within the context of the relatively early R\&D stage of many of these projects. Substantial technical uncertainties remain, and full business and economic potential are very difficult to predict in the face of both technical and economic uncertainties still remaining at this time. These caveats notwithstanding, early effects of ATP funding are identified and conditions necessary for significant future commercial success and national economic impact are monitored. With the further passage of time, and additional data collection and analysis, we will learn much more about the evolution of these projects. The ultimate outcomes of most ATP-funded projects will not be known for a number of years after ATP funding ends. 


\section{STIMULATION OF COLLABORATION AND RELATED EFFECTS}

\section{Stimulation of R\&D Collaboration}

Stimulation of collaborative R\&D relationships among companies, universities, and other research organizations is part of ATP's legislated mission. The objectives are to increase research efficiency and effectiveness, expand capabilities, reduce R\&D cycle time, and accelerate commercialization and competitiveness. The level of collaborative activity has been considerable from the beginning of the program. In the first competition, ATP funded five joint venture projects among the first 11 awards. From 1990 through 1999, the ATP funded 157 joint ventures, involving over 750 participants. Many of these joint ventures involve companies which had never worked together before and were formed explicitly to apply for ATP funding (Silber, 1996, p. 23). Of the 424 organizations in 199 FY 1993-1997 projects for which data are available after one or more years of ATP funding, 298 are members of 73 joint ventures. (See Chapter 1, Figure 2.) In addition to the formal joint ventures, the ATP has found that most of the "single company projects" it funds are, in fact, also rich in collaborative relationships. These are implemented through subcontracting arrangements and informal alliances.

\section{Figure 14. Stimulation of Collaborations}

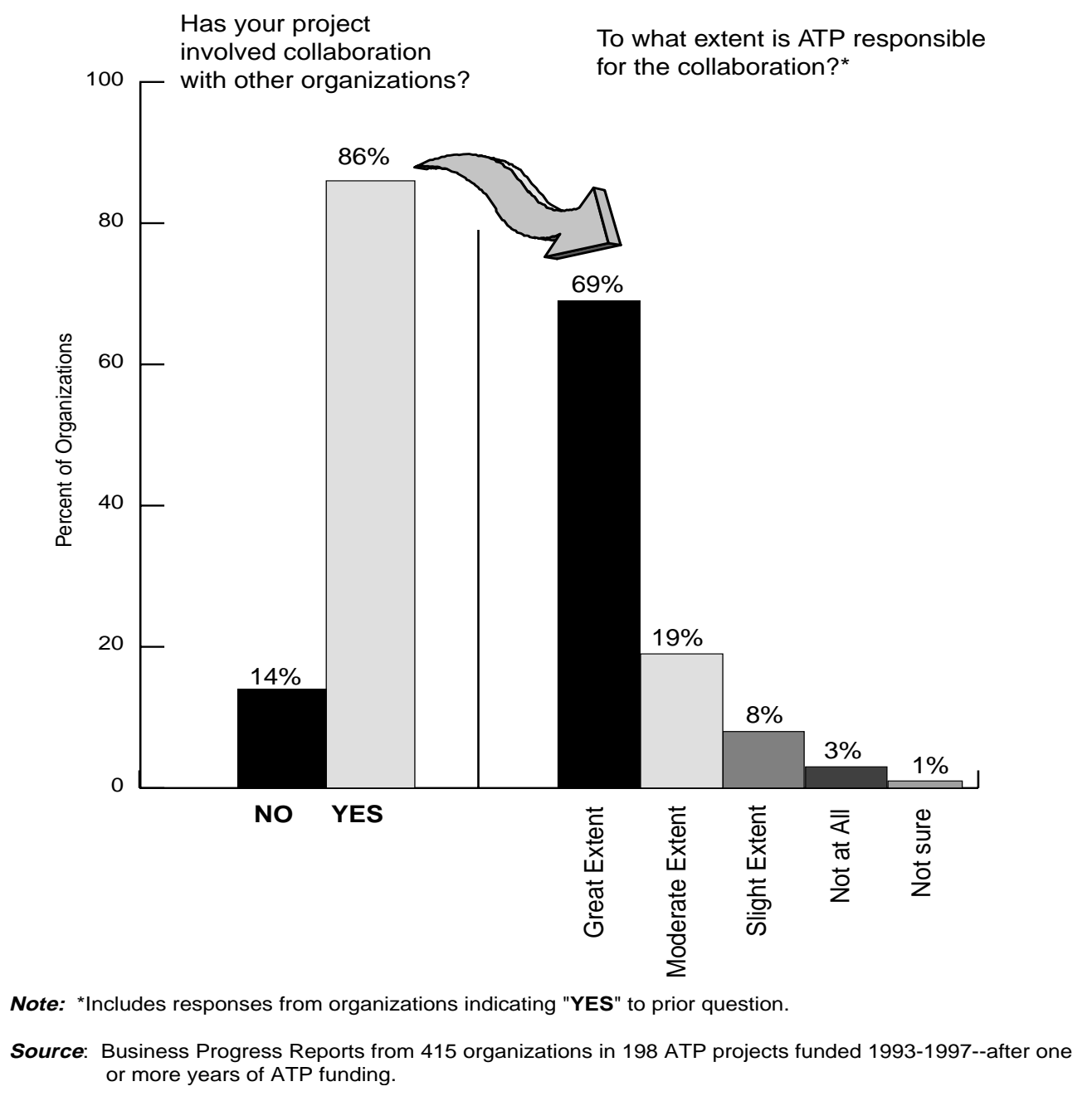


As shown in Figure 14, 86 percent of respondents reported their ATP project involved collaboration with other organizations. Of the group indicating their project involved collaboration, 69 percent indicated that the ATP was responsible for the collaboration to a great extent. Eighty-eight percent indicated ATP was responsible to a moderate or great extent.

As indicated above, many ATP collaborations reach beyond the formal joint venture relationship. Both single company award recipients and joint venture members form collaborative relationships through subcontractor arrangements and informal alliances. A total of 581 subcontractor arrangements, for example, have been reported by single company awardees and joint venture awardees filing BRS reports. Fifty-two percent of the subcontractors reported are small companies. Universities comprise 30 percent, and 18 percent of these subcontractors consist of medium-to-large companies, government-funded laboratories, and non-profit laboratories.

\section{Collaboration Effects}

Figure 15 shows effects most significantly enabled by ATP collaborations of these multiple types. At least 80 percent of respondents indicated that collaboration enabled these effects significantly or moderately. Ninety-seven percent indicated that collaborations had "stimulated creative thinking;" 80 percent indicated that collaborations had enabled the company to accelerate entry to the marketplace, and 85 percent indicated a general time savings (corroborating acceleration effects cited in Chapter 3); 86 percent reported that collaboration had enabled the company to obtain R\&D expertise; and 80 percent indicated that their experiences with ATP collaborations had encouraged them to consider future collaborations.

Figure 15. Effects Most Enabled by Collaboration

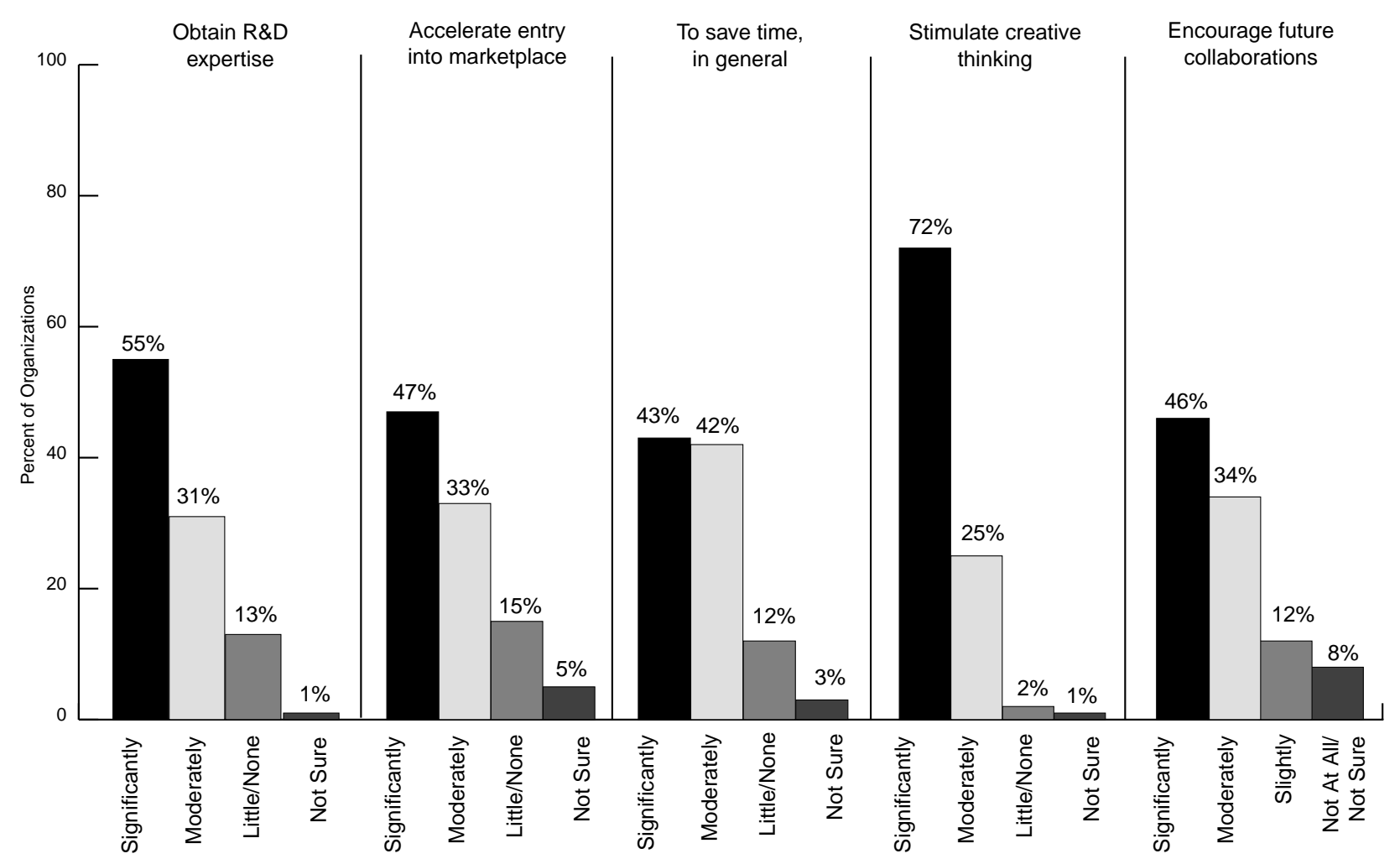

Note: Includes responses from organizations indicating "YES" to question--Has your project involved collaboration with other organizations?

Source: Business Progress Reports from 415 organizations in 198 ATP projects funded 1993-1997--after one or more years of ATP funding. 
Figure 16. Other Effects Enabled by Collaboration

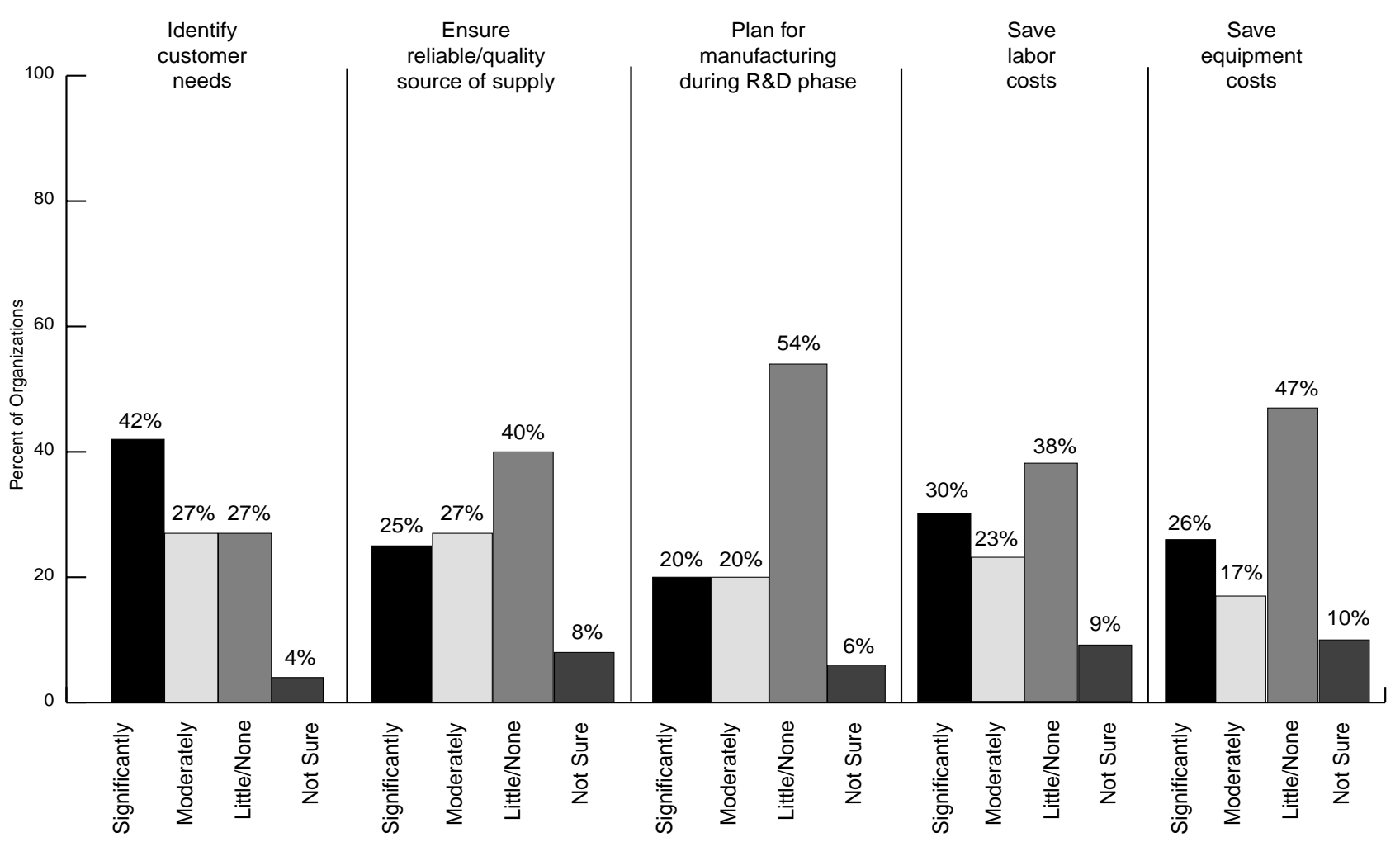

Note: Includes responses from organizations indicating "YES" to question--Has your project involved collaboration with other organizations?

Source: Business Progress Reports from 415 organizations in 198 ATP projects funded 1993-1997--after one or more years of ATP funding.

Figure 16 shows other effects of ATP collaborations. Among the other effects analyzed, "identifying customer needs" was cited as significantly or moderately enabled by 69 percent. Over 50 percent of respondents reported "ensuring a reliable/quality source of supply" and "labor cost savings" as significant or moderately enabled by collaboration; "planning for manufacturing" was cited by 40 percent; and "saving equipment costs" was cited as significantly or moderately enabled by 43 percent. These effects may be indicative of the relatively early project stage of many of the projects, and some may become more important as the companies move closer to commercial deployment.

There is no doubt that $R \& D$ joint ventures/consortia involve some project start-up time and costs, and possibly continuing costs not experienced by single-company awardees. However, these difficulties appear to have been relatively insignificant for the vast majority of ATP participants. As shown in Figure 17, of the organizations which reported collaboration experience in their ATP project, only nine percent reported a significant cost increase, although nearly half confirmed that project coordination and management costs had increased moderately as a result of collaboration. Eighteen percent indicated that associated delays in starting projects had resulted significantly or moderately as a result of collaboration, and only eight percent anticipated a delay of product entry into the marketplace as a result. 
Figure 17. Costs Attributed to Collaboration

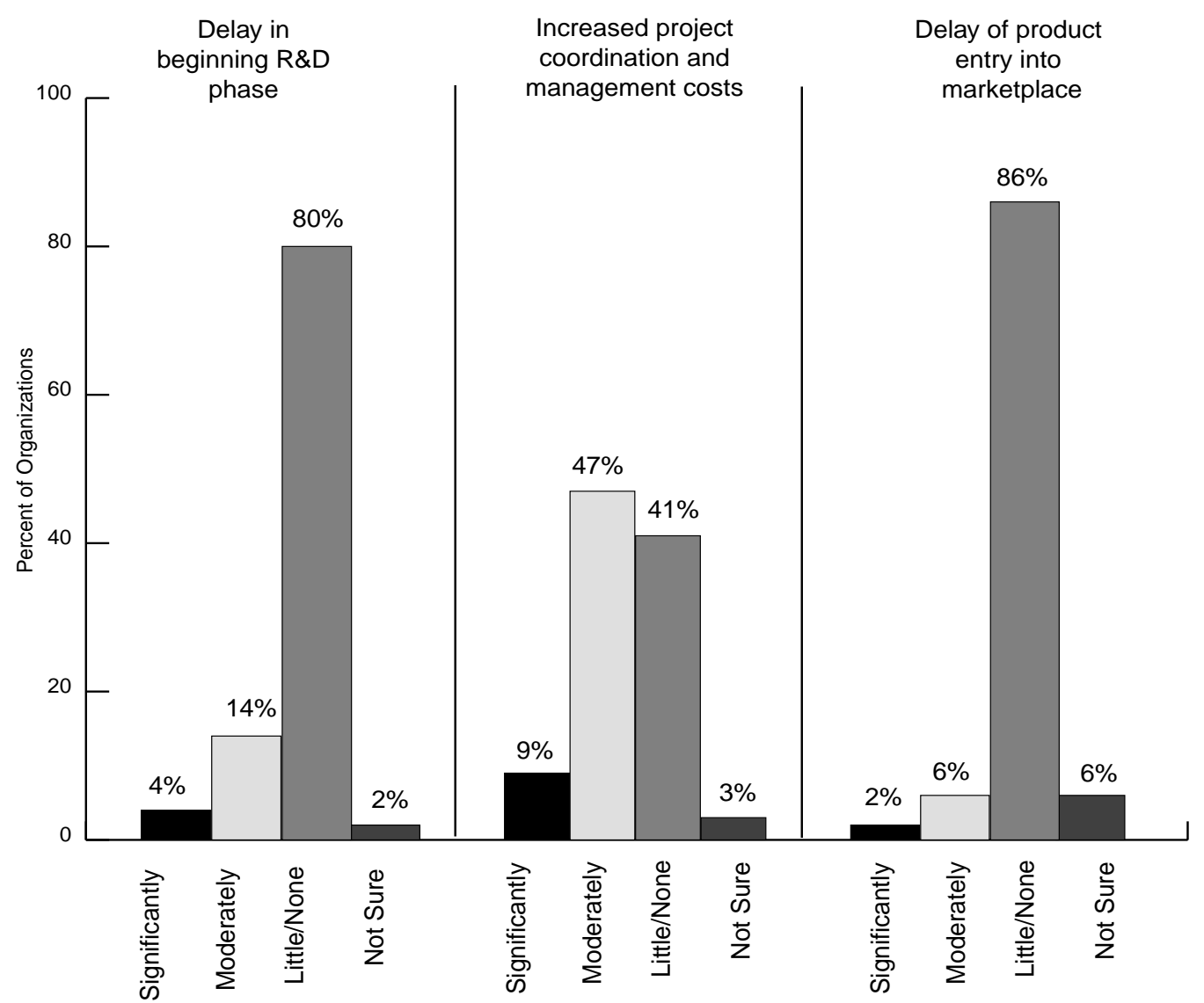

Note: Includes responses from organizations indicating "YES" to question--Has your project involved collaboration with other organizations?

Source: Business Progress Reports from 415 organizations in 198 ATP projects funded 1993-1997--after one or more years of ATP funding.

\section{Anecdotal Comments}

Anecdotal information from the BRS provides additional insight into effects of collaboration experienced by ATP-funded organizations and amplifies the statistical analysis. Some comments elaborate on the positive and negative impacts of ATP collaboration; others address issues not covered in specific reporting questions.

\section{Obtaining expertise not otherwise available}

"The work with our subcontractors [has] enabled us to utilize their expertise in fields [where we] are not staffed. The interactions with our joint venture partners provide us access to work they are doing in fields [where] we are not active." [Joint venture member]

"Critiques of work conducted independently [have] provided invaluable outside perspective to stimulate creative thinking and exposed several oversights early in the development process." [Single applicant]

"The breadth of experience brought in on these projects is extensive." [Joint venture member] 
"Excellent collaborative environment and complementary technical capabilities have improved the quality of technical output and effectiveness of the team. There has been tremendous synergy between the companies that are collaborating on this project. Each company brings a particular expertise that the others don't have and which would be difficult to develop. Each party is an enabler for the others." [Joint venture member]

"Collaboration has provided [us] with access to compounding, conversion, and fabrication resources, complementary ... materials and technical expertise that would not otherwise have been available." [Single applicant]

"In general, [subcontractor] has a wealth of experience and knowledge on ... processing and control. Their insight has been a primary driver on overcoming several technical problems and developing process simplifications." [Single applicant]

"Our collaboration with other partners has helped us to access first hand data for medical vocabularies, and understand size and complexity of that data." [Joint venture member]

"Exposed to new ideas, technologies that would otherwise not have been exposed to. Enabled us to leap forward with newer approaches into our architectural design." [Joint venture member]

"No one company has all the expertise required for the entire project. Collaboration has allowed in-house knowledge to be directly available to the overall effort." [Joint venture member]

"Medical expertise and related product requirement insight would not have been possible from within our own organization." [Single applicant]

"Through collaboration we have been able to bring experts in this field to our test facility and work with live systems." [Single applicant]

"The principal benefit of the collaboration has been to bring together a diverse team of varied expertise to address highly complex ... engineering problems. Systems development projects such as ... require individuals with many different technical and clinical skills to be successful. Collaboration has enabled us to bring professionals together from academia, the non-profit sector, and industry in a way that would not be possible within a single medical center." [Joint venture member]

\section{Obtaining assistance from universities}

"Our collaboration with [university] brought a very significant amount of experience in the basic technology that is underlying the diagnostic tests that we are developing; testing of our methods and comparison to those that they have developed in parallel allowed us to overcome technical hurdles faster." [Single applicant]

"Our collaboration involves working with two universities and an equipment vendor. The universities have done early work to explore ... possibilities. We have then followed up with more results-oriented experiments. This saves us time in helping to identify things that work and provides us with an estimate of the process regime in which decent results can be obtained." [Single applicant] 
"1. Significant input on optimized structural shape design from Dr....at [university]. 2. Structural testing facilities and equipment at [university] utilized for testing ATP prototype shape. Could not perform test with in-house laboratory facilities." [Single applicant]

"We have just begun the first phase of a collaboration with the ... center at [university], which involves the use of their clean room facilities. Duplicating those facilities at [our company] would have been completely impossible. In addition, we are being trained in various ... techniques, which speeds up the research phase considerably. The only negative impact has been the time required for setting up the legal structure of this collaboration." [Single applicant]

"There have been a number of positive collaboration effects, particularly with our work with the [university]. He has a group of excellent students, that have helped us to produce ... software, better ... layout technology, and also increase our research standing in the community of international researchers. Our company always had strong people working for it, but we have been able to attract, and keep several very talented people because of the NIST funding and are grateful for this. So I would say that the research collaboration with this university, sponsored through NIST has been very positive." [Single applicant]

"Our ability to use subcontractors from academic medical centers has greatly improved our ability to achieve the goals of our project. These collaborators have given us both a lab for testing and a reality check on what works." [Single applicant]

"University students are exposed to industry as summer students so they become acquainted with the needs of industry and the workings of an $R \& D$ industrial lab. The resulting collaborations result in joint publications and patents. [Single applicant]

\section{Learning more about potential markets and customer needs and accelerating entry into the marketplace}

"The most significant collaboration has come from securing a contract ... to install a pilot demonstration.... This has facilitated a number of discussions which has identified the real customer needs and therefore accurate functional and performance requirements of the products. In this process the team at ... working on the project have been introduced to domain knowledge that would have otherwise been difficult to obtain." [Single applicant]

"The manpower-multiplying and synergistic creative effects of using subcontractors has accelerated the $R \& D$ process to make it possible to plan and begin to initiate business alliances for the technology that capitalize on a fast-approaching market opportunity." [Single applicant]

"[We] have forged excellent strategic alliances with leaders in the ... industry which provide valuable customer input and resources during the development stages of the technology and will allow us to quickly commercialize this application." [Single applicant]

"Our collaboration with [a joint venture member] led to a rapid prototype development with a strong emphasis on customer needs.." [Joint venture member]

"The partnership which was established for this ATP project is a true vertical partnership of suppliers and a manufacturer. Unlike other $R \& D$ alliances in which [these companies] have participated, which were horizontal partnerships of manufacturing companies, this project had no 
inherent conflicts of interest. There is a single motivation in this project: to advance the state-ofthe-art of the ... technology ... to allow for broad substitution of composites for traditional materials. And to date the NIST/ATP project has been central to achieving this goal." [Joint venture member]

"The collaboration has allowed us to understand healthcare needs for the technology to which we have been able to focus our $R \& D$. This has greatly increased commercialization chances and technology impact. Collaborator has already started to use our technology and has hired our students as interns and employees, which represents an important form of technology transfer. More collaboration has occurred than originally planned." [University joint venture member]

"In general, the collaboration has allowed us to contact new potential collaborators and markets. Some of these markets are for new equipment using our technology in ways we had not considered. Due to the success of the JV, the various members are investigating projects outside the ATP." [Joint venture member]

"Without the joint venture and collaborations from the other members it would have been almost impossible to assess the market needs and define the customers and requirements. " [Joint venture member]

"The vertical structure of our joint venture (2nd tier vendor, 1st tier vendor, OEM) assures that our project direction is kept focused on real customer needs and addresses real customer concerns." "Better coordination of program brainstorming to advanced technology has enhanced the commercialfocus. Has accelerated the commercialization effort." [Two members of a joint venture]

"Collaboration with [our JV members] has been extremely positive. All members of the group have really worked together to solve common problems and foster creative solutions. This has allowed all of us to gain greater speed to market." [Joint venture member]

"It has created a greater awareness of the complete HDTV product environment. It has allowed [us] to pursue alliances outside of our narrowly defined ... product environment and work towards a greater understanding of new product and services offerings." " Complex system architecture issues are better studied in industry teams. This is made possible by the ATP grant." [Two members of a joint venture]

"There have been no negative impacts. Positively, the collaboration has increased our awareness of our partners' need for advanced materials and the partners' efforts in identifying opportunities in emerging markets which might match our long-term $R \& D$ material development work." "Assisted greatly in development of understanding of manufacturing costs and customer requirements, eventually leading to the abandonment of the ... effort." [Two members of a joint venture]

"The collaboration would have happened, eventually, but ATP has been the catalyst. The program has moved along much faster than anticipated and has been able to obtain managerial support and external assistance which would not have happened without ATP affiliation." "Intercorporate collaboration has fostered business relationships which are likely to continue beyond the ATP into product development and commercialization. This should greatly accelerate the application of the ATP-developed technology." [Two members of a joint venture] 


\section{Formation of stronger supplier-customer relationships}

"The other joint venture partners are also customers for [company]. General understanding of business practices and other developmental needs have had a positive impact on all parties. " [Joint venture member]

"Our collaboration with the equipment vendor has led to a promising new area of development. We hope to build a better throughput goals." [Single applicant]

"Established enhanced relationships with strategic suppliers of software necessary to perform our ... services, and to focus our software suppliers toward the directions we see as necessary in developing the next generation of ... tools, techniques, and methodologies." [Joint venture member]

"Our subcontractor has a good deal of credibility in the marketplace. We have gone farther with prospects and vendor alliance discussions because of the choice of the subcontractor." [Single applicant]

"Collaboration has helped to align ideas of users and suppliers greatly." [Joint venture member]

"As an end user of the core technology being developed for this program, we would not have early access to the technology without the collaboration. Collaboration at this phase allows us to influence the design to meet our end product needs during the development. We have no intention to manufacture the [component], but to use it in our product; therefore collaboration is essential." [Joint venture member]

"There has been an awakening to the advantages of networking with our suppliers on an informal basis. This has resulted in leveraging research within [our] supply chains." "The collaboration with [lead company] has given us much insight and understanding as to the interests, needs, values, and talents of one of our largest international customers." "Without collaboration on this project with a major customer, this project probably would not exist. Collaboration provides us an unusual opportunity to work together." [Three members of a joint venture]

\section{Strengthening credibility within the organization and with other organizations}

"'The fact [our company] has an ATP award has added credibility to our commercialization effort and in fact it has attracted some of our early collaborators and has been a major source of interest for our partners." [Single applicant]

"There is heightened credibility obtained from the concurrence of our competitors that we are doing the right things; i.e., if we tried to get this project approved in house alone, it might be perceived to not be as big a problem." [Joint venture member]

The joint venture with [partner] has focused our $R \& D$ effort to a specific application and our price performance objective.... We anticipate the most significant impact will come in the near future when [partner] can assist us in gaining the capital investment for the transition to manufacturing and in the well-established market share [partner] currently enjoys." [Joint venture member] 
"Provided visibility into automotive market segment which we wouldn't normally have had access to." [Joint venture member]

"Through our collaboration with [our subcontractors] we now have access to potential customers (the colleagues of our collaborators) who would have been less receptive had we approached them on our own." [Single applicant]

\section{Elaboration of the "benefits and costs" of collaboration}

"This vertical teaming has enabled a free flow of ideas between the two companies and has made this collaboration a positive experience to date. The only negative of the collaboration, which is a result of the "large company syndrome," is that while large companies such as ... offer tremendous manufacturing resources, scheduling these resources can be difficult at times." [Joint venture member]

"The main positive of collaboration is the sharing of expertise, and the stimulation of new approaches to the problem. The main negative has been that one of the companies was not really committed to provide sufficient resources to execute tasks on schedule and this slowed down all tasks in the critical path. Another negative (not major) has been the added approvals to change program directions, and the slow down in schedule due to co-ordination of tasks (technical and administrative)." [Joint venture member]

"Positive: Reduction of "not invented here syndrome"; reduction of capital cost on equipment available from JV partner; positive factor in negotiating other contract research with outside company that involves complementary technologies of both JV partners. Negative: Difficulties experienced in initial collaboration with JV partner revolving around issue of trust (viewing the other company as a potential competitor)." [Joint venture member]

"Positive: Direct contact with potential customer led to development of a prototype that matched customer needs. Exposure to different management and engineering approaches contributed to improvements/evaluation of our respective processes. Negative: Collaboration of multi-disciplinary teams located in various geographical locations was difficult. Different companies had different priorities and goals that at times conflicted with program goals." [Joint venture member]

"Positive Impacts: Elevated awareness of Healthcare marketplace. Understanding the healthcare information technology requirements. Negative Impacts: Very difficult to settle the intellectual property rights between multiple collaborators." [Joint venture member]

"On the positive side, there was a great exposure to other technologies and transfer of technical knowledge between large multinational companies and research institutions. On the negative side, the research has been delayed because of the effort required to establish collaborative agreements and work through conflict resolutions." [Single applicant]

"On the positive side, the collaboration has allowed a group of companies to come together that otherwise wouldn't have and work jointly through a leveraged investment of $R \& D$ efforts. On the negative side, not all of the business models of the participating companies were compatible which resulted in some serious business negotiation problems relative to intellectual property." [Joint venture member]

Development, Commercialization, and Diffusion of Enabling Technologies: Progress Report 


\section{Formation of Strategic Alliances Outside the ATP Project for Commercialization of ATP-funded Technologies}

The numerous ATP joint ventures represent concrete evidence of ATP's ability to stimulate strategic alliances. Some are largely horizontal R\&D collaborations attacking problems of mutual interest across an entire industry. Most involve complex R\&D and commercialization collaboration across the supply chain. For example, one project in the area of photonics manufacturing brings together a vertically integrated team of photonics manufacturing companies supplying optical devices (SDL, Inc.), and network systems (Nortel Systems) with software developers (RSoft and Hewlett-Packard as a subcontractor), consulting service providers (Telcordia Technologies and Science Applications International Corp.), and Columbia University. Led by Telcordia Technologies (formerly Bellcore), the project aims to develop an open architecture, integrated simulation tool for evaluating photonic components, systems, and network designs quickly, reliably, and inexpensively, and thereby reducing design-build-test cycle times across the supply chain of the communications sector by a factor of five, with potential application to other industries. Another project, led by Xerox, brings together a number of manufacturers with different applications of micro-opto-electro mechanical systems (MOEMS), a university, and a commercial foundry jointly to develop infrastructural process technologies supporting mass production of MOEMS at low cost. Ultimately each manufacturer (Xerox, Maxim Integrated Products, Microcosm Technologies, MicroScan Systems, and Optical Micro-Machines) will co-develop with the foundry (Standard Microsystems) its own products employing the technologies developed in the ATP project. These products span applications in telecommunications, imaging, medicine, entertainment, and information systems. The research joint venture between 3M Company and Perkin-Elmer Biosystems funded by the ATP in 1998 has resulted explicitly in joint commercialization plans. Building on the foundation provided by their ATP project, 3M Company and Perkin-Elmer Biosystems have entered into an agreement to jointly develop genetic analysis products. This agreement facilitates an anticipated long-term complementary relationship leveraging 3M's strengths in material science and manufacturing and Perkin-Elmer's capabilities in genetic analysis.

Some relationships between ATP-funded companies and their R\&D subcontractors have evolved into strategic alliances for commercialization. Among the publicized alliances, PharmaSeq (a one-person start-up company when funded by the ATP in 1998) and Sarnoff Corporation, one of the subcontractors on the ATP project, announced an agreement in early 1999 to develop jointly a prototype system that integrates PharmaSeq's novel DNA diagnostic method employing an assay of 3-D arrays of DNA molecules with Sarnoff's microtransponder technology. The aim of this alliance agreement is a highly accurate and cost efficient DNA detector system for use in biomedical research, drug discovery, infectious agent monitoring, genomics, industrial processing, and environmental monitoring.

Many other strategic alliances have been formed outside the ATP research project to commercialize ATPfunded technologies. Although information concerning negotiations with potential commercialization partners, and the resulting alliances, is provided to ATP on a confidential basis, articles published by the industry and trade press and company press releases sometimes provide public substantiation. Public sources confirm that partnering between ATP-funded small businesses developing DNA diagnostics technologies and pharmaceutical and medical instrumentation companies has been particularly active. Integra LifeSciences, recipient of ATP awards in 1993 and 1998, has announced strategic alliances with Linvatec and Bionx for developing fixation devices, e.g., screws, tacks, and anchors, using Integra's polymer technology funded in its first ATP award for reconstruction of ligaments and tendons in knees and shoulders. Affymetrix, a 1994 award recipient in the Tools for DNA Diagnostics Focused Program competition, has recently entered into agreements with OncorMed to collaborate in development of clinical validation of genetic testing services utilizing their GeneChip ${ }^{\mathrm{TM}}$ for analysis of genes associated 
with cancer. Under a separate distribution and instrumentation alliance between Affymetrix and HewlettPackard, Hewlett-Packard is developing and supplying a next-generation scanner to read the GeneChip ${ }^{\mathrm{TM}}$ (Regalado, 1996, p. 22). Affymetrix has other collaborations with Genetics Institute, Roche Molecular Systems, Incyte Pharmaceuticals, and Glaxo Wellcome (Regalado, 1996, p. 18). Hyseq, a tiny company funded by the ATP to develop a different DNA chip technology, has teamed up with Perkin-Elmer to market its chips (Perkin-Elmer and Hyseq Press Release, June 29, 1998). All of these partnerships are outside the ATP projects, but occurred while the ATP-funded R\&D was ongoing relatively early in the R\&D phase as a means of accelerating commercialization of the ATP-funded technology and raising capital for continuing R\&D.

Table 3 summarizes strategic alliance activity focused on commercialization of technologies funded by the ATP during 1993 to 1997 . The data reveal that a substantial amount of negotiation and discussion activity is underway. One hundred fifty-six alliances had been formed by March 31, 1998: 37 with suppliers; 52 with customers; 37 for joint production; and 30 with distributors. Forty-two license agreements had been signed by that time. Some of these alliances for commercialization evolve from R\&D partnerships among ATP joint-venture companies, but many companies are forming alliances with companies outside of their ATP projects.

\section{Table 3. Strategic Alliances and Licensing Agreements for Commercialization}

\begin{tabular}{|l|c|c|c|}
\cline { 2 - 4 } \multicolumn{1}{c|}{} & $\begin{array}{c}\text { Number of } \\
\text { Projects }\end{array}$ & $\begin{array}{c}\text { Number of } \\
\text { Companies }\end{array}$ & $\begin{array}{c}\text { Number of } \\
\text { Applications }\end{array}$ \\
\hline $\begin{array}{l}\text { Negotiations/discussions held with } \\
\text { potential strategic partners }\end{array}$ & 97 & 113 & 184 \\
\hline Alliances formed with suppliers & 37 & 37 & 48 \\
Alliances formed with customers & 49 & 52 & 71 \\
Alliances formed for joint production & 34 & 37 & 45 \\
Alliances formed with distributors & 30 & 30 & 39 \\
\cline { 2 - 5 } & $150^{*}$ & $156^{*}$ & 203 \\
\hline \hline Total alliances formed & 53 & 53 & 81 \\
\hline potential licensing partners & 42 & 42 & 59 \\
\hline License agreements signed & & & \\
\hline
\end{tabular}

Note: *Companies reporting more than one type of alliance are included twice.

Source: Business Progress Reports for 747 applications being pursued by 356 companies in 198 ATP projects funded 1993-1997 after one or more years of ATP funding. 


\section{IMPACT ON INDUSTRY R\&D}

\section{Stimulation of Private Sector Investment and Leveraging of Other Investment}

More than one-third of the organizations reporting believe there would have been no project at all without ATP; i.e., their combined cost-share commitment of $\$ 183$ million reflects an investment that they say would not have occurred at all without the ATP award. An additional 38 percent report they increased their investment in the ATP-funded technology area as a result of ATP funding, beyond what the investment otherwise would have been, by $\$ 145$ million in the aggregate. (See Figure18.)

According to the responses from the two groups of organizations combined, ATP has stimulated industry to invest more than $\$ 320$ million in internal company funds beyond what industry would have invested without the ATP awards (and above and beyond ATP funding). The increased industry investment represents an estimated 58 percent increase over what industry would have invested without ATP funding. The increased level of funding from industry sources, plus that from the ATP, has helped to accelerate the R\&D for ATP-funded projects and thereby has helped the companies enter the market within the critical windows of opportunity. (See Chapter 2.)

\section{Figure 18. Stimulation of Industry R\&D Investment}

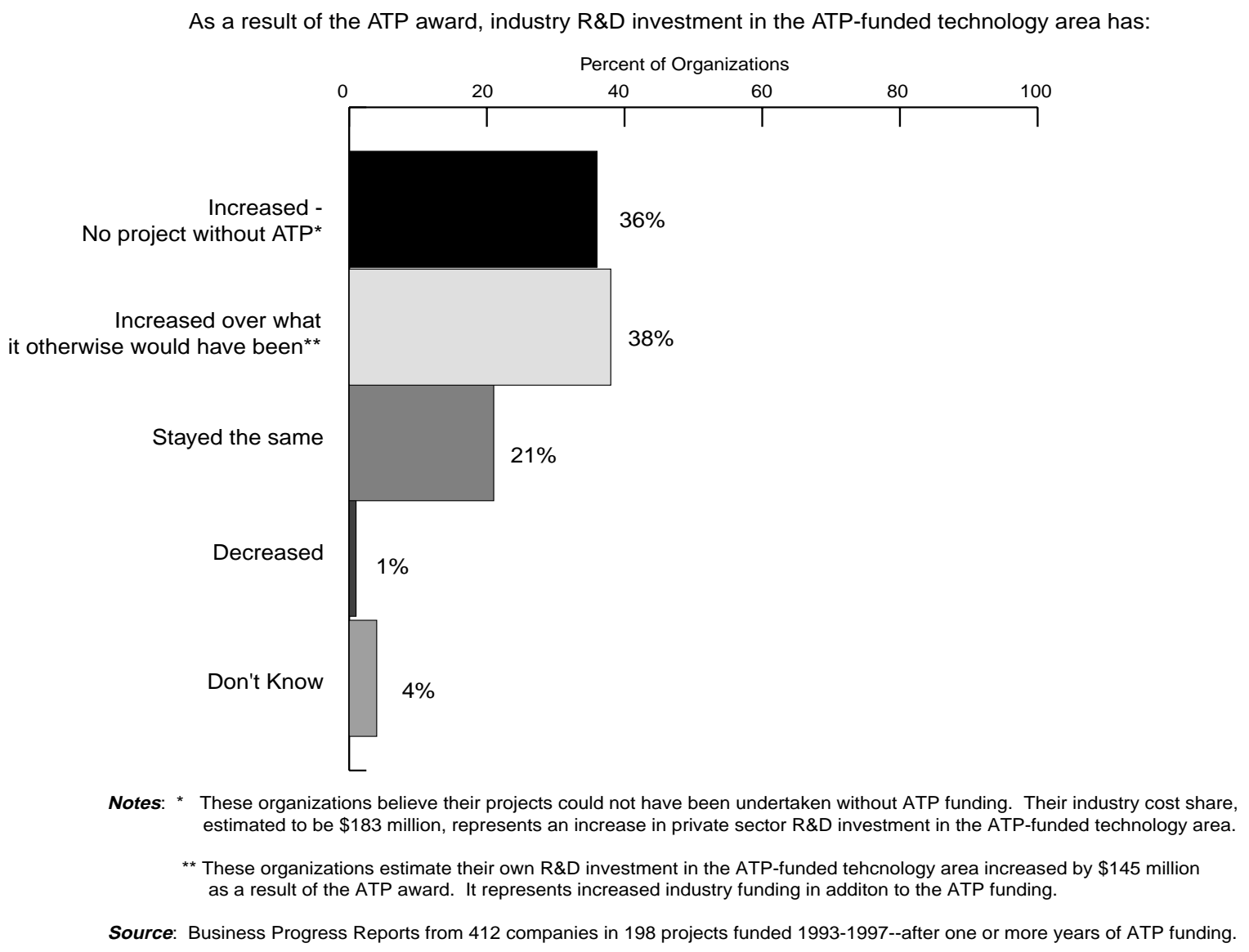


As shown in Figure 19,61 percent of the organizations indicated that they had increased the R\&D scope. Sixty-seven percent reported that ATP funding had increased their interest in long-term research. Both scope expansion and longer-term research give rise to increased challenge. Seventy-three percent of organizations reported they were more willing to accept technical risk as a result of ATP funding. Many of the remaining organizations reported they would not have pursued the project at all without ATP funding. From the combination of these various sets of data, it appears that ATP funding has stimulated pursuit of higher risk, longer-term, more ambitious R\&D projects than would have been undertaken without ATP funding.

Figure 19. Change in the Nature of Industry R\&D

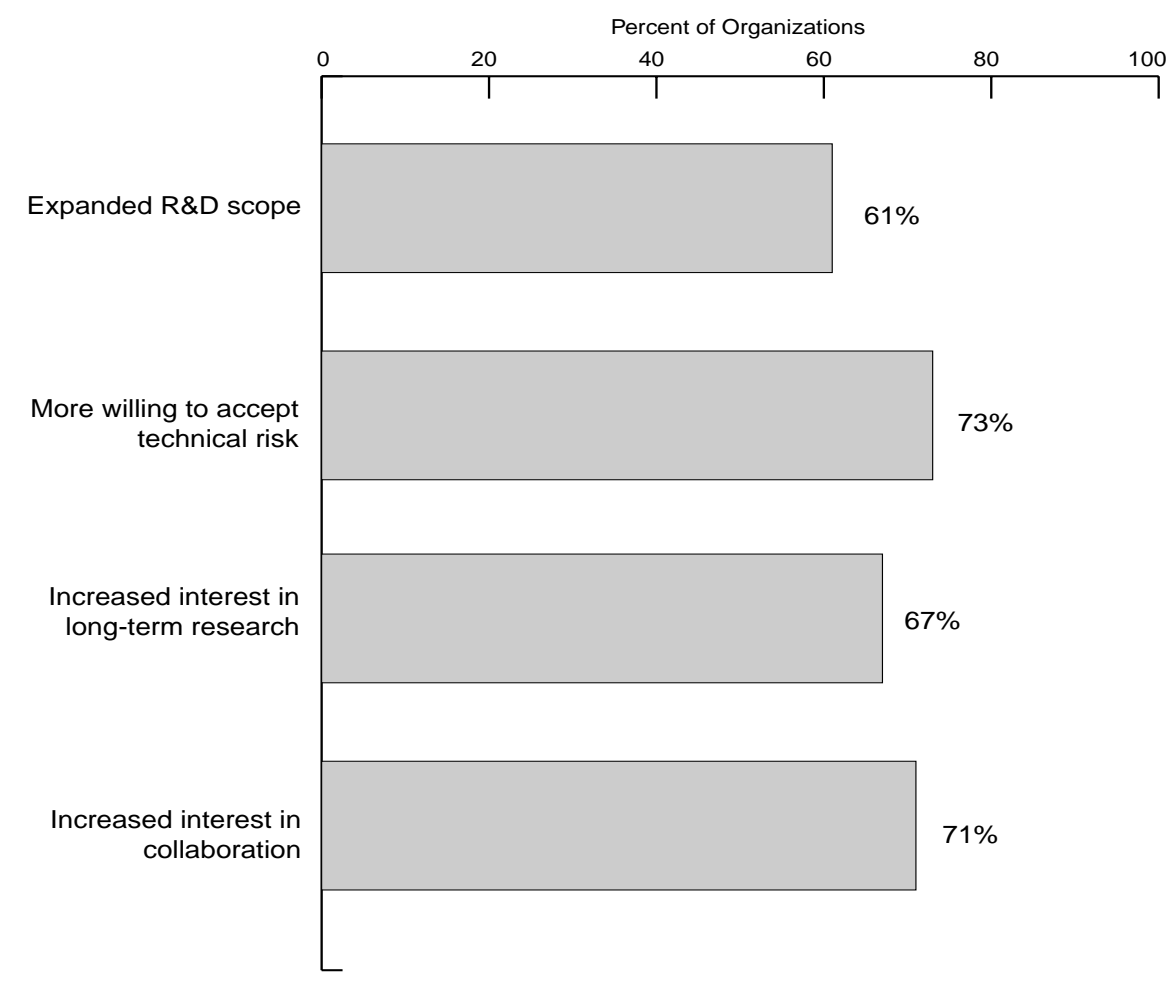

Source: Business Progress Reports from 403 organizations in 198 ATP projects funded 1993-1997-after one or more years of ATP funding.

\section{Increased Credibility}

A large percentage of organizations that have completed one or more years of funding cite increased credibility or enhanced prestige as a result of the ATP award, documenting that the ATP award has a "halo effect" on organizations and technologies receiving awards, apart from the award's monetary value. The most frequently cited "halo effect" was by researchers with "upper" management (or owners) in their own organizations. As shown in Figure 20, respondents from 85 percent of all the organizations reported increased credibility with management; 75 percent indicated improved credibility with customers; 60 percent with suppliers; and 44 percent believed the ATP award had a "halo effect" with investors. Ninety-three percent of organizations reported increased credibility with one or more of these parties.

The "halo effect" may be expected to be of particular benefit to ATP-funded small businesses, particularly start-ups, which have little if any market presence and typically very limited financial resources at th resources at the time of the ATP award. A comparison of results for the small companies 
Figure 20. Increased Credibility

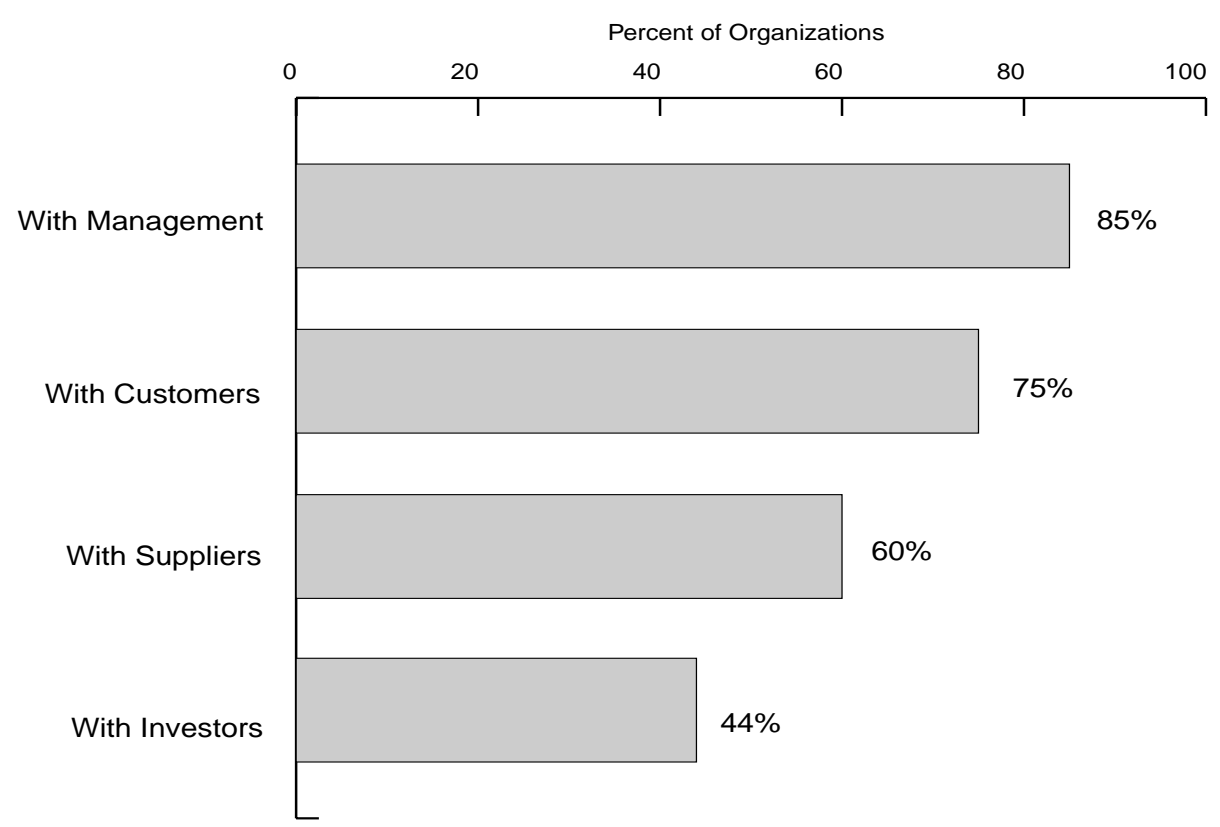

Note: Ninety-three percent of organizations reported increased credibility with at least one of these parties.

Source: Business Progress Reports from 412 organizations in 198 ATP projects funded 1993-1997 -after one or more years of ATP funding.

versus the entire group shows that the "halo effect" with outside firms and investors was indeed stronger for small businesses than for the group as a whole. Small businesses likely have greater need for this assistance and therefore have greater sensitivity to its benefit.

Figure 21. Increased Credibility - Small Businesses

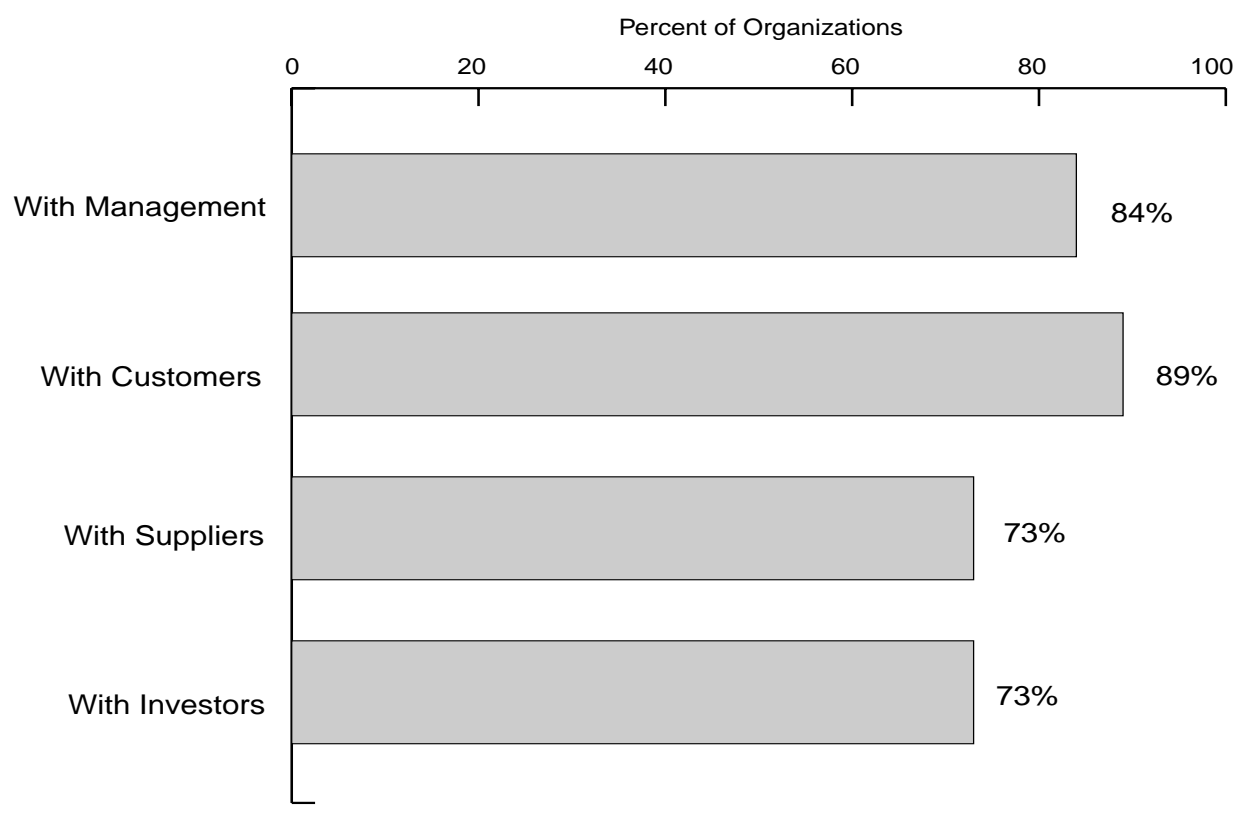

Note: Ninety-five percent of small businesses reported increased credibility with at least one of these parties.

Source: Business Progress Reports from 150 organizations in 118 ATP projects funded 1993-1997 -after one or more years of ATP funding. 
As shown in Figure 21, 89 percent of small business experienced increased credibility with customers (compared with 75 percent for the group as a whole); 73 percent with suppliers (compared with 60 percent for the group as a whole). Some anecdotal examples of "halo effects" related to joint venture and other ATP-stimulated collaborations are included in Chapter 4.

A significant number of organizations have attracted new sources of capital following announcement of their ATP award. The new funding has gone to support the ATP-funded research area or related commercialization efforts. Of the 412 organizations reporting after one or more years of ATP funding, 76 (18 percent) had received new funding from external sources, amounting to more than $\$ 200$ million, to pursue their technology development and commercialization activities.

As shown in Figure 22, the most common sources of new funding were owner/angel/friends capital contributions, non-ATP Federal grants and contacts, and other/corporate partners. Some companies report receiving more than one type of funding.

In general, the new federal funding appears to support R\&D in technology areas related to the ATPfunded technology but outside the scope of the ATP project; state funding appears directly to support ATP-funded research by companies, thereby leveraging ATP and private cost-share funds, for example, from owner/angel/friends, venture capital, and internal sources.

Figure 22. Attraction of Capital

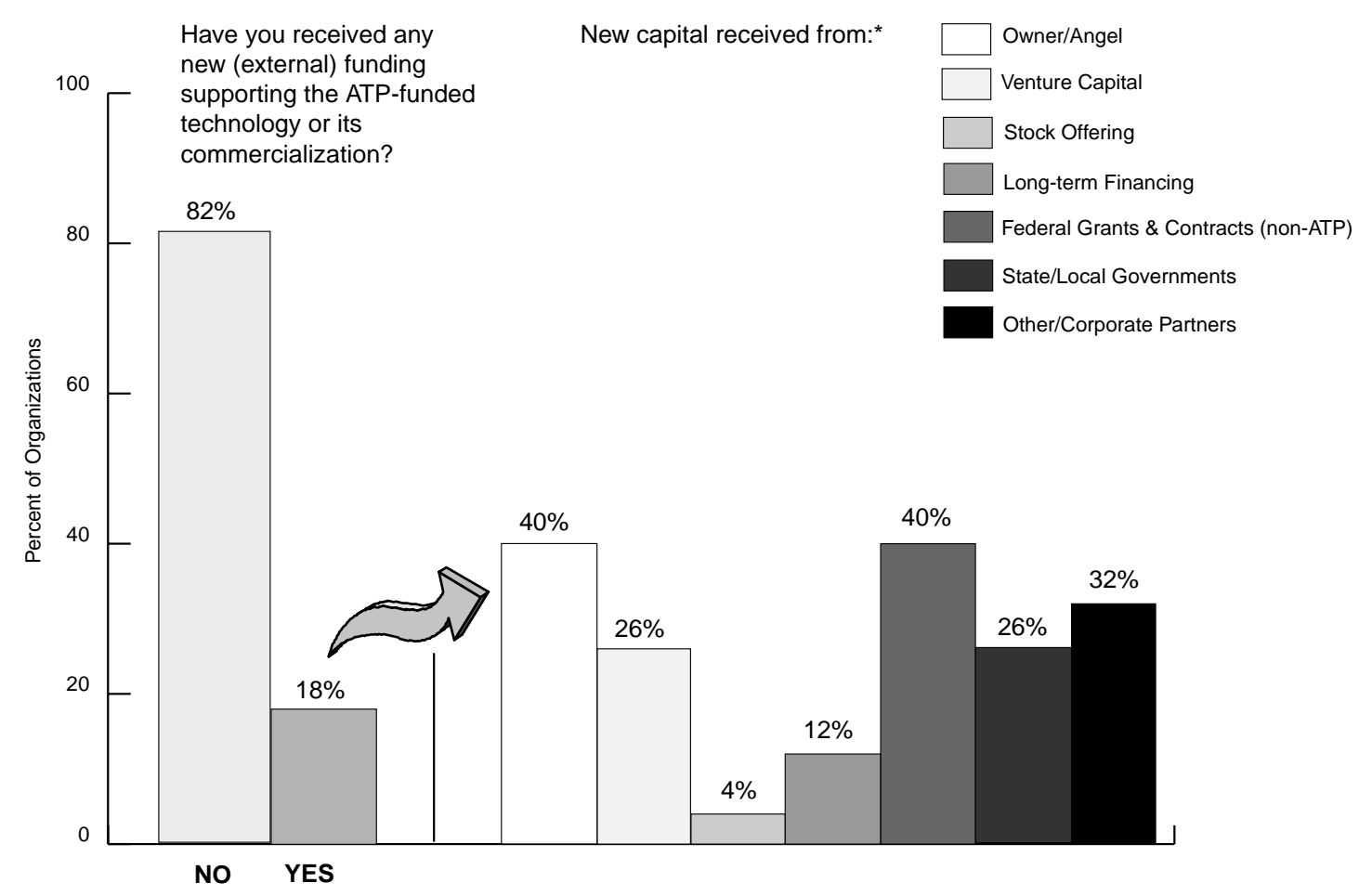

Note: *Includes responses from organizations indicating "YES" to prior question.

Organizations report receiving over $\$ 200$ million in new (external) funding to support ATP-funded technologies or their commercialization.

Source: Business Progress Reports from 412 organizations in 198 ATP projects funded 1993-1997--after one or more years of ATP funding. 


\section{EARLY COMMERCIALIZATION ACTIVITIES}

Even for applications where commercial production is several years off, successful, timely entry into the marketplace is likely to entail a significant level of effort in market analysis, capital planning and acquisition, and negotiation with potential partners over the entire R\&D phase. The trend to shorter product life cycles in many industries dictates that companies engage in market analysis and planning for manufacturing and scale-up from the earliest stages of R\&D in order to have a new product or process ready in time to compete successfully in international markets (See Laidlaw, Chapter 1, 1997). ATP monitors this activity as part of its project management and evaluation process both to assess the likelihood that successful commercialization will result and to measure the level and significance of progress. This chapter provides a statistical snapshot of commercialization progress for companies reporting after one or more years of ATP funding, along with some specific examples from individual companies and projects.

\section{Commercialization Planning Activities}

As shown in Figure 23, companies in 84 percent of the projects have completed product/process definition for at least one application; companies in 70 percent of the projects have completed concept testing with customers for at least one application; and concept testing has been conducted for 44 percent of all applications being pursued.

Figure 23. Market Analysis Progress

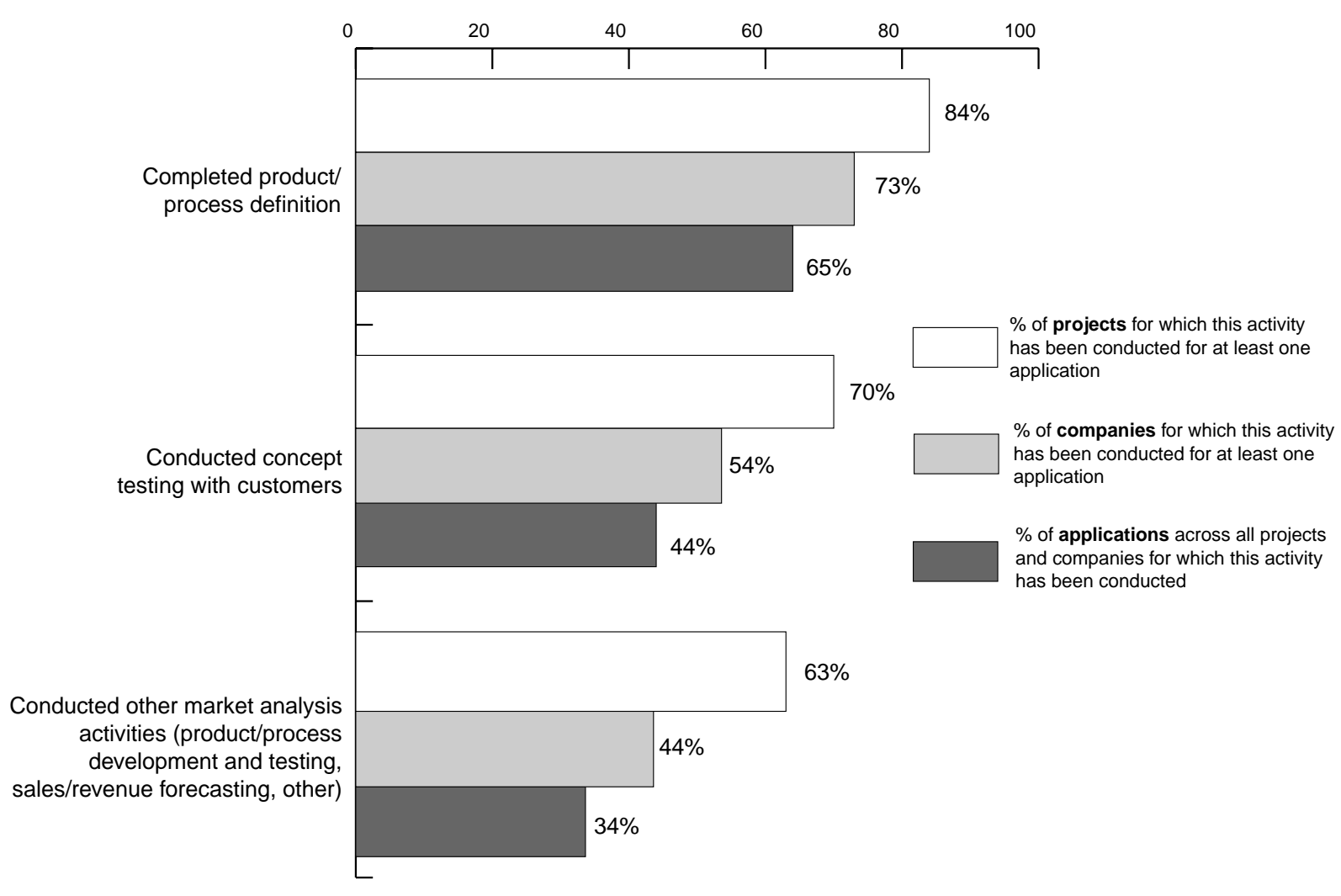

Source: Business Progress Reports from 747 applications being pursued by 356 companies in 198 ATP projects funded 1993-1997-after one or more years of ATP funding. 
Figure 24. Progress Towards Commercial Production

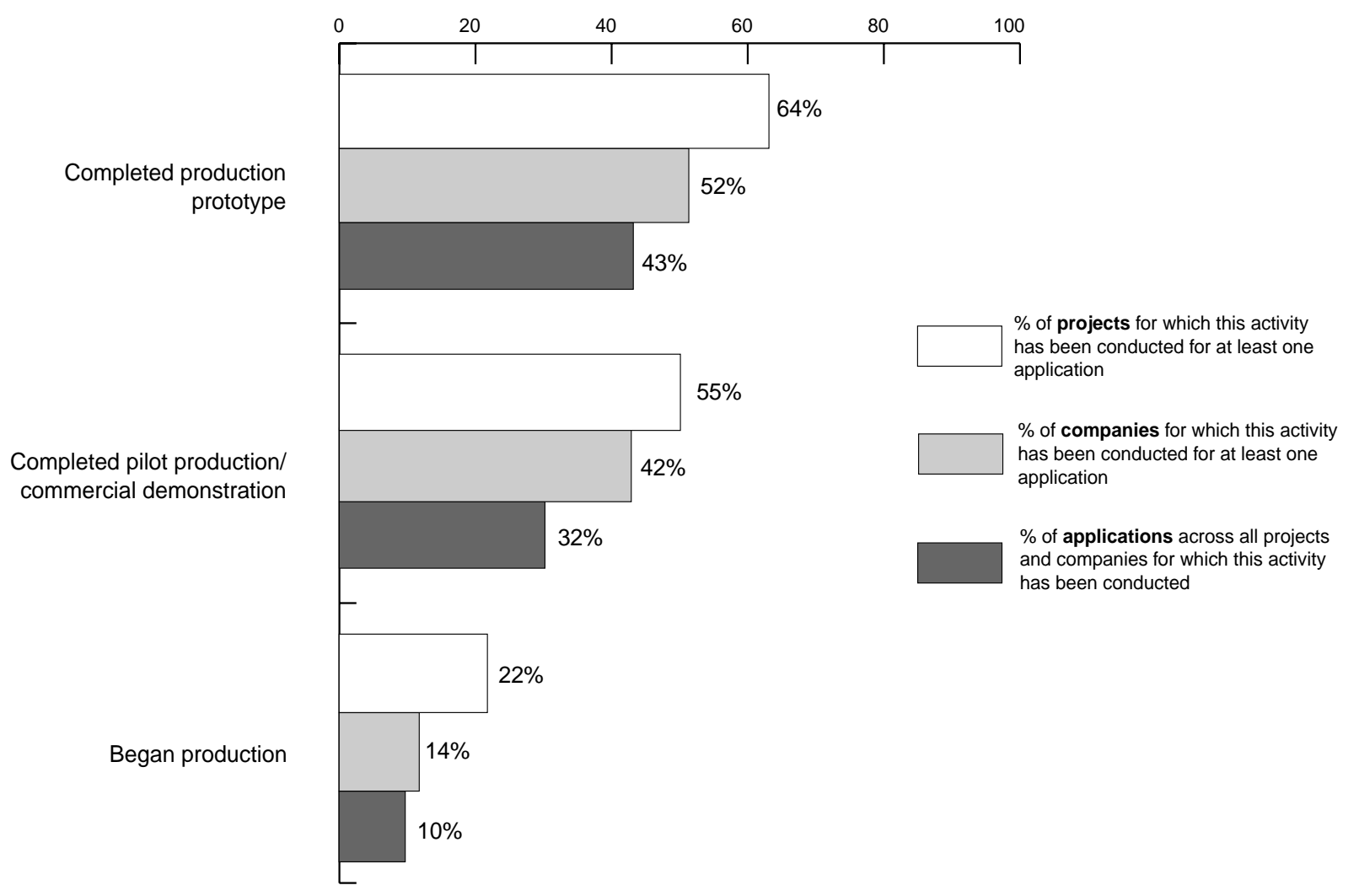

Source: Business Progress Reports for 672 product or process applications being pursued by 330 companies in 191 ATP projects funded 1993-1997-after one or more years of ATP funding.

Companies are engaged in the long-term process of planning for scale-up from preparation of smallsample prototypes to commercial production. As shown in Figure 24, 52 percent of companies, participating in 64 percent of projects, indicate they have completed a production prototype, and 42 percent of companies participating in 55 percent of projects have completed pilot production or a commercial demonstration for at least one application of the ATP-funded technology. A small percentage of the companies (14 percent of companies from 22 percent of the projects) indicate they have actually begun production for at least one application. Production has begun for 10 percent of applications.

Figure 25 provides a statistical summary of early progress towards earning revenues or other benefits from use of the ATP-funded technology. Fifty-four percent of companies, participating in 66 percent of the projects, believe they are now able to make a new or better product as a result of their ATP project; 39 percent of companies, participating in 51 percent of projects, have adopted process improvements embodying ATP-funded technology; 17 percent of companies, participating in 27 percent of projects, report revenues from sales of prototypes and early spin-off products that amounted to more than $\$ 67$ million from 12 percent of applications by March 31, 1998. Licensing royalties, reported by four percent of companies, amounted to $\$ 5$ million by that date. 
Figure 25. Progress Towards Early Products and Processes

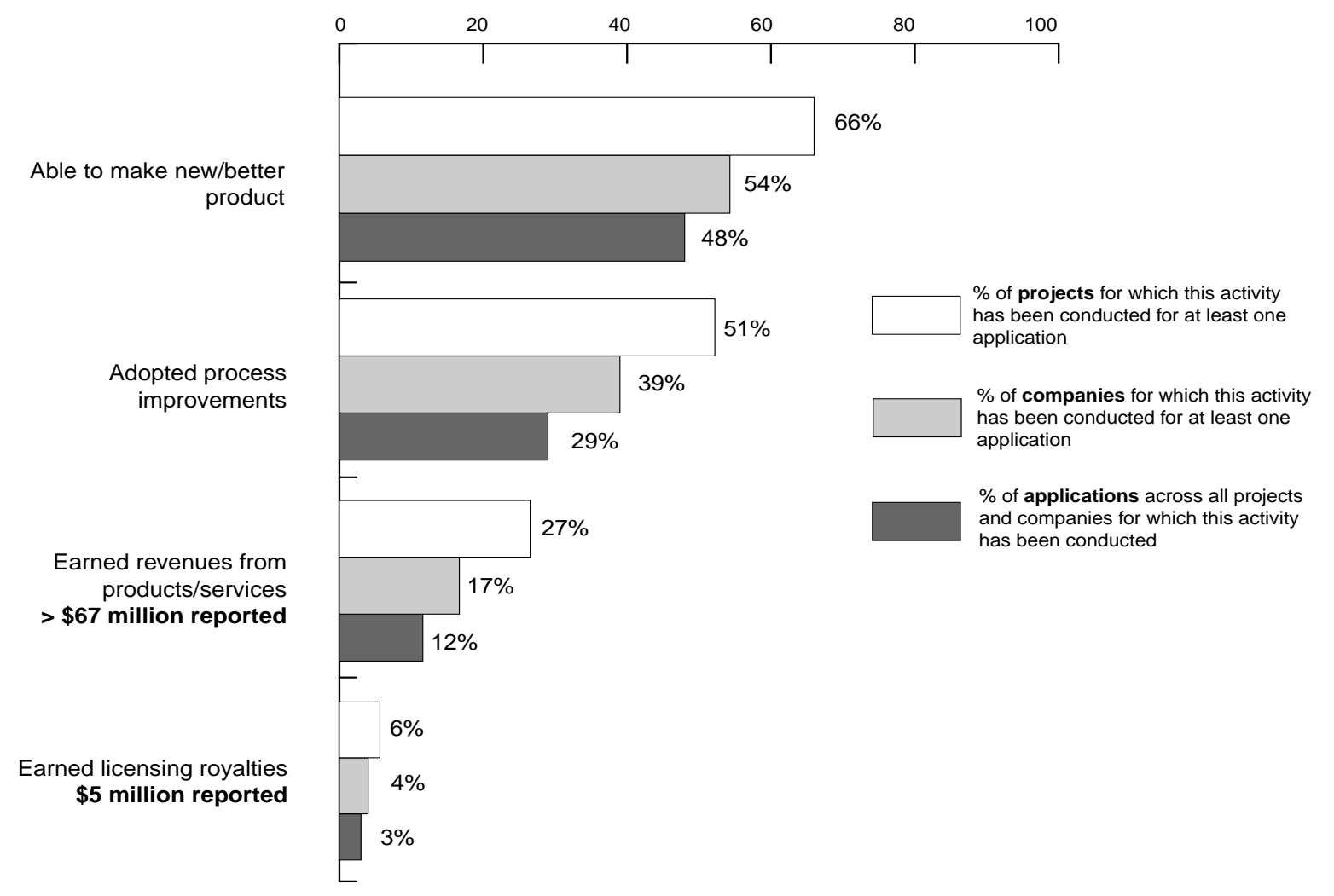

Source: Business Progress Reports for 703 applications being pursued by 332 companies in 192 ATP projects funded $1993-1997$-after one or more years of ATP funding.

\section{Early Commercial Products}

A number of new products have been announced by ATP participants. Many of the earliest announcements of commercialized ATP-funded technologies involve software products, which typically have shorter development cycles than hardware products and are often marketed over the Internet. The following are some examples from company press releases and product announcements.

CVideo-Mail ${ }^{T M}$. Developed by Cubic Videocomm, Inc., CVideo-Mail" ${ }^{\mathrm{TM}}$ is a "video e-mail software package, camera and microphone" that allows users to easily create and send video clips or still photos with audio as attachments to e-mail messages. The viewer can be sent with the video so the recipient does not need any special decoding software to view the e-mailed video. The full image is preserved with each compressed frame, allowing rapid compression and efficient distribution of live video to remote desktop computers. With CVideo-Mail ${ }^{\mathrm{TM}}$, children can receive specialized tutoring from remote teachers, businesses can train and update employees, and professors can teach distance learning courses over the Internet. PC Computing called this video compression technology "the best we've ever seen." $P C$ Magazine gave it a top rating due to its ease in set-up and fine user manual.

BusinessWare. Introduced by Vitria Technology, Inc., a small startup company in Mountain View, CA, Business Ware is the "first comprehensive product for transparent application integration at the business level." This software provides businesses with a tool to manage operations transparently across work-inprogress and inventories, scheduling operations, and an array of other essential activities. The four critical 
integration components -- business process automation, real time analysis, communication integration, and data integration -- run inside Business Ware's production environment, allowing users to effectively manage and respond to operations in real time, even when located at different sites.

SmartVoice ${ }^{T M}$. Berdy Medical Systems has launched a system to assist physicians with medical data input. SmartVoice ${ }^{\mathrm{TM}}$, unlike other systems, "converts spoken language into discreet data elements (not text documents) so they can be stored in any database or propagate any repository." The SmartVoice ${ }^{\mathrm{TM}}$ system does not require specialized speaker training, allowing physicians to use a normal speaking voice. Smart Voice ${ }^{\mathrm{TM}}$ "can run as a stand-alone system and be used to propagate any hospital repository that can accept data in the HealthCare industry's standard HL-7 protocol." It thus provides a basis, using spoken language input, for a Computer-based Patient Record (CPR) System.

Graph Layout and Graph Editor Toolkits. Developed by Tom Sawyer Software, the Graph Layout and Graph Editor Toolkits are a family of products that allow users to automatically create diagrams to visualize relationships within complex data and then to integrate the graph displays with Windows applications.

Component-based software for virtual reality applications. Aesthetic Solutions, a small company in Aliso Vieja, CA, has developed tools to "allow non-technical users to create complete three-dimensional web sites in a matter of hours." One product, WorldVisions ${ }^{\mathrm{TM}}$ is a collection of interactive "living" threedimensional graphics-based components that users can "drag and drop" into their own 3-dimensional creation. Among the extensive libraries of graphics-based components in Aesthetic Solutions' toolkit, "many of these components will have 'brains,' making them capable of executing 'behaviors' like obeying the laws of physics, making decisions, and interacting with other components and users. Balls bounce. Characters run. Tanks explode when struck by missiles." With WorldVisions ${ }^{\mathrm{TM}}$, users do not need any programming or enhanced skills to build interactive 3D VRML models.

Business Advisor. Since launching Process Advisor, for advanced process modeling and optimization, its first software product with ATP-funded technology, AI Ware has added a second product, Business Advisor, a modeling and decision support system for analyzing business issues and making business predictions and forecasts for strategic planning and decision making.

Virtual Reality Surgical Simulators. HT Medical has introduced three virtual reality surgical simulation products using its ATP-funded TELEOS technology. CathSim ${ }^{\mathrm{TM}}$ Intravenous Training System is used to train students to insert intravenous catheters. It "moves the student trainee as far as possible up the learning curve prior to real patient contact." HT Medical's PreOp ${ }^{\mathrm{TM}}$ Endoscopy Simulator is a training system for performing endoscopy procedures. It teaches "the motor skills and cognitive knowledge necessary to perform these procedures." The PreOp ${ }^{\mathrm{TM}}$ Endovasular Simulator is being developed to teach skills for performing balloon angioplasty and stent placement. Like the other programs, this simulator enables clinicians to practice procedures as many times as necessary before performing the procedure on a patient.

Fragment Length Polymorphism for DNA Diagnostics. In mid 1996, Third Wave "launched its initial product from its lead product platform, Cleavase ${ }^{\mathrm{R}}$ Fragment Length Polymorphism $\left(\right.$ CFLP $\left.^{\mathrm{R}}\right)$ developed as part of its ATP project, into the life science research market." They had two distributors and over $\$ 300,000$ in sales by the end of the year. This product is part of the "tool box" of faster, cheaper, and more user-friendly technologies for detecting and manipulating DNA that Third Wave is developing for molecular human diagnostics applications such as assessing tissues for transplantation suitability, forensic 
and paternity tests, diagnosing hereditary and infectious diseases, assessing susceptibility to specific diseases, and monitoring the response of disease pathogens to specific medical treatments.

\section{Anecdotal Comments}

Anecdotal comments provided in the business reports help establish a clearer perspective for the commercialization progress reported above at relatively early stages of the R\&D.

\section{Ability to make new and/or better products}

Many of the 54 percent who report an ability to make new and/or better products are not yet ready to start commercial production. Market launch may be some years off; however, key technical barriers to commercialization have been overcome.

"We are able to make ....drills with life expectancy 10-20X."

"We can now make good quality, repeatable automotive lighting fixture parts. The performance is good, and samples have gone past the prototyping stage, and are now in the designed-in stage of development."

"Five-inch diagonal proof of concept display built."

"We are now producing ... plugs made with insulators that have been injection molded using this technology."

"We have taken an observation made just prior to ...ATP proposal... and transformed it into a revolutionary product line ... that we manufacture and that are distributed by '2' of the world's largest and most respected life science companies."

"We are able to make a better metrology product for the fuel injector industry. Based on test results and direction from our strategic partner..., we have reduced the amount of residual instrument error.... Work continues ... to improve its thermal stability. Further, we have achieved better accuracy while implementing phase diffractive optics."

"Higher density of the part was achieved. Extended the range of usable materials. Enhanced magnetic properties."

"The ... database is clearly ahead of its time. With one more iteration, the database will likely be ready for commercialization together with the software, which is now quite stable."

\section{Prototyping and customer testing}

"We are currently conducting field molding trials at five different potential customers. A wide variety of specialty electrical parts are being prototyped with significant positive response."

"Our first prototype fabrication allows us to make a manufacturing cost estimate based on experience and known processes. It predicts [our product] will be at least $2 X$ less expensive than other optical technologies and competitive with comparably performing copper interconnections." 
"We have gone from concept to a demonstrable prototype and will soon have scalability and performance data to match."

"We now have enough of the technology visible that we are discussing installation/evaluation with a large number of companies."

\section{Implementation of new or improved production processes}

The 39 percent of companies reporting implementation of new or improved production processes embodying some part of ATP-funded technology (Figure 26), in experimental or actual production lines, further described early effects on production efficiency, costs, and/or product quality.

"Implemented continuous cable assembly fabrication technique, which should result in lower cost cable assemblies."

"Robotic handling techniques have been introduced to the process to speed up post mold processing and demonstrate the cost savings attributed to automation."

"There have been many offshoot process improvements resulting from ATP funding. Core technology improvements in primer extension biochemistry have been adapted to our currently commercialized platforms. Software improvements have been integrated across the company for data analysis and reporting, enabling service lab volume to increase without an increase in data analysis labor.

"Improved raw materials screening, improved process control and improved measures to assure product consistency."

"We have reduced necessary on-site time by approximately one third and developed much better reporting systems."

"From the process research that we have so far performed, we have improved our abrasive media formulations, identified key process variables and have improved the control of these variables with advanced controls and data collection."

"We established a new way of casting ...with the proper coefficient of expansion as well as other parameters such as 1) size, 2) thickness. This achievement is unique as only one in the industry has been able to achieve same."

"ATP has enabled [us] to begin building an interoperability lab for testing interoperability between different video and network devices from multiple vendors. This interoperability lab will enable us to build better products and solve interoperability issues before products reach the field."

"We have developed engineering scale automated cleaning-in-place and testing systems for membrane separations and are developing new applications." 


\section{CHANGES IN COMPETITIVENESS}

\section{Trends in Competitiveness and Competitive Conditions}

Is the progress of ATP-funded technologies keeping pace with developments in fast-moving international markets? Many companies report that the competitive standing of their ATP-funded technology has improved over the course of the ATP project. The window of opportunity appears to remain open for successful market entry of many new products and processes which are currently in the planning or early commercialization stage. However, some companies have fallen behind in the race for international market position for at least some applications and/or have encountered new competitors.

Figure 26 illustrates the overall changes in competitive standing along with changes in some underlying, external conditions that affect the competitiveness of ATP-funded technologies for companies reporting after one or more years of ATP funding. From the lower part of the figure, in the first panel, we see that 42 percent of this group of companies report that their competitive standing has improved for at least one application of their ATP-funded technology. Across all applications (upper part of the figure), companies report that their competitive standing has improved for 32 percent of all applications of the ATP-funded technology currently on the market or being planned, but that it has worsened for nine percent of applications. Overall competitive standing is believed to be unchanged for most applications.

Figure 26. Changes in Competitiveness

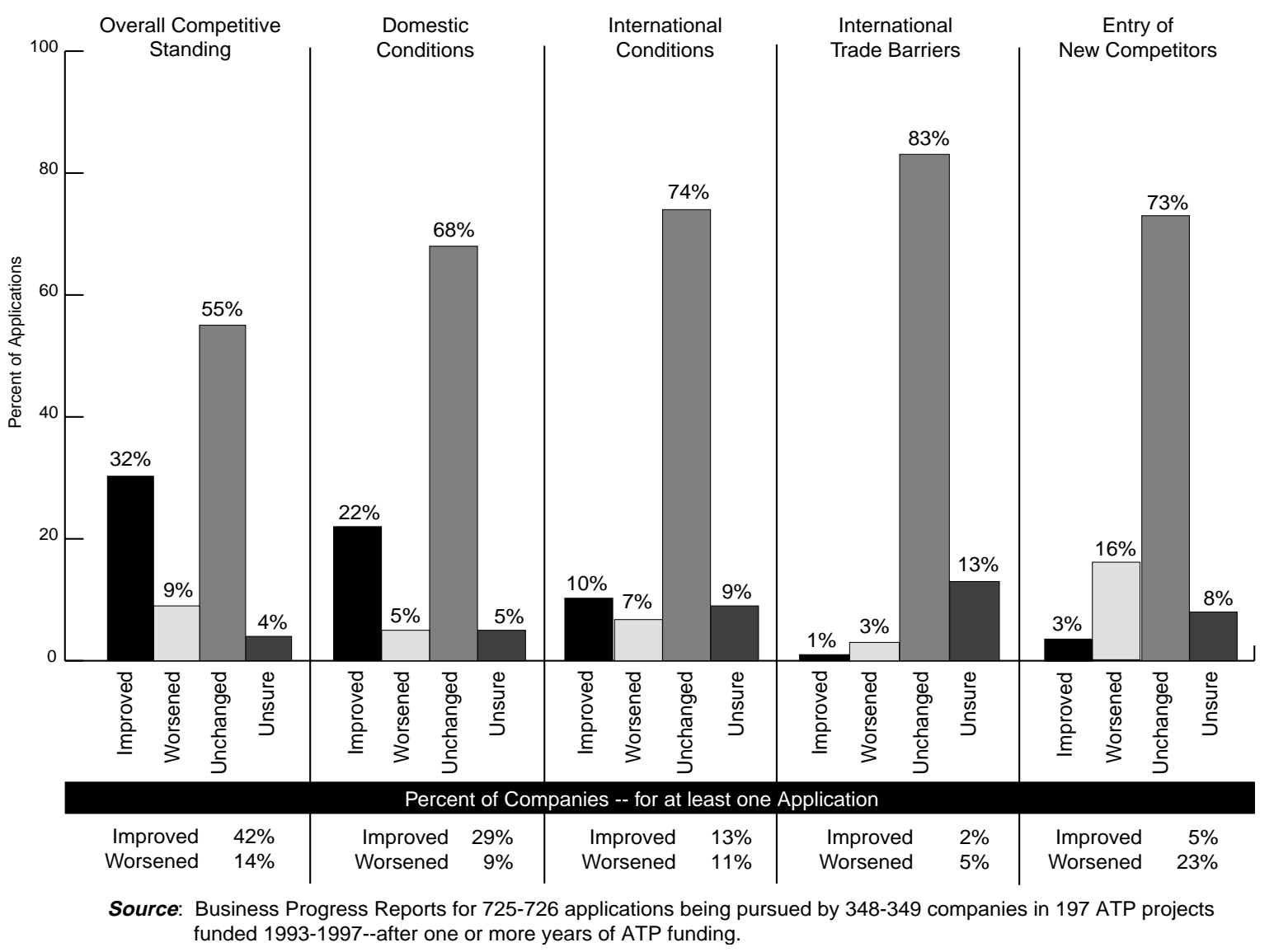


Subsequent panels consider specific conditions affecting competitiveness. Those conditions examined remained unchanged for two-thirds or more of applications. Nevertheless, twenty-nine percent of companies report that domestic economic conditions have improved for at least one application, and only nine percent that conditions have worsened. On the other hand, for only 13 percent of companies have international political and/or economic conditions improved for at least one application; they have worsened for 11 percent of companies. Twenty-three percent of companies had encountered competitors. International trade barriers do not appear to have affected competitiveness.

A more in-depth analysis (not illustrated) indicates that companies reporting a worsened competitive standing or new competitors span the entire spread of technologies funded by ATP. Worsening conditions do not appear to be heavily concentrated in particular technology areas or target industries.

\section{Status of Competitors}

Figure 27 provides more detail concerning how ATP-funded companies have been doing relative to their competitors and illustrates possible future trends in competitiveness. Companies report that their own position has not changed for 52 percent of applications. Nevertheless, their competitors, although still behind have advanced for 17 percent of applications, and have pulled even or are ahead for nine percent of applications.

Figure 27. Status of Competitors

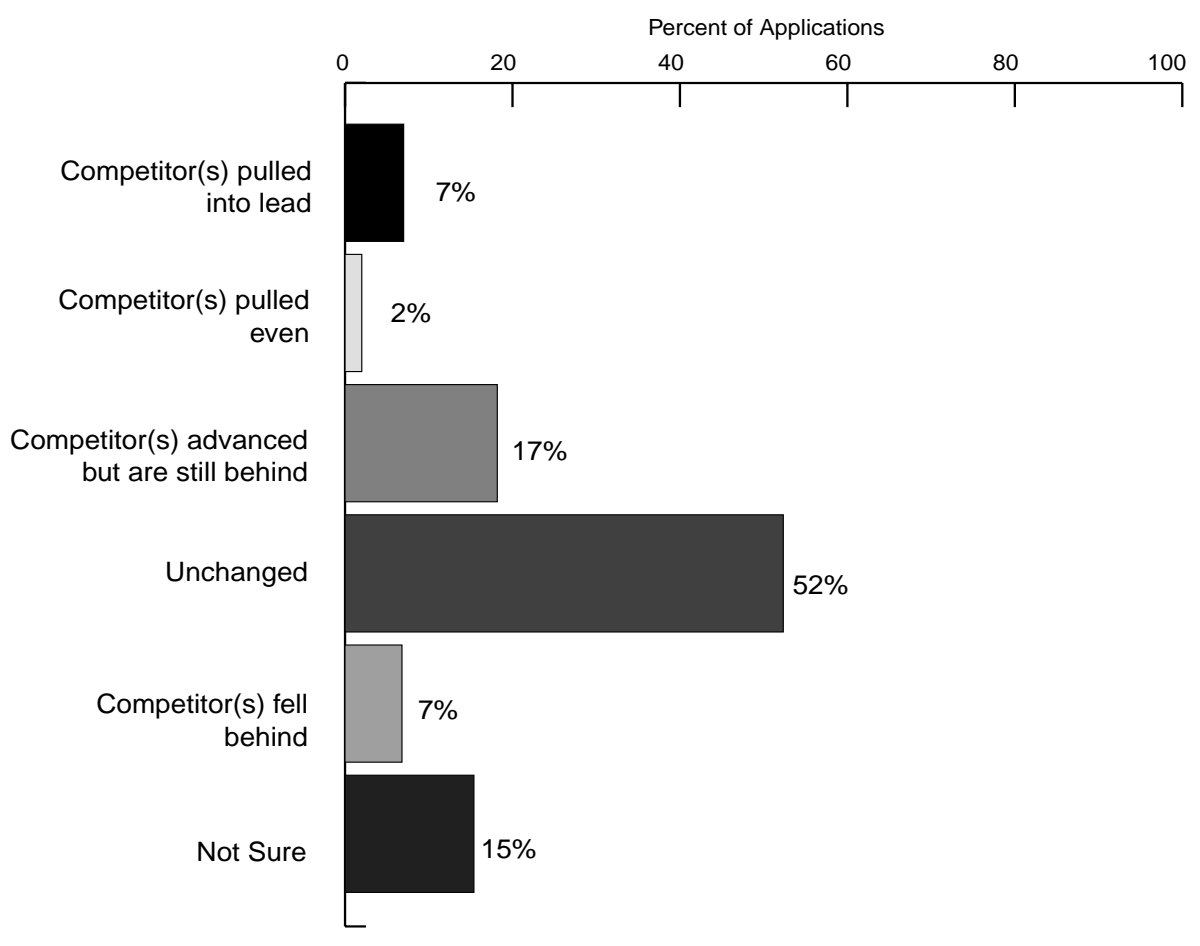

Source: Business Progress Reports for 769 applications being pursued by 366 companies in 197 ATP projects funded 1993-1997-after one or more years of ATP funding.

These results suggest that some ATP-funded companies face highly competitive, dynamic product markets in commercializing their technologies. The entry of ATP-funded technologies into the marketplace will tend to increase the level of competition in existing markets as increased investment and advances by ATP-funded firms stimulate others to "catch-up" or to make their own advances. ATP 
funding also helps increase the visibility of promising new technology areas, and this helps spawn entirely new firms and product markets.

The window of opportunity remains open for the vast majority of applications currently planned by ATPfunded companies, but these companies will likely be under pressure to meet technology-development goals on a timely basis and to identify new applications as the technologies evolve and market conditions change. 


\section{INTELLECTUAL PROPERTY PROTECTION AND DIFFUSION OF TECHNOLOGY}

\section{Protection and Disclosure of Intellectual Property}

Protection of intellectual property through formal patent and copyright mechanisms provides legal protection against use of an invention without permission or compensation. The patent or copyright converts the intellectual property into a potential income-earning asset and, for many applications and industries, is critical to the ability of the innovator to commercialize a new technology. In return for patent protection, however, the innovator must agree to public disclosure of the patented invention and (to a lesser extent) copyrighted material. Disclosure provides a means of attracting commercial partners interested in licensing or joint production opportunities, and thus reinforces the private commercial purposes of the intellectual property protection; however, it also is a mechanism for unintended knowledge spillovers--to competitors or others who may be in a position to exploit the knowledge without paying for it. (See Jaffe, 1996.) Patent and copyright activity is an important component of the direct pathway to national economic benefits in that it provides necessary protections for ATP-funded companies to commercialize their technologies profitably; simultaneously, it provides an indirect pathway to national economic benefit through knowledge spillovers to others in a position to benefit from the ATP-funded innovation.

Figure 28. Intellectual Property Strategies Planned

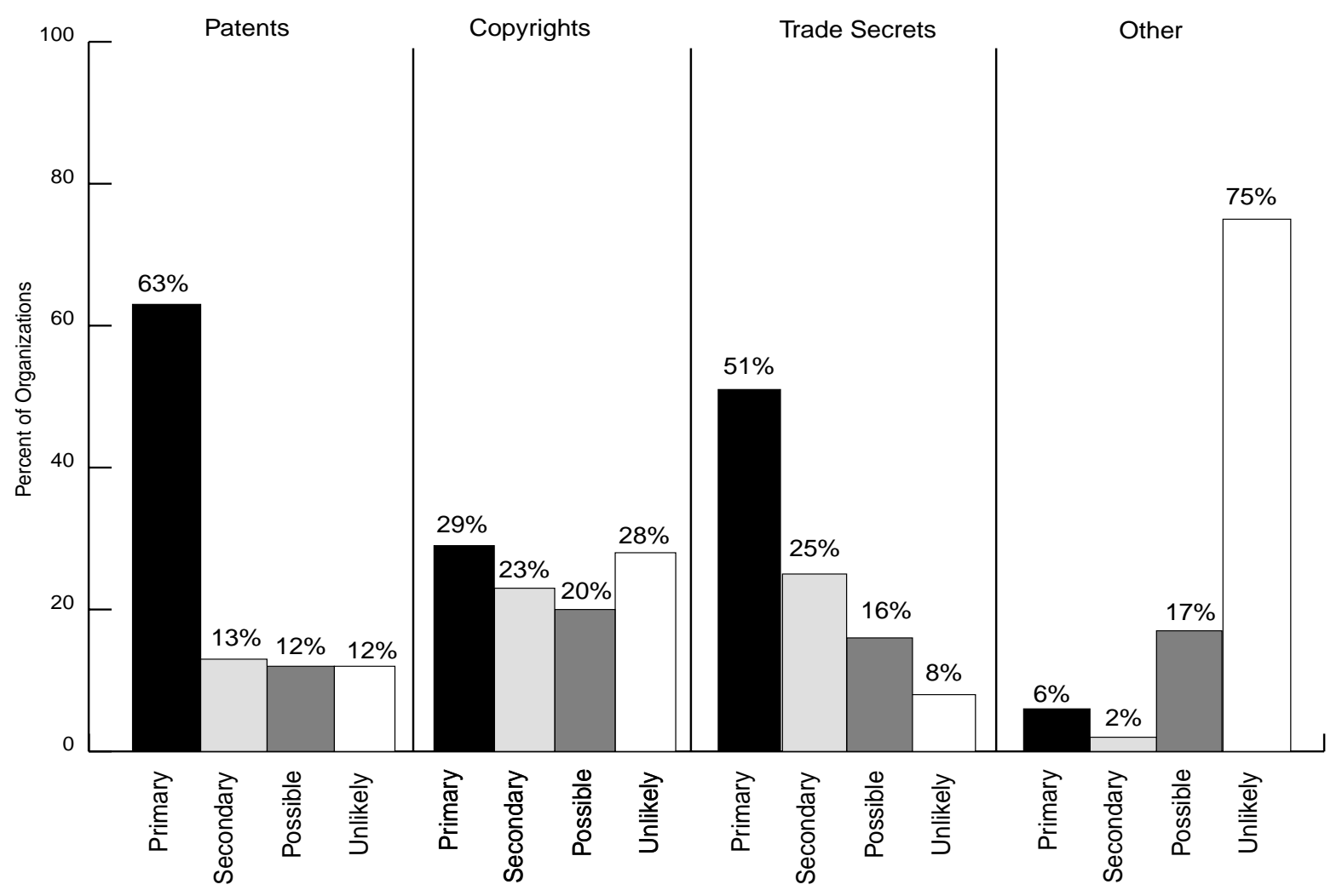

Source: Business Progress Reports from 522 organizations in 260 ATP projects funded 1993-1997. 
Both aspects of patent and copyright protection are important to achieving maximum commercialization, diffusion, and social benefit of the ATP-funded technologies: Patent and copyright protection afford ATP-funded firms incentives, in the form of protection of title to their innovations, to undertake costs of product development and marketing needed to launch a commercial product, and may help open new licensing and other partnering opportunities. The wider the commercial use of the technology and the greater the spread of information concerning resulting products and processes, the greater the opportunity for market spillovers to users and customers and for knowledge spillovers to others in a position to make use of the knowledge for their purposes.

Most companies report plans to protect intellectual property created in their ATP project, whether they plan to produce in-house or to license the technology to others. As shown in Figure 28, patent protection, copyright protection, and maintenance of trade secrets are listed respectively as primary strategies by 63 percent, 29 percent, and 51 percent of companies. A more detailed analysis (not shown) indicates that eight percent of the companies listed all three strategies as primary; 13 percent listed both patents and copyrights as primary; and 22 percent listed both patents and trade secrets as primary strategies. Thus some combination of legal protection and secrecy/first mover advantages appears to be a common strategy. Of course, to the extent that companies patent their technology they cannot expect to maintain the same knowledge secret; but companies may identify some aspects of their technology best protected by patent and other aspects best protected by secret, and thus combine the two strategies.

Organizations receiving ATP awards in the FY 1993-1997 competitions report that the ATP-funded technologies build on [and intellectual property rights are protected by] over 2,000 pre-existing patents. Companies seeking title to new intellectual property created with ATP funding have reported to NIST 239 new patents filed, eight copyrights filed, and 23 patents issued. Often foundational patents predate the ATP project, and the ATP project focuses on bringing the technology beyond a rough concept.

\section{Dissemination of Non-Proprietary Information}

Published papers, conference participation, news articles, press releases, and internet sites provide additional dissemination of information about ATP-funded technologies. Many companies are very active in publishing papers, issuing press releases, and making public presentations concerning their $R \& D$ activities - some more than others. Universities and other research organizations, with the agreement of the for-profit companies holding title to ATP-funded intellectual property, have also been active in disseminating non-proprietary information about their ATP-funded technology development. Table 4 provides a summary of the activity through March 1998 in published professional journal articles and conference papers alone.

\section{Table 4. Dissemination of Non-proprietary Information from ATP-funded Projects}

\begin{tabular}{|l|c|c|}
\cline { 2 - 3 } \multicolumn{1}{c|}{} & $\begin{array}{c}\text { Papers in Professional } \\
\text { Journals }\end{array}$ & $\begin{array}{c}\text { Papers Presented at } \\
\text { Conferences }\end{array}$ \\
\hline Total Number of Papers & 250 & 706 \\
Number of Organizations Reporting Papers & 74 & 186 \\
Number of Projects Reporting Papers & 64 & 143 \\
\hline
\end{tabular}

Note: Across the 199 projects reporting, an average of 1.3 professional journal articles were published and 3.6 conferences papers presented per project. Thirty-two percent of the projects produced at least one professional journal article; 72 percent of the projects produced at least one conference paper.

Source: Business Progress Reports from 199 ATP projects funded 1993-1997-after one or more years of ATP funding. 
According to the BRS data, more than half the projects covered in this study have produced published conference papers, and approximately one-fourth have produced published articles in professional journals. On average, about 3.6 conference papers have been presented and 1.3 professional journal articles published per project. 


\section{RELATIONSHIP TO PRIOR WORK AND CONCLUSIONS}

Although nearly all the ATP projects funded 1993-1997 were still in the R\&D phase as of early 1998, an analysis of the business reports from 199 projects after at least one year of funding suggests that the necessary conditions for achieving national economic benefits are evolving, although not necessarily at the same rate or to the same extent for all projects.

\section{Relationship to Prior Work}

Findings from the BRS data are largely consistent with the findings of two third-party surveys of projects not in the BRS. Silber \& Associates surveyed projects funded from 1990 through 1992 after approximately two-to-three years of funding (Silber \& Associates, 1996). Solomon Associates surveyed ATP's first competition awardees after just one year of funding (Solomon, 1993). The BRS captures much greater detail than the third-party telephone surveys, explicitly covering the evolution of a myriad of applications. And, of course, the BRS captures the voices of awardees directly without a third party intervening. Although specific summary statistics differ somewhat, analyses of BRS data generally confirm earlier survey results that ATP awards are "enabling [industry] to afford and engage in high risk research," "stimulating collaboration and formation of strategic alliances," "shortening the R\&D cycle," "helping attract additional funding," and "creating new business opportunities," among the many other effects reported by those earlier studies. Results of the current study parallel results of Powell's study of ATP projects funded 1993-1995 (Powell, 1997) but with the current study showing increased commercialization activity commensurate with the more advanced average level of ATP project completion. (See Appendix B.) A more recent study by Powell based on BRS data focused on ATPfunded small firms. This study identified a number of factors that have contributed to the success of small firms in winning ATP awards and found that small firms are keeping up with larger firms in achieving major milestones toward commercialization at least through the period of funding of R\&D and that those in joint ventures appear to be making particularly rapid progress (Powell, 1999).

\section{Summary of Findings}

Opportunities for economic spillovers from the portfolio of projects in the BRS appear strong, and for the most part consistent with the original basis for project selection. Project participants have identified more than 1,200 applications of the technologies under development and reported on commercialization plans for over 970 applications spanning the spectrum of SIC (or NAICS) industries. Most applications involve new products with significant performance improvements over existing/defender technologies, offering dramatic possibilities for productivity improvements. Many are "new-to-the-world-products" aimed at brand new markets. Most companies seek to address stages of production relatively early in the production chain, for example, materials processing or component manufacture, creating maximum opportunity for intermediate producers/customers at multiple later stages, and even in multiple application areas, to experience market spillovers.

Opportunities for additional economic spillovers through technology diffusion are being enhanced by patent and licensing activity and dissemination of non-proprietary information. ATP projects build on more than 2,000 existing patents, and more than 90 percent of companies plan to patent or copyright their ATP-funded technologies as a primary intellectual property strategy. More than two hundred patents have been filed, and 23 patents have been issued. Licensing to others is a primary or secondary strategy for commercializing 47 percent of the planned applications. Conference activity and publication of papers has been very vigorous, with an average of 3.6 conference papers presented and 1.3 professional journal articles published per project. 
Consistent with ATP's mission to accelerate the creation and commercialization of advanced technologies, acceleration of the R\&D process and time-to-market reduction appear to be important project goals, with acceleration of at least two years anticipated for 65 percent of applications. In many cases the time saved may be critical to meeting the narrow window of opportunity in fast-paced, highly competitive technology and product areas. Eighty-six percent of organizations indicate they are already ahead in their R\&D cycle as a result of ATP funding; of these, 24 percent believe they would not have started the project without ATP funding; 55 percent are one to three years ahead after just one or more years of ATP funding.

ATP funding appears to have stimulated increases in private sector investment in high risk R\&D. Some projects would not have been undertaken at all with ATP funding, and others received a higher level of private investment as a result of ATP funding. An estimated $\$ 320$ million of company internal funds have been invested in or committed to ATP projects beyond what industry alone would have invested in the absence of the ATP awards, an estimated 58 percent increase in industry's investment in the ATPfunded technology areas. This increased industry investment is in addition to the ATP funding and the funding industry would otherwise have invested. Approximately $\$ 200$ million of new funding from outside the awarded organizations has been attracted to support the ATP-funded technology development and commercialization of current or future products. Most organizations further report that the ATP award has changed the nature of their R\&D program to encompass a broader scope, higher level of technical risk, and/or longer-term R\&D horizon.

The ATP appears to be meeting its legislated objectives of stimulating successful collaborations among companies and among industry, universities, and research laboratories. Eighty-six percent of organizations, from a mix of joint venture and single-company projects, report that their project has involved collaboration with other organizations. Of these: 88 percent indicated that the ATP was responsible to a moderate or great extent for the collaborations; 97 percent reported that stimulation of creative thinking was significantly or moderately enabled by collaboration; 85 percent reported saving time as a result of collaboration were significantly or moderately enabled by collaboration; and 80 percent or more reported that obtaining R\&D expertise, accelerating entry into the marketplace, and/or encouraging future collaborations were significantly or moderately enabled by collaboration. Of the same group, 56 percent indicated that project coordination and management costs were significantly or moderately affected by collaboration; however, only 18 percent reported delays in beginning the R\&D, and only 8 percent anticipated delays in product entry into the marketplace or other difficulties as a result of collaboration costs.

Companies report active engagement in the commercialization planning activities needed to enter the marketplace in a timely manner, once the technology is ready. Companies in 84 percent of the projects have completed product/process definition for at least one application; companies in 70 percent of the projects have completed concept testing for at least one application. Although production has begun for only 10 percent of applications being planned, 64 percent of projects have completed a production prototype for at least one application, and 55 percent of projects have completed pilot production or a commercial demonstration for at least one application. Alliances are being negotiated with strategic partners for commercialization, with small companies particularly focused on this activity.

Progress towards achieving revenue goals is also reported. Most expect revenue one-to-three years after the project ends, but for 19 percent of applications, revenue is expected from spin-off activities before the end of ATP funding, and for nearly eight percent of applications and organizations, revenue is not expected until four or more years after the ATP project ends. Fifty-four percent of the companies, representing 66 percent of the projects, report they are now able to make a new or improved product, even 
though the product may not be ready for the marketplace for some time. Thirty-nine percent of companies, representing 51 percent of projects, report they have adopted process improvements resulting from ATP funding. Seventeen percent of companies, representing 27 percent of projects, indicate they had already earned some early product revenues, amounting to more than $\$ 67$ million by March 1998 , from sales of samples and prototypes and early "spin-off" products. Some companies have also realized their first licensing revenues. The nature and timing of the first revenues appear consistent with the R\&D status of these projects and projected timeline for revenues (see Figure 14).

\section{Plans for Future Work}

The ATP plans to continue the BRS data collection for future projects and participants funded by the program. In addition to providing a large volume of data covering more projects for a longer time period, the BRS will continue to provide an evolving picture, with statistical summary metrics, of the status of ATP projects towards meeting ATP's legislated economic objectives.

A new study underway extends the analysis of BRS data through September 30, 1999. This study covers 300 ATP projects funded through FY98, and includes reports from nearly 600 project participants reporting on more than 1,500 commercial applications of ATP-funded technologies.

Besides routine data collection and maintenance, work is anticipated in a number of areas:

- Extension of the BRS -- Extension of this database is focusing on development of questions for postproject reports required every two years for six years following the end of the ATP award. These questions will update commercialization activity and probe in more detail for evidence of intraindustry and inter-industry diffusion of ATP-funded technologies and of benefits to users, for example, health and safety impacts, as well as longer-term economic impacts on the companies funded. This information will be invaluable in studies of economic spillovers. Data collection is now underway for organizations funded in FY93 and FY94.

- Revision of the BRS -- A major revision of the BRS routine reporting questions is also underway. The major purpose of the revision is to develop a more user friendly web-based reporting format. In the course of that revision process, some content changes are being made, drawing on our experience in using the BRS to date and on feedback from other economists, as well as from ATPfunded organizations reporting to us.

- Additional, detailed studies using the BRS -- The BRS supports detailed analysis of many aspects of ATP's project portfolio. For example, projects can be sorted by type, industry sector, technology, geographical location, and other attributes. The BRS database is part of the broader ATP relational database structure and can further be linked to external, establishment-level national data sources by 4-digit SIC code. Under appropriate restrictions to maintain confidentiality of company information, the data are used by economic researchers in studies of ATP project and program progress and impact. The BRS data can also be used in conjunction with information from diverse sources to support a variety of evaluation studies, including detailed case studies. 


\section{REFERENCES}

Jaffe, A.B. (1996). Economic Analysis of Research Spillovers: Implications for the Advanced Technology Program. Gaithersburg, MD: National Institute of Standards and Technology.

Leifer, R. (1997). Managing Discontinuous Innovation in Established Firms: Reducing Uncertainty and Resistance. (forthcoming)

Laidlaw, F. (1997). Acceleration of Technology Development by the Advanced Technology Program: The Experience of 28 Projects Funded in 1991. Gaithersburg, MD: National Institute of Standards and Technology.

Mansfield, E. (1996). Estimating Social and Private Returns from Innovations Based on the Advanced Technology Program: Problems and Opportunities. Gaithersburg, MD: National Institute of Standards and Technology.

Mansfield, E., Rapoport, J., Wagner, S. and Beardsley, G. (1977). "Social and Private Rates of Return from Industrial Innovations." Quarterly Journal of Economics.

Powell, J. (1997). Development, Commercialization, and Diffusion of Enabling Technologies: Progress Report for Projects Funded 1993-1995. Gaithersburg, MD: National Institute of Standards and Technology.

Powell, J. (1999). Business Planning and Progress of Small Firms Engaged in Technology Development Through the Advanced Technology Program. Gaithersburg, MD: National Institute of Standards and Technology.

Regalado, A. (1996). "The DNA-Chip in Diagnostics." Start-Up. September 1996.

Ruegg, R. (1997). "ATP's Evaluation Plan and Progress." Paper presented at the 7th International Forum on Technology Management, and published in Conference Proceedings November 1997.

Ruegg, R. (1996). Guidelines for Economic Evaluation of the Advanced Technology Program. Gaithersburg, MD: National Institute of Standards and Technology.

Sedlak, B. (1996). "GeneTrace Systems Bets its Future in Genomics on TOF Mass Spectroscopy." Genetic Engineering News. December 1996.

Service, Robert F. (1998) "Microchip Arrays Put DNA on the Spot," Science, Vol. 282, Number 5388, October 1998.

Silber \& Associates (1996). Survey of Advanced Technology Program 1990-1992 Awardees: Company Opinion About the ATP and Its Early Effects. Gaithersburg, MD: National Institute of Standards and Technology.

Solomon Associates (1993). The Advanced Technology Program - An Assessment of Short-Term Impacts: First Competition Participants. Gaithersburg, MD: National Institute of Standards and Technology. 
von Hippel, E. (1994). "Sticky Information and the Locus of Problem Solving: Implications for Innovation," Management Science 40, no. 4 (April). 


\section{APPENDICES}

\section{Appendix A. Planned Diverse Applications of ATP-funded Technologies}

\section{Appendix A.1 Planned Diverse Applications of ATP-funded Technologies- Information Systems}

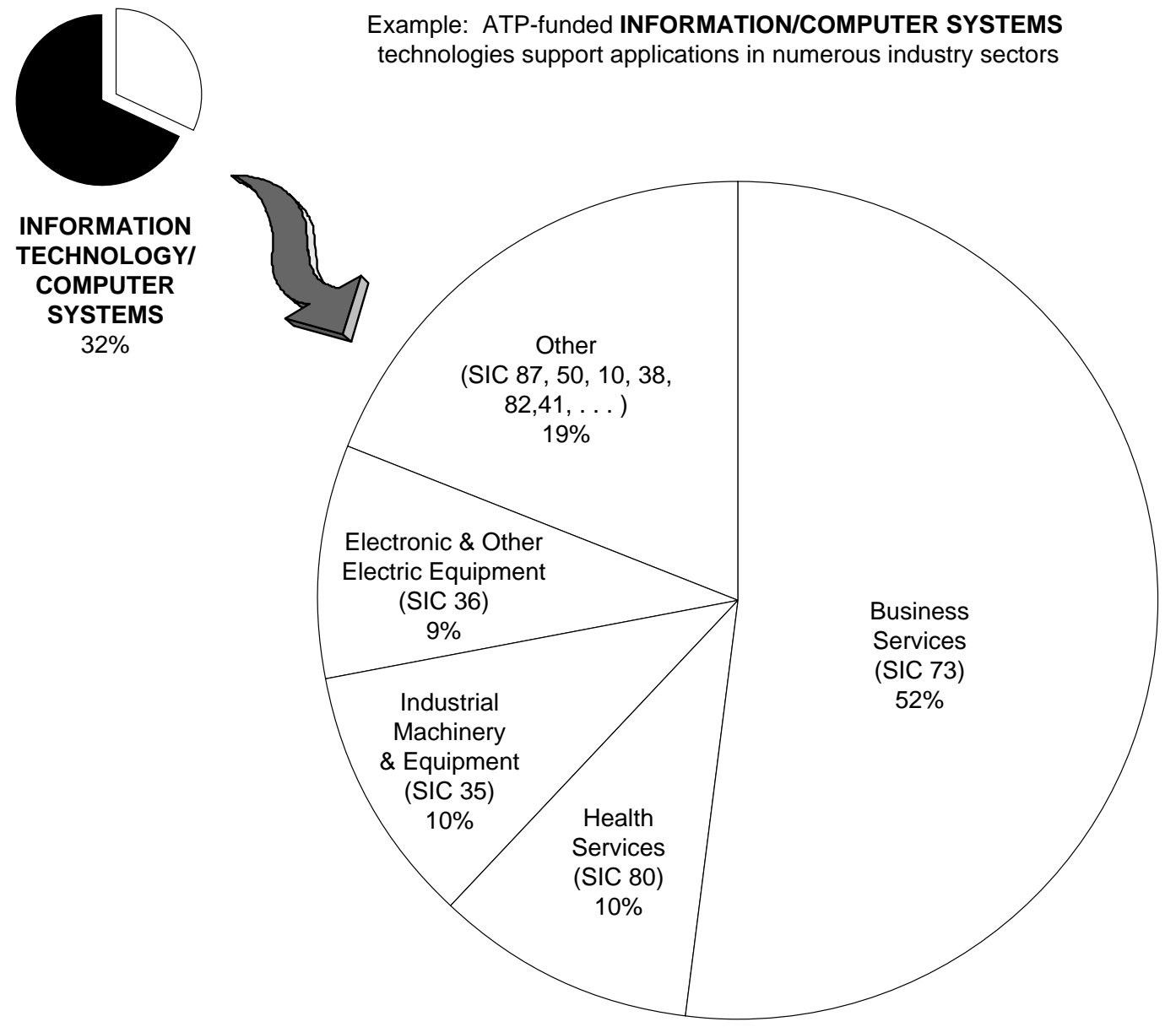

Note: "Other" SIC categories are defined in Appendix A.7

Source: Business Progress Reports for 974 applications being pursued by 463 companies in 256 ATP projects funded 1993-1997. 


\section{Appendix A.2 Planned Diverse Applications of ATP-funded Technologies-- Manufacturing (Discrete)}

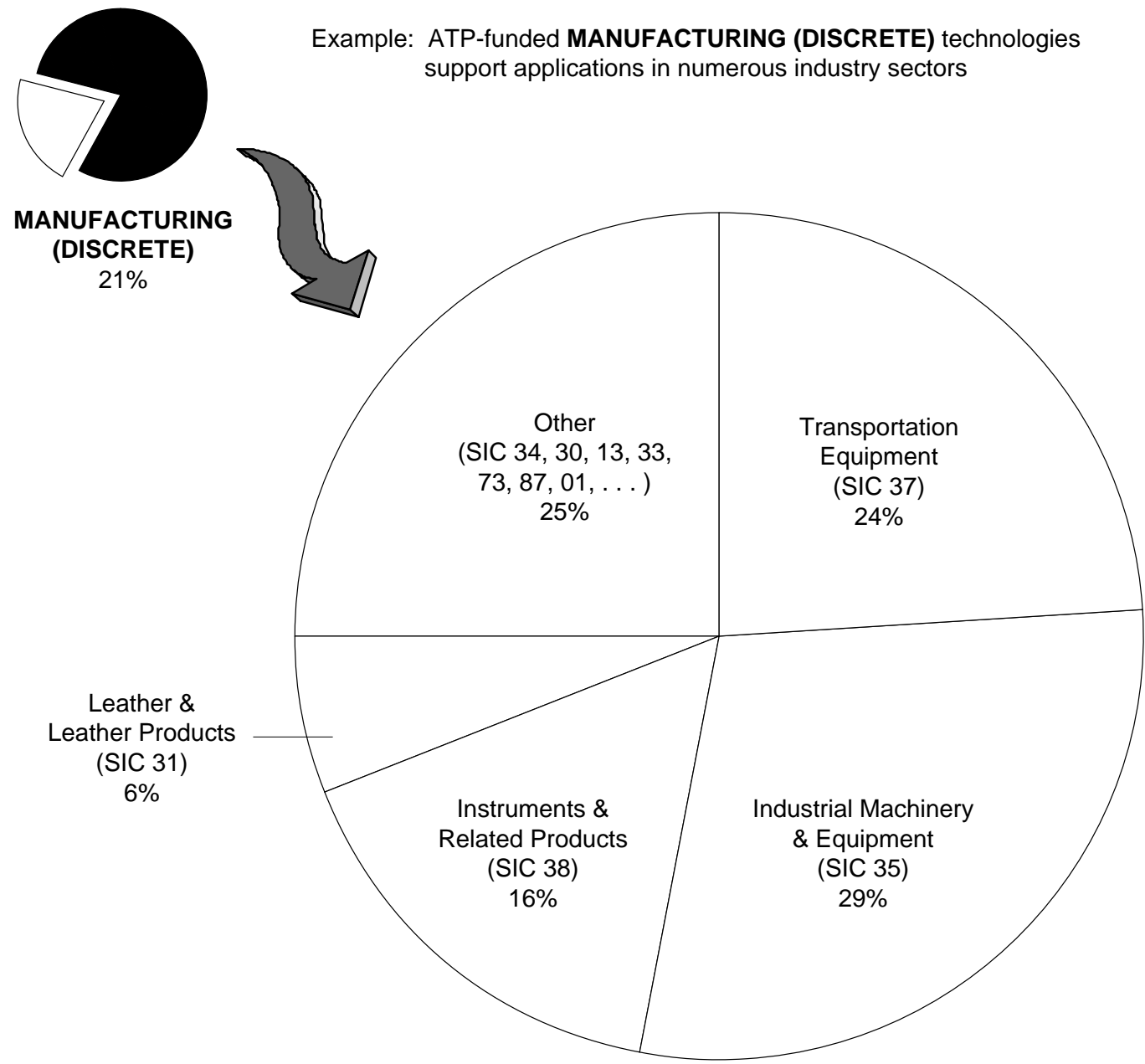

Note: "Other" SIC categories are defined in Appendix A.7.

Source: Business Progress Reports for 974 applications being pursued by 463 companies in 256 ATP projects funded 1993-1997. 


\section{Appendix A.3 Planned Diverse Applications of ATP-funded Technologies-- Biotechnology}

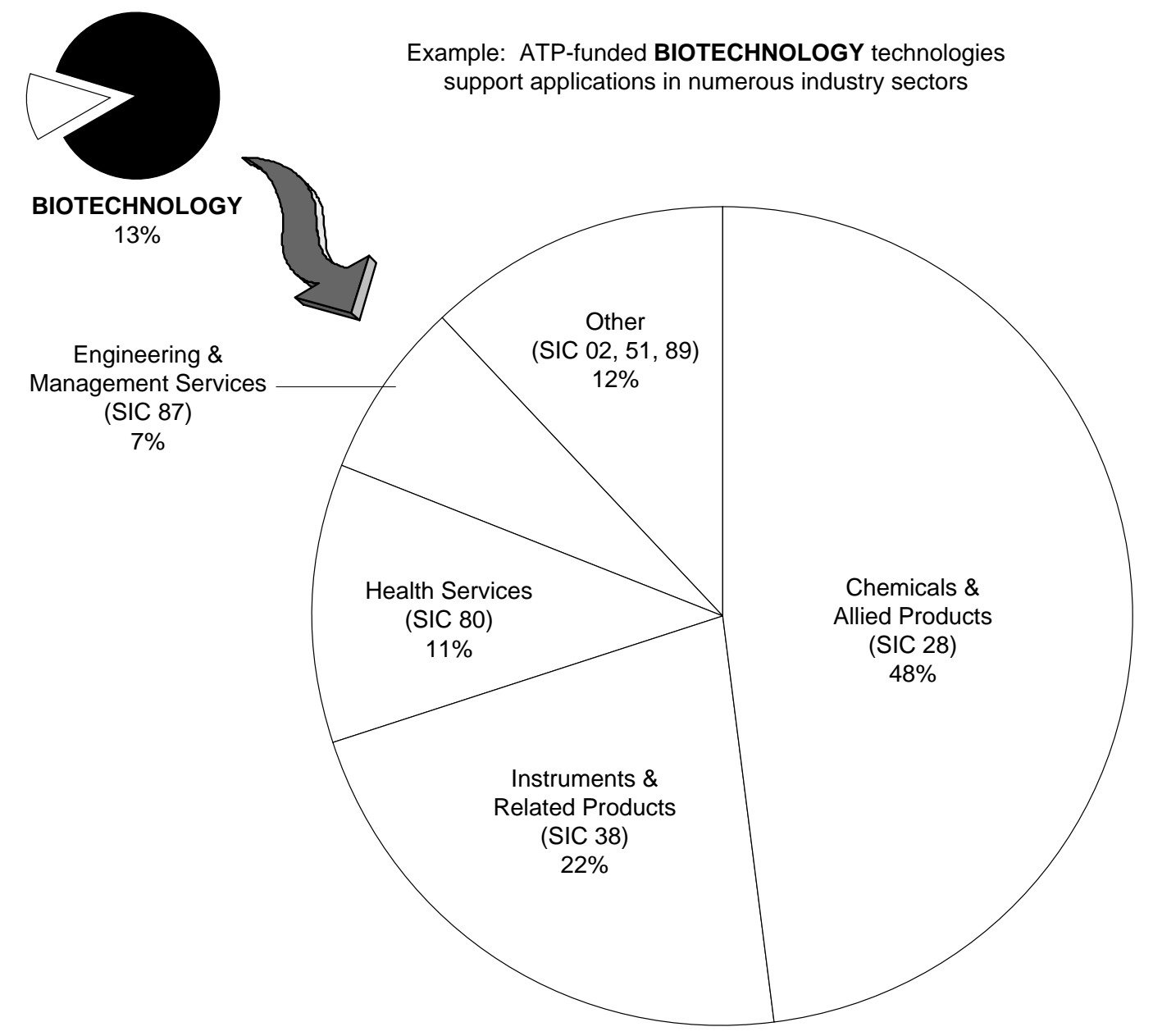

Note: "Other" SIC categories are defined in Appendix A.7.

Source: Business Progress Reports for 974 applications being pursued by 463 companies in 256 ATP projects funded $1993-1997$. 


\section{Appendix A.4 Planned Diverse Applications of ATP-funded Technologies-- Electronics}

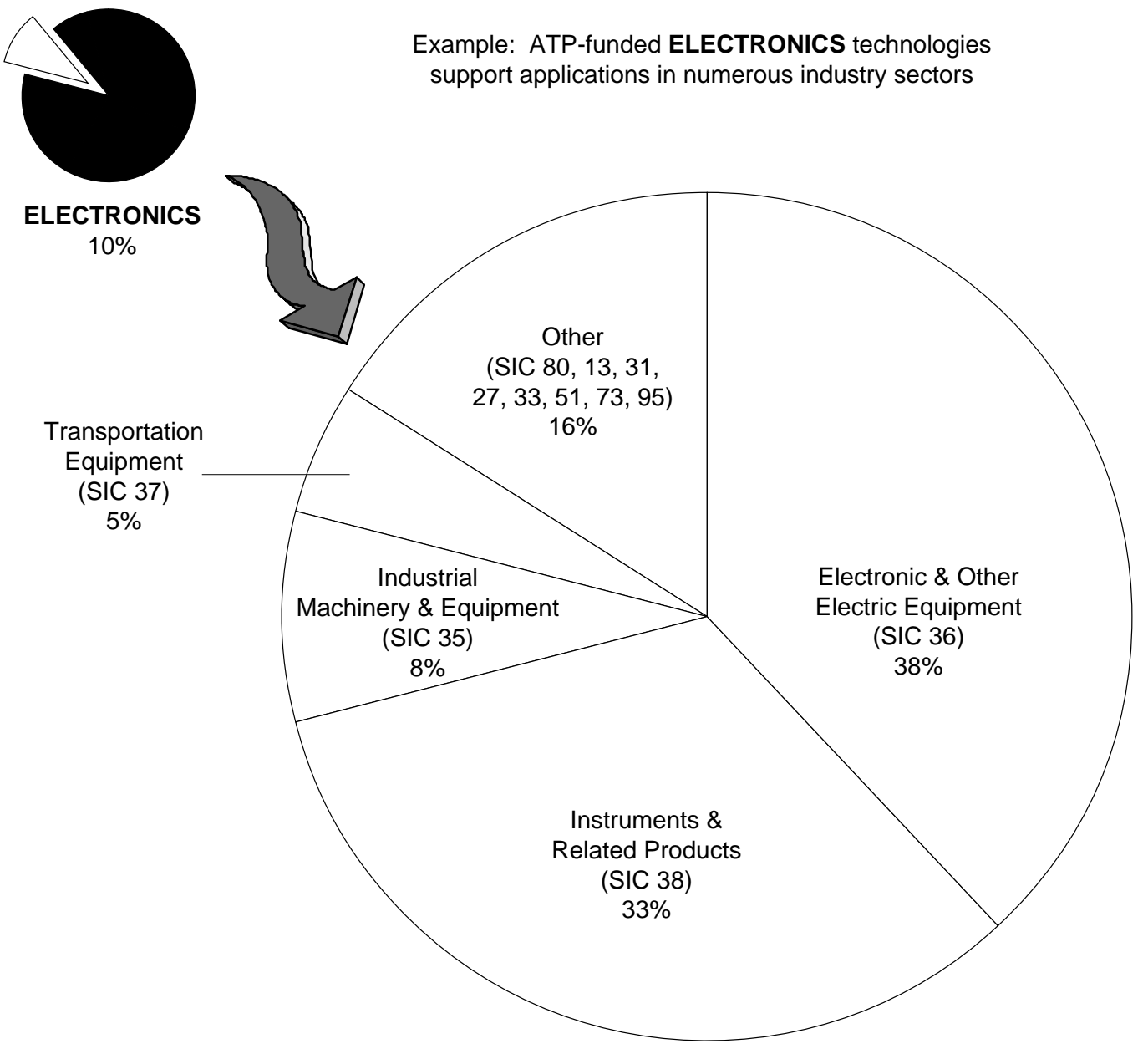

Note: "Other" SIC categories are defined in Appendix A.7.

Source: Business Progress Reports for 974 applications being pursued by 463 companies in 256 ATP projects funded $1993-1997$. 


\section{Appendix A.5 Planned Diverse Applications of ATP-funded Technologies-- Chemicals \& Chemical Processing}

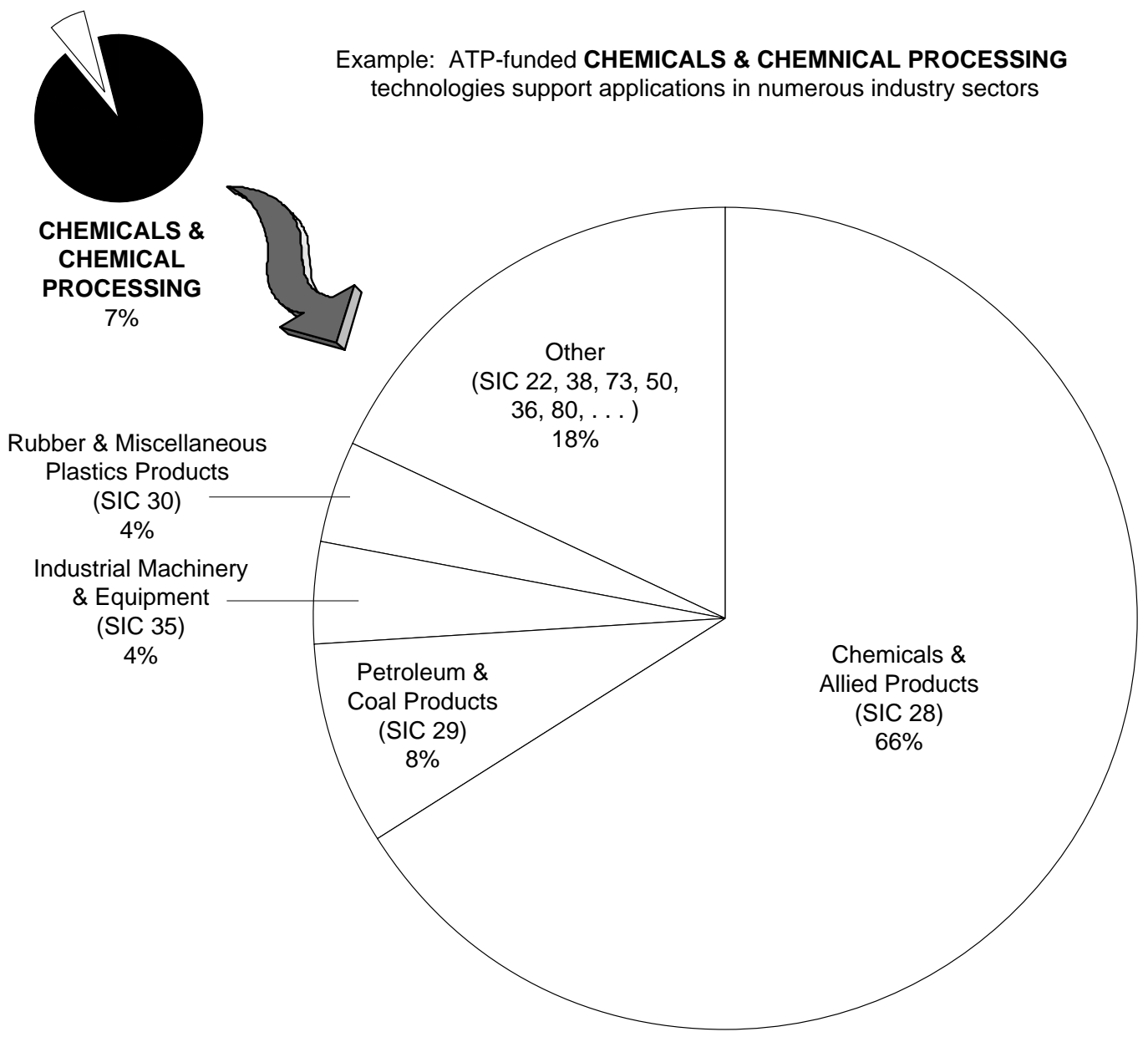

Note: "Other" SIC categories are defined in Appendix A.7.

Source: Business Progress Reports for 974 applications being pursued by 463 companies in 256 ATP projects funded 1993-1997. 


\section{Appendix A.6 Planned Diverse Applications of ATP-funded Technologies--Energy and Environment}

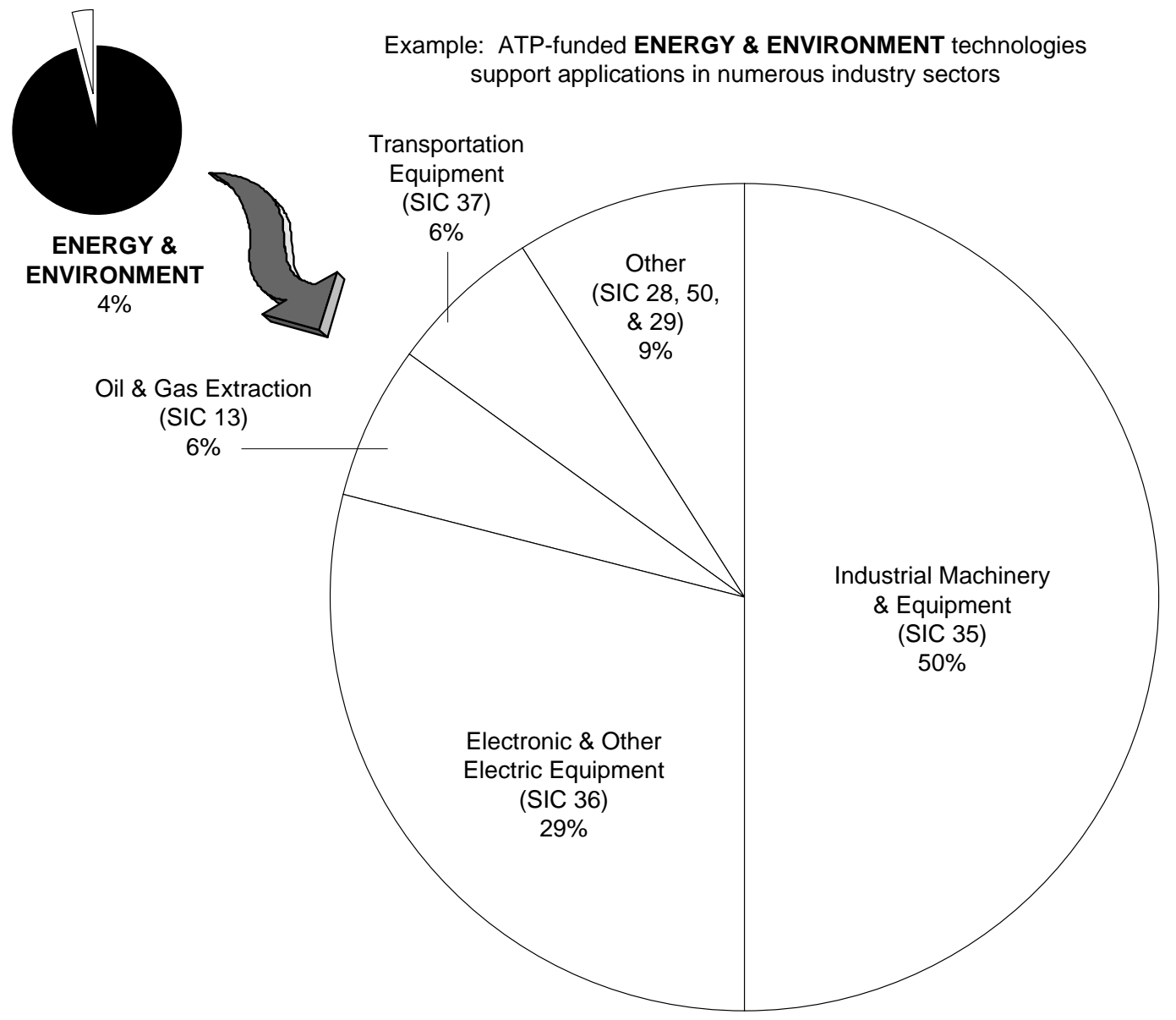

Note: "Other" SIC categories are defined in Appendix A.7.

Source: Business Progress Reports for 974 applications being pursued by 463 companies in 256 ATP projects funded $1993-1997$. 


\section{Appendix A.7: SIC Codes Included in "Other" Category}

\section{Applicable to Figure 4 and Appendices A.1 through A.6}

01 Agricultural Production - Crops

02 Agricultural Production - Livestock

10 Metal Mining

13 Oil and Gas Extraction

16 Heavy Construction, Ex. Building

22 Textile and Mill Products

23 Apparel and Other Textile Products

27 Printing and Publishing

28 Chemicals and Allied Products

29 Petroleum and Coal Products

30 Rubber and Misc. Plastic Products

31 Leather and Leather Products

32 Stone, Clay, and Glass Products

33 Primary Metal Industries

34 Fabricated Metal Products

35 Industrial Machinery and Equipment

36 Electronic and Other Electric Equipment

37 Transportation Equipment

38 Instruments and Related Products

41 Local and Interurban Passenger Transit

42 Trucking and Warehousing

49 Electric, Gas, and Sanitary Services

50 Wholesale Trade - Durable Goods

51 Wholesale Trade - Nondurable Goods

73 Business Services

76 Miscellaneous Repair Services

78 Motion Pictures

80 Health Services

82 Educational Services

87 Engineering and Management Services

89 Services, Nec

92 Justice, Public Order, and Safety

94 Administration of Human Resources

95 Environmental Quality and Housing

97 National Security and International Affairs 


\section{Appendix B. Comparison of ATP Progress at Two Points in Time}

This ATP progress report for projects funded 1993-1997 parallels the ATP progress report Development, Commercialization, and Diffusion of Enabling Technologies published in December 1997 for projects funded 1993-1995. In combination, the two reports provide snapshots of progress towards commercialization and diffusion of ATP-funded technologies at two points in time for a growing group of ATP projects funded since 1993. Drawing upon the analyses performed for the two separate reports, Appendix B compares progress at the two points in time: 1996 and 1998. The comparative results are based on Anniversary and Close-out Business Reports; i.e., they reflect reports from project participants which had received a year or more of project funding as of the time of data collection. None had yet completed a Post-Project Report.

\section{Appendix B.1 Distribution of Types of Participation and Types of Organizations}

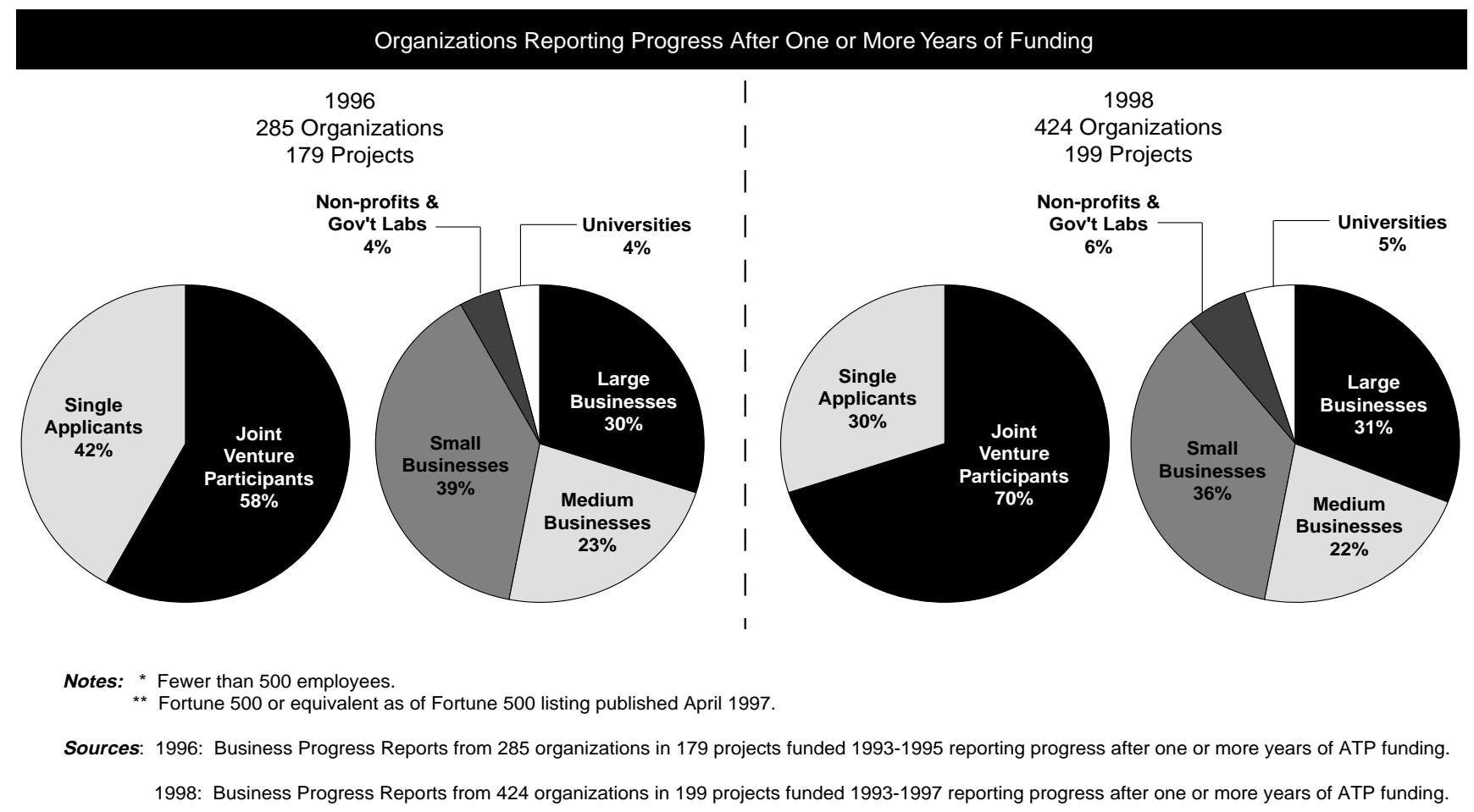

The number of projects for which comparable information was available increased by only 20 between 1996 and 1998; however, the number of reporting organizations increased by 139. This is because the additional projects included in the later report were mostly large joint ventures. As a result, the distribution of types of participation is more heavily weighted to joint venture participants in 1998 than in 1996. The distribution of types of organizations changed relatively little, though there was a slightly smaller percentage of small businesses (with <500 employees) and a slightly larger percentage of large businesses (Fortune 500 or equivalent) in 1998 than in 1996. This is due to the fact the new joint venture projects included in the 1998 data contained more large firms than was typical of the projects covered in the 1996 data. 


\section{Appendix B.2 R\&D Status}

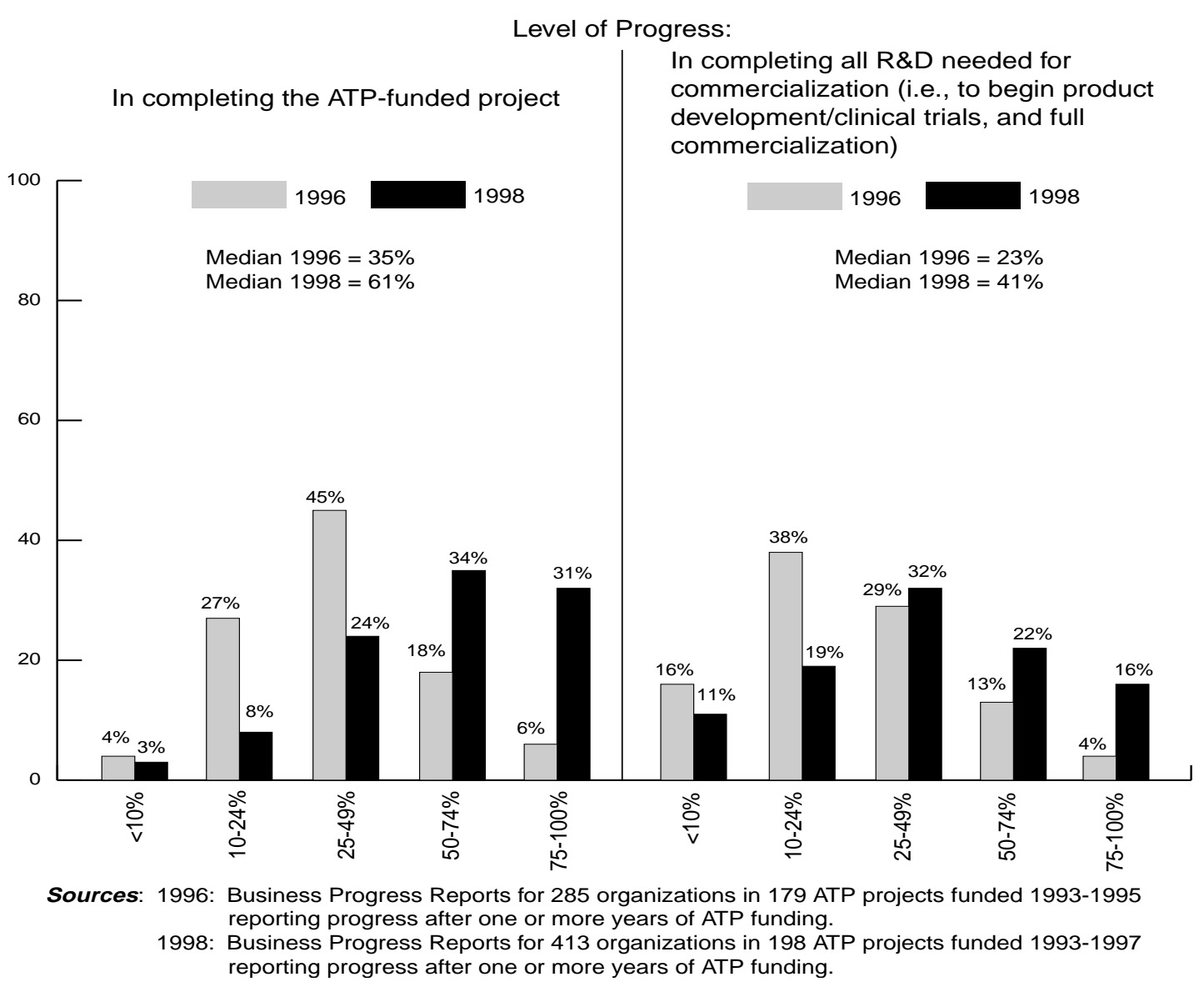

In 1998, compared with 1996, the portfolio of projects funded since 1993 had progressed considerably further towards completing their period of ATP funding; i.e., the projects as a whole had "aged" considerably despite the addition of new projects. (This picture will change as data becomes available for the large number of projects funded in 1997 and 1998.) In 1996, half the reporting organizations indicated their ATP projects were at least 35 percent complete; while in 1998, half the reporting organizations indicated their ATP projects were at least 61 percent complete. In 1998, 31 percent of reporting organizations indicated their ATP projects were 75-100 percent complete, compared with only 6 percent in 1996.

Although some project participants have engaged in early types of commercialization activity by the time ATP funding ends, most face additional R\&D. In 1998, half the reporting organizations indicated the total R\&D required was at least 41 percent complete; while in 1996, half the reporting organizations indicated the total $R \& D$ required was at least 23 percent complete. In 1998, only 16 percent of reporting organizations believed they had completed 75-100 percent of the R\&D required for full commercialization, compared with 31 percent of the same group which had achieved 75-100 percent completion of their ATP project and compared with only 4 percent of the 1996 group that had achieved this level of completion of all R\&D needed. 


\section{Appendix B.3 Early Commercialization Activities-Strategic Alliances and Licensing Agreements}

\begin{tabular}{|l|c|c|c|c|}
\cline { 2 - 5 } \multicolumn{1}{c|}{} & \multicolumn{2}{c|}{ Number of Projects } & \multicolumn{2}{c|}{ Number of Companies } \\
\cline { 2 - 5 } \multicolumn{1}{c|}{} & 1996 & 1998 & 1996 & 1998 \\
\hline $\begin{array}{l}\text { Negotiations/discussions held with potential } \\
\text { strategic partners }\end{array}$ & 69 & 97 & 77 & 113 \\
\hline $\begin{array}{l}\text { Alliances formed with suppliers } \\
\text { Alliances formed with customers }\end{array} \begin{array}{l}\text { Alliances formed for joint production } \\
\text { Alliances formed with distributors }\end{array}$ & 24 & 37 & 27 & 37 \\
\cline { 2 - 5 } & 24 & 49 & 24 & 52 \\
\cline { 2 - 5 } & 16 & 34 & 17 & 37 \\
\cline { 2 - 5 } & 8 & 30 & 8 & 30 \\
\hline \hline $\begin{array}{l}\text { Negotal alliances formed } \\
\text { licensing partners }\end{array}$ & $72^{*}$ & $150^{*}$ & $76^{*}$ & $156^{*}$ \\
\hline License agreements signed & 32 & 53 & 32 & 53 \\
\hline
\end{tabular}

Note: *Projects/companies reporting more than one type of alliance are included multiple times.

Sources: 1996: Business Progress Reports from 271 companies in 178 ATP projects funded 1993-1995 reporting progress after one or more years of ATP funding.

1998: Business Progress Reports from 356 companies in 198 ATP projects funded 1993-1997 reporting progress after one or more years of ATP funding.

As they moved towards ATP project completion, companies stepped up their commercialization activity (at their own expense). Building on market research and identification of customers performed earlier in their R\&D cycle, companies worked to strengthen relationships with potential customers and suppliers, or with potential licensing partners, and to build strategic alliances across their supply chains. The number of alliances formed with customers, joint production partners, and distributors, as well as the number of license agreements signed, more than doubled between 1996 and 1998. 


\section{Appendix B.4 Early Commercialization Activities-Commercial Production and Sales}

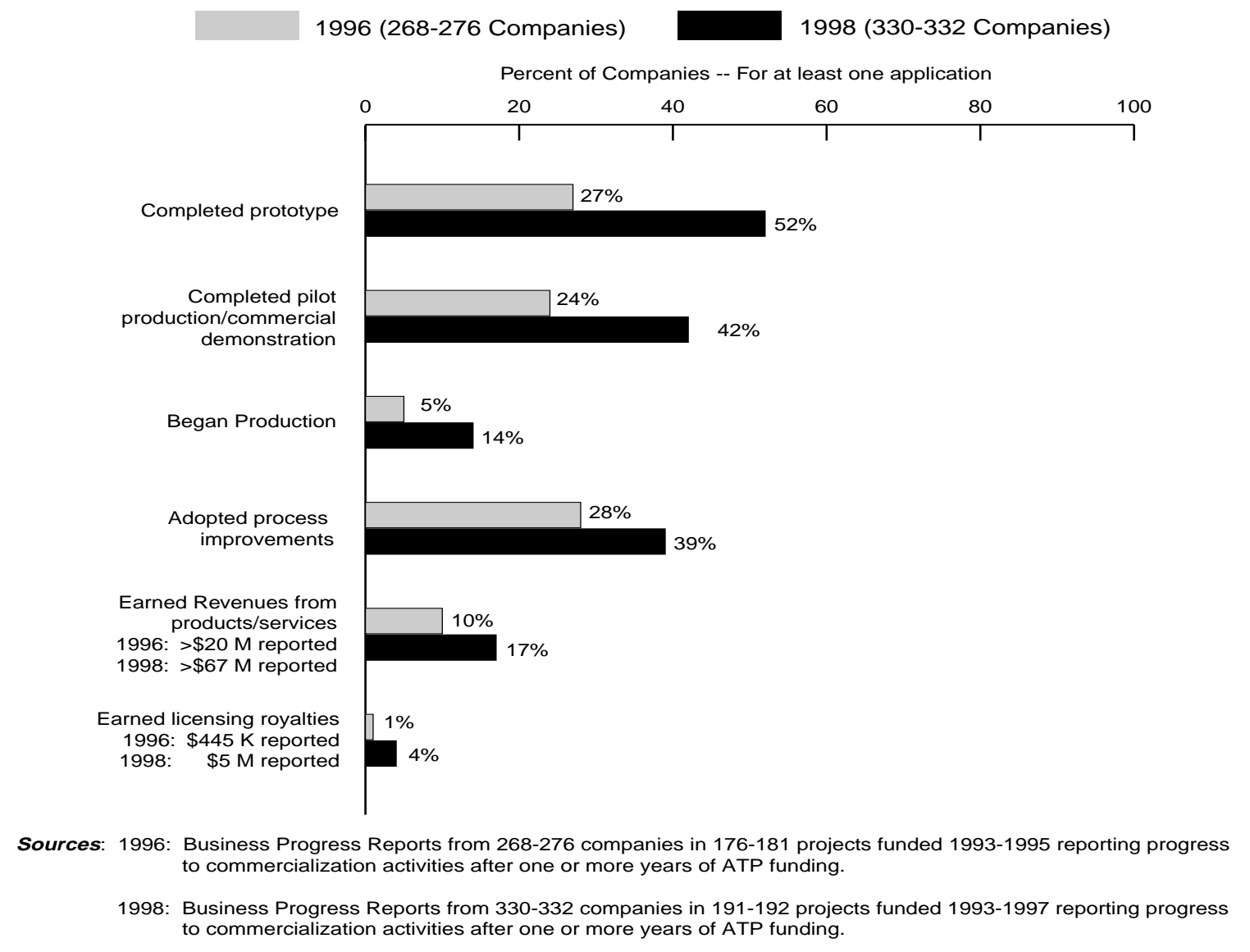

Companies are achieving important business milestones towards use of ATP-funded technology in commercial products and processes, and making steady progress over time. By 1998, with 31 percent of companies having completed 75-100 percent of their ATP project and half having completed at least 61 percent of their project, 52 percent of the companies had completed a production prototype for at least one application, 42 percent had completed pilot production or a commercial production for at least one application, and 39 percent had adopted process improvements deriving from the ATP project for at least one application. In 1996, when only 6 percent of the projects were 75-100 percent complete and half were only 35 percent complete, 27 percent of companies reporting commercial applications indicated completion of a production prototype, 24 percent of pilot production or a commercial demonstration, and 28 percent indicated adoption of process improvements deriving from their ATP projects.

Sales and licensing activity is occurring even before ATP-funded R\&D is complete, as companies seek to solidify customer relationships at early stages of technology development and build cash flow. In 1998, 17 percent of companies reporting commercial applications had already earned some revenues from ATP-funded technology, for example, from sale of prototypes or spin-off products, compared with 10 percent in 1996. By 1998, actual revenues of $\$ 67$ million from products or services, and of $\$ 5$ million from licensing ATP-funded technologies, were reported. 


\section{Appendix B.5 Protection of Intellectual Property and Dissemination of Non-proprietary Information}

\begin{tabular}{|l|c|c|c|c|c|c|}
\cline { 2 - 7 } \multicolumn{1}{c|}{} & \multicolumn{2}{c|}{ Total } & \multicolumn{2}{c|}{$\begin{array}{c}\text { Average Per } \\
\text { Organization }\end{array}$} & \multicolumn{2}{c|}{$\begin{array}{c}\text { Average Per } \\
\text { Project }\end{array}$} \\
\cline { 2 - 7 } & $\mathbf{1 9 9 6}$ & $\mathbf{1 9 9 8}$ & $\mathbf{1 9 9 6}$ & $\mathbf{1 9 9 8}$ & $\mathbf{1 9 9 6}$ & 1998 \\
\hline Patents Filed & 105 & 239 & 0.4 & 0.6 & 0.6 & 1.2 \\
\hline $\begin{array}{l}\text { Papers in Professional } \\
\text { Journals }\end{array}$ & 131 & 250 & 0.5 & 0.6 & 0.7 & 1.3 \\
\hline $\begin{array}{l}\text { Papers Presented at } \\
\text { Conferences }\end{array}$ & 372 & 706 & 1.3 & 1.7 & 2.1 & 3.6 \\
\hline
\end{tabular}

Sources: $\quad$ 1996: Business Progress Reports from 262-285 organizations in 179 ATP projects funded 1993-1995 reporting progress after one or more years of ATP funding.

1998: Business Progress Reports from 377-424 organizations in 199 ATP projects funded 1993-1997 reporting progress after one or more years of ATP funding.

Patenting of ATP-funded technology and dissemination of knowledge created in ATP projects, through such mechanisms as professional papers and conference presentations, create opportunities for economic spillovers to other organizations and industries besides ATP award recipients. For many projects, these activities start early in the project and continue for some time after ATP funding ends. The total number of patents filed, and the average per project, more than doubled between 1996 and 1998. The average number of professional papers and conference presentations per project increased substantially but these activities apparently occur more evenly over the ATP project life while patenting activity, on average, occurs later in the project life.

\section{Appendix B: Summary}

Based on analyses performed for the two ATP progress reports Development, Commercialization, and Diffusion of Enabling Technologies for projects funded 1993-1995 and Development, Commercialization, and Diffusion of Enabling Technologies for projects funded 1993-1997, this Appendix summarizes the evolution of ATP-funded technologies towards commercialization and opportunities for technology diffusion according to several key measures for which comparable data were collected for the two reports. Because relatively few new projects became eligible for data collection during the intervening time period, both reports cover largely the same populations of projects, but assessed at two different points in time, 1996 and 1998. This relative consistency in the portfolio across the two reports facilitates comparisons for the two time periods and it affords us the opportunity to watch business and economic progress unfold simultaneously with R\&D progress for a substantial number of projects.

The comparative analyses show that as the "average" (median) ATP project participant progressed from having completed about one-third of its R\&D on the ATP project to nearly two-thirds between 1996 and 1998, the frequency of strategic alliance and licensing activity doubled, patenting activity doubled, the percentages of project participants which had completed production prototypes increased commensurately, and sales and licensing revenue from ATP-funded technologies started to become significant, reaching $\$ 72$ million by early 1998 (up from $\$ 20$ million in 1996). 

